\title{
Out-group Threat and Xenophobic Hate Crimes: Evidence of Local Intergroup Conflict Dynamics between Immigrants and Natives
}

\author{
Sascha Riaz Nuffield College, University of Oxford \\ Daniel Bischof Aarhus University \& University of Zurich \\ Markus Wagner University of Vienna
}

February 3, 2023

\begin{abstract}
This study examines the relationship between crimes attributed to immigrants and hate crimes against refugees at the local level. We argue that local crime events can lead natives to engage in vicarious retribution against uninvolved out-group members - refugees in our setting. Our empirical analysis relies on fine-grained geo-coded data on more than 9,400 hate crimes and 17,600 immigrant-attributed crime events that occurred in Germany between 2015 and 2019. Using a regression discontinuity in time design, we show that the daily probability of a hate crime against refugees rises sharply in the immediate aftermath of an immigrant-attributed crime event in a local community. Additional analyses suggests that immigrant-attributed crime acts an emotional 'trigger', particularly in areas with strong radical-right support and recent demographic change. Our findings imply that individual, commonplace crime incidents can give rise to inter-group conflict dynamics at the local level.
\end{abstract}

\footnotetext{
Please send correspondence to sascha.riaz@nuffield.ox.ac.uk. For research assistance, we thank Lukas Aebi, Nikolaus Kowarz, and Sebastian Weber. We are grateful for comments from Moritz Bondeli, Carl Mueller-Crepon, Alan Gerber, Anselm Hager, Hanno Hilbig, Tyler Jager, Macartan Humpreys, Isabela Mares, Moritz Marbach, Hunter Rendleman, Hannah Smidt, Amanda Weiss, and seminar participants at Harvard University, University of Zurich, Yale University and WZB Berlin. Daniel gratefully acknowledges funding from the Swiss National Science Foundation (SNF Ambizione Grant, NO. 179938).
} 


\section{Introduction}

\section{Introduction}

At $3 \mathrm{am}$ in the morning on the 25th of August 2018 in the East German city of Chemnitz, a group of young men begins to argue about cigarettes. Three men are stabbed; one - 35-year old Daniel H. - dies in a hospital later that night. The suspected perpetrators are refugees from Syria and Iraq, while the victims are Germans. Protests against immigration ensue, the radical right mobilizes, and a dynamic of hatred and violence unfolds, culminating in an organized manhunt on suspected migrants and refugees in Chemnitz, just one day after the knife attack (Grunert 2018; Kampf, Pittelkow, and Riedel 2019). What started off as a dispute about cigarettes between two groups had severe consequences for intergroup relations in the city. Chemnitz is an extreme example of how crimes attributed to immigrants can trigger violent intergroup conflict dynamics.

This paper studies such local-level dynamics: how behavior attributed to migrants elicits retributive reactions on the part of the native population. We argue that everyday crimes by migrants - news about which is spread by local media and in personal networks - can act as a trigger for individuals to perpetrate hate crimes.$^{1}$ In this study, the target of these hate crimes are uninvolved out-group members, in our case refugees, a vulnerable, weakly integrated, yet highly visible part of the immigrant population. The hate crimes we study are thus a form of 'vicarious retribution' (Lickel et al. 2006): 'punishment' of uninvolved out-group members by in-group members themselves uninvolved in the original act. We argue that the events in Chemnitz exemplify a more general dynamic: threatening events attributed to migrants - the out-group in our setting - can lead to a temporary surge in the rate of xenophobic hate crimes against refugees in a local community.

We test this argument in the German context. Similar to other European democracies, Germany has experienced both a sharp increase in the foreign-born population and a surge

'We conceptualize hate crimes as criminal behavior motivated by prejudice toward the victim's putative social group (Green, Mcfalls, and Smith 2001; Dancygier and Green 2010). While a variety of factors can lead to hate crimes, our focus in this paper are hate crimes driven by vicarious retribution dynamics. 
Figure 1: Increase in hate crimes across Europe

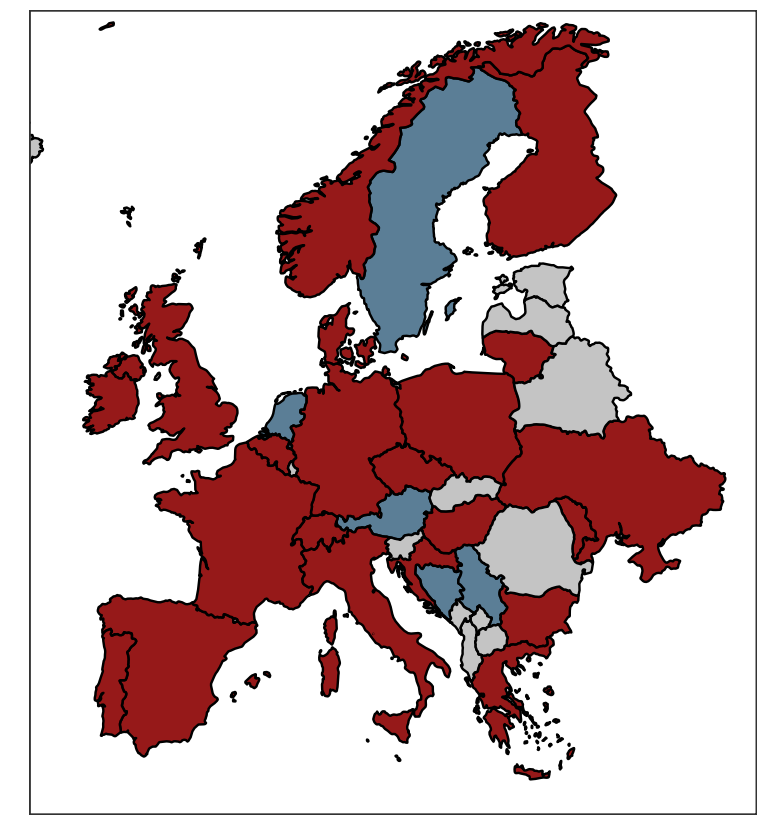

Change in hate crimes (2014 - 2020)

Decrease/no change

Increase

Missing data

Note: The map shows the change in racist and xenophobic hate crimes by country between 2014 and 2020. The map is based on data collected by the Organization for Security and Co-operation in Europe (OSCE). For Ireland, 2019 is the most recent available year. For Denmark, data for the year 2014 is not available; we use the year 2015 as the baseline instead.

in racist and xenophobic hate crimes in recent years (see Figure 1). Our empirical analysis draws on two original data sources. First, we collected event-level data on all 9,400 hate crimes against refugees that were recorded by official agencies between January 2015 and March 2019. We complement this data with detailed geocoded information on more than 17,600 crimes attributed to immigrants in Germany during the same time period. This data is based on official police press releases and reports in the local news media. We focus on crimes attributed to perpetrators from African and Muslim-majority countries, which are most likely to trigger backlash against refugees. We argue that due to (i) the objective distribution of refugees across nationalities and (ii) racialized patterns of categorization, natives are most likely to link perpetrators from these countries to the out-group of refugees (see section 3.1 for more details). To causally identify the effect of immigrant crimes on hate crime against refugees in the same locality, we use a sharp regression discontinuity in time (RDiT) design. We estimate the rate of xenophobic hate crimes right before and after the occurrence of immigrant-attributed crime 
events within a small temporal bandwidth of two to five days.

We find a significant increase in anti-refugee hate crimes right after crime events attributed to immigrants. We estimate that the daily probability of a xenophobic hate crime in a county increases by about 1 percentage point in the immediate aftermath of an immigrant crime event. This corresponds to a $65 \%$ increase relative to the pre-treatment baseline. Additional analyses reveal that our results are driven by violent crime events (e.g. stabbings, sexual assaults). In line with our theoretical expectations, we do not find any evidence that non-violent petty crimes or crimes attributed to non-refugee immigrant groups (e.g. Romanians or Bulgarians) lead to backlash against the local refugee population.

Previous research has emphasized that hate crimes are linked to specific local contexts such as support for far right parties or a recent influx of migrants (Krueger and Pischke 1997; Jäckle and König 2018; Smångs 2017). Building on this line of research, we tested whether characteristics of a locality - such as economic, social and political conditions - moderate the vicarious retribution dynamics we identify. We find suggestive evidence that migrant-attributed crimes are more likely to lead to hate crimes against refugees in areas with deeper support for far-right parties. This suggests that the hate crime dynamics we uncover can be linked to broader local political trends that may legitimize vicarious retribution or create in-group dynamics that foster prejudice and aggression. In addition, vicarious retribution is more likely where the foreign population has recently increased, i.e. where immigrant-attributed crime may be perceived as more threatening and act as a stronger motivational prime. These additional analyses suggest that vicarious retribution against migrant crime events is linked to threat perceptions and to in-group norms and dynamics even if, naturally, the motives of individual hate crime perpetrators are difficult - if not impossible - to isolate in our setting.

Our research adds to a large and growing literature on hate crimes and attitudes towards out-groups more generally (e.g., Hopkins 2010; Hangartner et al. 2019; Enos 2014; Liebe and Schwitter 2021). First, we build on prior research that has shown a surge in hate crimes after salient 'focusing events' that attract national media attention. For example, Frey (2020) demonstrates a notable spike in anti-refugee hate crimes after the 2015/16 New Year's Eve sexual assaults in Germany. Prior research has identified similar patterns in the aftermath of the July 7 bombings in London (Hanes and Machin 2014), the 9/11 terrorist attacks (Disha, Cavendish, 
and King 2011), contentious court cases (King and Sutton 2013), and after Islamic terrorist attacks more generally (Jäckle and König 2018; King and Sutton 2013). These prior studies have mostly examined over-time variation in the countrywide rate of hate crimes before and after singular events that attract nationwide or even international media attention. However, such events are relatively rare and only account for a small fraction of natives' overall exposure to crime. In contrast, constituents are frequently exposed to highly localized information about crimes in their vicinity. In our setting, about one-third of local news articles cover crime - most often events that occurred within the local coverage region of a given newspaper (van Um, Huch, and Bug 2015). By drawing on a large-scale data set of more than 17,000 localized crime events attributed to immigrant perpetrators, we substantially extend the scope of prior related work. Most importantly, our study demonstrates that vicarious retribution dynamics are much more widespread and frequent than previous research suggests. Moreover, local events may help to explain regionally specific dynamics in intergroup conflict. Beyond salient events that attract nationwide attention, vicarious retribution occurs at the local level on an everyday basis. Our work thus establishes the generalizability of vicarious retribution dynamics to a much larger set of cases and contexts than prior research suggests.

Second, our results shed new light on the mechanisms underlying vicarious retribution dynamics. Going beyond prior work, our empirical strategy allows us to trace the temporal persistence of vicarious retribution at the local level. We find a surge in the rate of hate crimes in the immediate aftermath of crime events attributed to immigrants. After about four days, the likelihood of hate crimes reverts back to its pre-treatment level. This suggests that out-group crime events primarily lead to hate crimes by acting as an emotional 'trigger' rather than through more long-term processes of attitudinal change. In addition, we do not find evidence that vicarious retribution dynamics 'spill over' to geographically proximate, neighboring local communities. This suggests that the effects we identify are highly localized and thus distinct from the focusing events studied in prior research.

Finally, our findings suggest that vicarious retribution dynamics are driven by different contextual factors at the local than at the national level. For instance, Frey (2020) finds that hate crimes primarily increased in localities with previously low levels of anti-immigration sentiment after the sexual assault cases in Cologne. In contrast, we find that vicarious retribution at the 
local level primarily occurs in regions with high levels of far-right support. We interpret this as suggestive evidence that distinct dynamics underlie the 'focusing events' studied in prior work and the more localized events we examine in this study.

\section{A dynamic perspective on intergroup conflict triggered by galvanizing local events}

While much has been learned about the cross-sectional causes of intergroup conflict (see Liebe and Schwitter 2021), researchers have recently started to focus on the dynamics of intergroup conflict, aiming to identify variable drivers of tension and aggression rather than comparatively stable factors (e.g., Balcells, Daniels, and Escribà-Folch 2016; Colussi, Isphording, and Pestel 2021). ${ }^{2}$ Our study adds to this research by putting forward a dynamic perspective on hate crimes at the local level: in a nutshell, we argue that localized threatening events attributed to an out-group - crimes attributed to immigrants in our setting - can lead to hate crimes by acting as a trigger for natives with preexisting prejudice against the out-group.

Our theoretical framework builds on a large literature that highlights how salient, galvanizing events can be a potent trigger for aggression and violence. Cognition and affect are two key pathways in this context (Anderson, Bushman et al. 2002). First, galvanizing events may increase negative attitudes towards the relevant out-group - immigrants in our case - as well as perceptions of how threatening this group is (Sniderman, Hagendoorn, and Prior 2004). Heightened threat perceptions can galvanize action (Sniderman, Hagendoorn, and Prior 2004), especially if an event can be interpreted as an attack on the in-group (Lickel et al. 2006). In addition, threatening events may act as a prime, heightening the salience and centrality of xenophobic attitudes; even if the attitudes themselves remain stable (Allen, Anderson, and Bushman 2018). As Peffley et al. (2015) and Jungkunz, Helbling, and Schwemmer (2019) suggest,

${ }^{2}$ There has been extensive sociological and criminological work on the kinds of people that engage in hate crimes against out-groups such as migrants or LGBTQ persons (for summaries see, e.g., Green, Mcfalls, and Smith 2001; Walters 2011; Dancygier and Green 2010; Green and Spry 2014). Perpetrators of hate crimes tend to hold biased perceptions of and grievances towards the targeted out-group (King and Sutton 2013), and many engage in hate crimes out of a desire to exact revenge and protect the in-group (Lickel et al. 2006). 
such attitudinal effects may occur mainly among individuals with preexisting xenophobic grievances. In our setting, crimes attributed to immigrants - violent crimes in particular - may reinforce anti-immigrant attitudes and increase threat perceptions among natives. However, shifts in attitudes do not necessarily translate into changes in behavior (Guyer and Fabrigar 2015; Frey 2020). Hence, affect - i.e., emotional reactions - may play an important mediating role (Anderson, Bushman et al. 2002). For example, a galvanizing threat may increase anger among the in-group members predisposed towards hate crimes (Nussio 2020). This anger can act as an important motivational driver of vicarious retribution (Zeitzoff 2014).

Prior work on galvanizing events has almost exclusively focused on highly salient events that receive sustained national media attention. ${ }^{3}$ With regards to attitudes, research has shown that such events - for instance terrorist attacks - have led to reinforced negative stereotypes about immigrants and Muslims, as well as an increase in the perceived threat posed by these groups (Legewie 2013; Hopkins 2010; Kam and Kinder 2007; Peffley et al. 2015; Disha, Cavendish, and King 2011; Frey 2020; Godefroidt 2021). However, the effects of threatening events are not limited to attitudes and perceptions. Prior research has demonstrated a surge in hate crimes after, for example, the July 7 bombings in London or the 2015/16 sexual assault cases in Cologne (Hanes and Machin 2014; King and Sutton 2013; Lickel et al. 2006; Frey 2020; Devine 2020; Nussio, Bove, and Steele 2019; Ivandic, Kirchmaier, and Machin 2019; Christensen and Enlund 2019). King and Sutton (2013) even suggest that such 'considerable publicity' is a necessary precondition for antecedent events to spark vicarious retribution.

Yet, focusing on highly salient national events is potentially misleading, as it might imply that vicarious retribution is an unusual occurrence limited to exceptional periods of nationwide tension. However, we argue that salient local events - specifically, crimes attributed to immigrants - can also lead to retributive hate crimes. Importantly, these local events occur with much higher frequency than nationally salient events. While the kind of highly salient events studied hitherto are natural candidates for strong reactions, localized threatening events may

${ }^{3}$ One exception to this national focus is research on lynching (e.g. Green, Mcfalls, and Smith 2001; Smångs 2016), which however largely examines a different kind of retribution that is generally more direct and more public than hate crimes. 
also be effective in causing a shift in attitudes or acting as an affective 'trigger' for individuals with high levels of preexisting prejudice against immigrants. Indeed, because localized crimes will appear more immediate than distant national events, it is plausible that local events may be particularly effective in changing threat perceptions and generating affect. The type of local event should also matter for its impact: in our setting, we expect particularly violent events (e.g. sexual assault cases, homicides) to elicit stronger reactions compared to relatively minor crimes attributed to immigrants. More threatening types of crimes likely constitute a stronger trigger for hate crimes through vicarious retribution. The events in Chemnitz described in the introduction are an extreme example of such dynamics.

How do natives - including potential hate crime perpetrators - hear about immigrantattributed crime in their locality? We suggest that information about local crime events attributed to immigrants can reach xenophobic natives through two principal channels: (1) direct exposure to media reporting and (2) indirect exposure through social networks. Social media can amplify both of these channels (Müller and Schwarz 2020), especially if social media contacts or broader organizations share related content. The Chemnitz incident cited in the introduction, for example, was coordinated on social media (Kampf, Pittelkow, and Riedel 2019). We revisit this point and provide a more detailed discussion of how information about individual crime events reaches hate crime perpetrators in our setting when we discuss our data sources in section 3.1.

Against the backdrop of our theoretical framework outlined above, our main empirical hypothesis is:

$H$ : The probability of a xenophobic hate crime in a given county increases in the immediate aftermath of immigrant-attributed crime in the same county.

Our empirical application focuses on hate crimes directed specifically against refugees. Importantly, we assume that citizens - especially potential hate crime perpetrators - are not discerning when it comes to out-group membership: crimes attributed to a broad range of immigrant groups may lead to hate crimes against refugees. We argue that - for perpetrators of hate crimes - refugees are part of broader out-group population comprised of immigrants that are perceived as particularly threatening and culturally distant, namely those from African- 
and Muslim-majority countries (Di Stasio et al. 2021; Czymara and Schmidt-Catran 2016). In addition, hate crimes against refugees are a particularly plausible reaction as this subset of the population is particularly vulnerable and less socially embedded (Smångs 2017). We provide a more detailed discussion of the connection between crimes attributed to perpetrators from Muslim-majority and/or African countries and hate crimes against refugees when we discuss our specific data sources in section 3.1.

The mechanisms outlined above imply that migrant-attributed crime might be more likely to lead to hate crimes in specifically fertile contexts, which are areas where such crimes are perceived to be more threatening and more likely to act as an affective trigger (for an overview see: Green, Mcfalls, and Smith 2001; Smångs 2017). A diverse set of local social and economic aspects may be relevant here, with a given migrant-attributed crime potentially more likely to trigger backlash in contexts where there are many immigrants or where their number has been increasing rapidly (Hopkins 2010; Dinas and van Spanje 2011). Indeed, empirical evidence suggests that natives' perceptions of immigration are primarily shaped by over-time increases in the immigrant population rather than the overall size of that group (Hopkins 2010; Newman and Velez 2014). The argument is that rapid change in immigrant populations is "more likely to capture the attention of local citizens than the size of these populations" (Newman and Velez 2014). It might also be the case that the social cleavage between immigrants and natives - a crucial scope condition for the dynamics we describe - tends to fade over time, i.e. in localities that have experienced immigration inflows for decades. In localities where immigration has been a more recent phenomenon, on the other hand, immigrants might be perceived as more threatening and different from the native population. Following these arguments, we would expect vicarious retribution dynamics to be more likely in places that have only recently experienced a rapid rise in the immigrant population.

In addition, migrant crime may be seen as more threatening in areas with weaker economies and higher unemployment rates, particularly among natives (Green, Glaser, and Rich 1998; Krueger 2007; Dancygier 2010), but the evidence here is not conclusive (see, e.g., Krueger and Pischke 1997); similar debates characterize research on lynching (Green, Mcfalls, and Smith 2001; Smångs 2017). As noted above, certain types of crimes, violent crimes in particular, might likewise be perceived as particularly threatening. 
Second, local contexts may vary in the extent to which vicarious retribution is seen as legitimate, i.e. whether group norms hinder or foster such reactions (Allen, Anderson, and Bushman 2018). Perceptions of hate crime legitimacy among radicalized individuals may be greater where there is a sustained presence of and electoral support for radical right parties in a community, as well as the associated levels of anti-immigrant discourse and hate speech (Karapin 2002; Dancygier and Green 2010; Bischof and Wagner 2019). When a community fails to condemn hate crimes, this can lead to further legitimization, i.e. the erosion of anti-violent social norms (Romarri 2020; Weaver 2019). In Germany, such patterns of legitimization may be particularly relevant given the recent rise of the Alternative for Germany (Alternative für Deutschland, AfD). More generally, organizations may act as mobilizing forces (Smångs 2016). Indeed, there is cross-sectional evidence that support for the radical right is associated with higher levels of hate crimes (Romarri 2020; Jäckle and König 2018), while lynchings were less likely to occur in Republican-dominated areas (Smångs 2017).

In addition to creating a legitimizing environment, there may be a purely numeric effect, with migrant-attributed crime more likely to elicit vicarious retribution if the number of individuals predisposed to such action is already substantial. As the number of radicalized individuals increases, so will the likelihood that one or more of these opt for vicarious retribution. Moreover, group dynamics among groups of radicalized individuals may also make aggression more likely (Allen, Anderson, and Bushman 2018; Smångs 2016). Such group dynamics will be more likely where sizable groups already exist. Again, support for radical-right parties such as the AfD is a useful proxy in this regard. We revisit these hypotheses and empirically examine effect heterogeneity along a number of potential moderator variables in section 4.2.

\section{Data \& Empirical Strategy}

\subsection{Data}

Hate crimes against refugees To measure hate crimes, we collected detailed information on more than 9,400 xenophobic hate crime incidents that occurred in Germany between January 2015 and March 2019. The German police does not release event-level information on hate crimes. However, the German socialist party - Die Linke - inquires about hate crimes 
directed at refugees and refugee accommodations that occurred in Germany through quarterly 'parliamentary requests' ('kleine Anfrage`). The federal government responds with a detailed list of hate crimes based on information from the German police and intelligence services. Along with a description of the law violated in each specific incident, we also observe the precise location and date of each event. We provide more details on the hate crime data in section SI.3.2. ${ }^{4}$

We emphasize that our data only covers hate crimes specifically targeted at refugees: it covers arson, raids, damage to property, and violent and verbal attacks directed against refugees and refugee housing..$^{5}$ Our data does not cover other forms of hate crimes, for example crimes motivated by antisemitism or religious fundamentalism. The fact that our data only covers a subset of all hate crimes in Germany could constitute an issue if one were to study the determinants of hate crimes more generally. However, this study is interested specifically in immediate vicarious retribution against refugees. Our data hence allows us to focus on precisely the kind of xenophobic violence and bigotry we intend to measure. The three most common types of offenses we observe are (1) hate speech, (2) criminal damage, and (3) battery. Crimes in these three categories cumulatively account for more than half of the hate crime events recorded in our data set.

We visualize the temporal and spatial distribution of hate crimes in Figures SI 11 and SI 12.

4We provide background information on the German context in section SI.1. We discuss Germany's historical experience with immigration, the issue salience of immigration during our study period, and the role of radical-right parties.

5It is, however, likely that our arguments travel beyond "refugees" as a group: Perpetrators almost certainly use descriptive characteristics, such as skin color and language, to identify their victims, making it difficult to differentiate between minority groups based on their legal status. However, we also believe that locating refugees may be easier in some cases. This is because refugees are often required to reside in specific buildings designated for their use, which defines the locations where they live and frequently go, for example, to purchase groceries. This information is likely known by the local community, which may make it easier for perpetrators to target refugees compared to other migrants. 
Hate crimes occur more frequently in East Germany (Krueger and Pischke 1997), even though the overall share of the foreign-born population in East Germany only stands at about 5\%, compared to about $15 \%$ in the West. The number of hate crimes has increased sharply in the wake of the influx of refugees into Germany since 2014, in particular after the 2015-16 New Year's Eve sexual assaults in Cologne (Frey 2020). We investigate the cross-sectional correlates of hate crimes in more detail in figure SI 13, where we follow Krueger and Pischke (1997) and regress the total number of hate crimes in a given county on a variety of county-level covariates.

A potential concern regarding our hate crime data is under-reporting by either German authorities or victims of hate crimes (FRA 2021). Some incidents might not appear in our data because refugees are hesitant to report attacks against them to the German police. Likewise, it might be the case that the German police fails to register some incidents targeted specifically at refugees. As a result, the true rate of xenophobic hate crimes might be substantially higher than what official numbers suggest. For our study, it would be particularly problematic if under-reporting systematically varied across space and time. Our identification strategy that compares the rate of hate crimes right before and after crimes attributed to migrants in a given county (see section 3.2) requires that the probability of hate crime reporting is constant right before and after immigrant-attributed crime events. We view this assumption as likely satisfied but note that we cannot test it formally. Measuring the probability of hate crime reporting would require that we observe all hate crime incidents, including those that were only ever known to the victim and perpetrator. To partially address concerns about reporting bias, we validated our hate crime data by comparing it to information on hate crime events compiled by independent NGOs (Benček and Strasheim 2016). While this data likewise does not allow us to observe unreported attacks against refugees, we argue that it allows us to alleviate concerns about bias on the part of the police itself. We provide a detailed discussion of the validation checks we performed in section SI.3.3.

Crimes attributed to immigrants We complement our hate crime data with detailed information on salient "immigrant crime events" recorded between January 2015 and March 2019. Event-level data on crimes committed by foreigners is not published by the German police or any other agency. Our data source for immigrant crime events is the website refcrime.info, 
which explicitly seeks to draw attention to crimes committed by first- and second-generation migrants in order to reduce public support for immigration. ${ }^{6}$ In addition to the date and precise location of each crime event, we also observe the type of crime that occurred (homocide, battery, theft, rape, etc.). We are hence able to distinguish between the effects of violent and non-violent crimes. A detailed overview of how we classified violent and non-violent crimes can be found in the SI (see section SI.2.8). We provide summary statistics of the immigrant crime data in table SI 1 and figure SI 1 in the appendix.

In total, about 60,000 crime events were recorded on the website between January 2015 and March 2019. However, we only consider a subset of these events for our main analysis in order to align the measurement of our outcome variable, treatment variable, and theoretical framework. We first note that this study examines group-based vicarious retribution at the local level. Empirically, our outcome variable measures hate crimes against refugees - a highly salient out-group during our study period. For the definition of our treatment, we accordingly focus on those crime events that xenophobic natives are most likely to link to the group of refugees as a whole. We assume that this cognitive process is partly determined by objective factors, namely the true distribution of asylum seekers by nationality during our study period, and partly determined by racial categorization and stereotypes.

We argue, for example, that crimes attributed to Syrians, Eritreans, or Afghans can lead to backlash against refugees because the vast majority of individuals from these countries are in fact refugees in our setting. As of $2020,83 \%$ of Eritreans, $79 \%$ of Afghans, and $75 \%$ of Syrians who resided in Germany entered the country as refugees (Statistisches Bundesamt 2019). In other words, the probability of refugee status conditional on nationality is very high for these immigrant groups. In contrast, the share of refugees is very low for European countries such as Romania, Poland or Bulgaria. Fewer than 30 individuals from these countries applied for asylum in Germany in 2016 (BAMF 2016). While a large share of crime events in our data set is attributed to Eastern European perpetrators, we would not expect these events to lead to backlash against the local refugee population.

Beyond the true distribution of asylum seekers, we expect racialized stereotyping and

${ }^{6}$ We note that the website went offline in late $2020 /$ early 2021. 
categorization to be an important factor in our setting (Blumer 1958; Meuleman et al. 2019). For example, while the share of refugees is comparatively low for immigrants from Senegal, Kenia, and Tunisia, we nevertheless expect perpetrators from these countries to be categorized as Muslims and/or Africans, rather than Senegalese, Kenyans, or Tunisians. In other words, we argue that potential perpetrators of hate crimes do not make fine-grained differentiations between nationalities but rather use nationalities as heuristics to distinguish between different broader categories of out-groups (see also section 2). Against this background, we use the subset of 17,600 crimes attributed to perpetrators from Muslim-majority or African countries for our main analyses. We provide a detailed overview of our nationality classification in section SI.2.9. The nationalities we retain in our sample account for more than $91 \%$ of all asylum applications in 2016, and thus cover the vast majority of refugees during our study period (BAMF 2017).

Most of the crimes we exclude from our analysis are attributed to Eastern Europeans mainly immigrants from Romania, Poland, or Bulgaria. We also drop cases where the nationality of the perpetrator is not explicitly mentioned in the police press release. These cases generally contain cues (e.g. 'Southern appearance'), but cannot be clearly linked to specific nationalities. The construction of our sample aligns with prior research that suggests that anti-immigrant attitudes and xenophobia are most pronounced for immigrants from Muslim-majority and African countries in European societies (Valentino et al. 2019; Di Stasio et al. 2021) and Germany specifically (Czymara and Schmidt-Catran 2016, 2017). In a supplementary analysis, we use crimes attributed to perpetrators from other nationalities for a series of placebo tests (see table 2). In line with our theoretical expectations, we do not find any evidence that crimes attributed to other groups (e.g. Romanians or Poles) lead to backlash against the local refugee population. ${ }^{7}$

How do perpetrators of hate crimes learn about the immigrant-attributed crime events covered by our data set? While we do not have access to a survey sample of hate crime

${ }^{7}$ We also demonstrate that our main results are robust to sequentially dropping nationalities from the sample, and thus to not appear to be driven by idiosyncratic choices about the sample composition (see figure SI 26). 
perpetrators to directly answer this question, we argue that two primary channels are most likely. First, a small subset of xenophobic natives might directly obtain information from refcrime. In addition to its website, the events recorded on refcrime were also publicized on Twitter (@RefugeeCrimeMap) and Facebook. While the audience of refcrime is likely a very small share of the German population, potential hate crime perpetrators are likewise a highly selected, small group with high levels of preexisting prejudice against immigrants. Against this background, it seems plausible that a subset of potential hate crime perpetrators directly obtains information on immigrant-attributed crimes from refcrime. Second, perpetrators might learn about immigrant-attributed crime events from other news sources (e.g. local news media, social media, etc.) which rely on the same primary data source as the refcrime website, namely police press releases. During our study period, about one in two Germans consumed local news - either online or in print - on a weekly basis (Reuters Institute 2018). Moreover, reporting on crime is a central facet of German local news, with one study - a quantitative analysis across 31 German local newspapers - showing that one-third of local news articles are about crime, while violent crimes such as homicides and sexual assaults receive disproportionate attention compared to their overall relative frequency (van Um, Huch, and Bug 2015). Prior research also highlights that German newspapers frequently report the nationality of crime perpetrators, if such information is available from police press releases (Hestermann 2019). In sections SI.2.4 and SI.2.5 in the appendix we conduct further tests to establish the plausibility of this channel. Specifically, we demonstrate that (i) local news outlets base most of their crime reporting on information released through police press releases, and (ii) refcrime - in addition to police information - draws on information covered in a large number of different outlets across the German media landscape. Naturally, information about local crime events might also be shared within social networks and through interpersonal communication - both online and offline (Müller and Schwarz 2020).

The political motivation behind our data source raises concerns that the website might misreport crimes committed by migrants, or that there might be other systematic biases in the data. We address such concerns systematically in section SI.2.2 by implementing a number of quality checks of the immigrant crime data to ensure that i) the reported information is accurate and ii) reporting is not systematically biased. We find that the events reported on the 
website are, in almost all cases, confirmed by credible sources. $93 \%$ of the reported events are substantiated by official police press releases. The remaining cases are mostly based on local news articles and, in some cases, the websites of TV channels, or local radio stations. In section SI.2.4 in the appendix, we provide a list of all news sources that refcrime draws on in addition to police press statements. The website draws on a large number of established national and local news outlets.

The total number of crimes recorded by the German police in 2019 was 5.43 million. For these crimes, the police identified about 2 million crime suspects, of which about 700,000 had foreign citizenship (34.6\%). Our data hence only covers a small subset of all crimes in Germany, with a focus on the most egregious types of crimes that can most easily trigger a response (e.g. stabbings, sexual assault, etc.). While many crimes were committed by foreigners but not recorded on the website, our data source does capture the most salient events that likely attracted the most attention in the media and right-wing (online) networks.

We examine the cross-sectional predictors of immigrant-attributed crime events in our database in figure SI 7 in the appendix. We find a strong, statistically significant relationship between the events recorded in the refcrime database and the local presence of foreigners. As expected, this empirical relationship is particularly strong for the share of immigrants from outside the EU (see also figure SI 2). We do not find a statistically significant association between refcrime event counts and other covariates, including electoral support for the AfD (see also figure SI 3). Finally, we recognize the ethical challenges involved in relying on data collected by anti-immigrant political activists. As discussed above we see the data as a proxy for crime attributed to foreigners. Using this data does not legitimize the motivation and goals by the data distributor. On the contrary, as our results and implications show, we see the efforts by refcrime as highly problematic and adding to an atmosphere of out-group anger, fear and hatred.

\subsection{Estimation and identification strategy}

To estimate the causal effect of migrant crimes on hate crimes, we use an interrupted timeseries approach. More specifically, we use a regression discontinuity in time design (RDiT) in which time is used as the running variable (Hausman and Rapson 2018). Our data is well-suited 
for this approach as we observe the precise date and location for all recorded incidents of migrant crimes and xenophobic hate crimes.

In contrast to previous studies using RDiT models on a single event such as the September 11 attacks or the sexual assault cases in Cologne, we observe more than 17,600 individual migrant crime events. To analyze this rich dataset in an RD-framework, we transform our raw data into a panel where immigrant-attributed crime events are the main unit of analysis. Before delving into the formalization of our approach, we illustrate our procedure for one exemplary event in our data set: the stabbing that occurred in Chemnitz on August 26, 2018, which we discussed in the Introduction of the paper. In Figure 2, we see that between August 12 and August 25, no hate crimes occurred in Chemnitz. Starting on August 26 - the day immediately following the crime attributed to refugees - the rate of hate crimes surged. Ten hate crimes occurred on August 26 alone. Multiple additional hate crimes occured over the following days. After about 4 days, the effect fades and the rate of hate crimes in the county of Chemnitz reverts back to its pretreatment level. We apply this data transformation procedure to every crime event recorded in the refcrime data: for each event, we measure the rate of hate crimes in a given locality in the two-week period before and after the event. We then use a regression discontinuity approach to compare the average rate of hate crimes before and after immigrant-attributed crime events.

More formally, for each migrant-attributed crime, we consider the two-week period before and after the event. ${ }^{8}$ Hence, for each migrant-attributed crime event, we start out with 29 daily observations of our outcome variable - hate crime $Y_{i, t, c}$. Here, $i$ denotes the index of the immigrant crime event, $c$ the county in which it occurred, and $t$ is the date. Our main outcome $Y_{i, t, c}$ variable is the daily number of hate crimes that occurred in county $c$ on a given day $t$. To facilitate the interpretation of the effect estimates, we also conduct an additional analysis where we model the daily probability of hate crime before and after a migrant crime event. To do this, we code a binary indicator variable that takes on the value one if at least one hate crime occurred in county $c$ at a given date $t$ (see table 1 ).

Our running variable is the time in days before and after a migrant crime event. We denote this period variable by $P_{i, t, c} \in[-14,14]$. It captures the temporal distance from the immigrant

${ }^{8}$ We examine longer-term effects of immigrant-attributed crime on hate crimes in figure SI 16. 
Figure 2: Illustration of empirical strategy

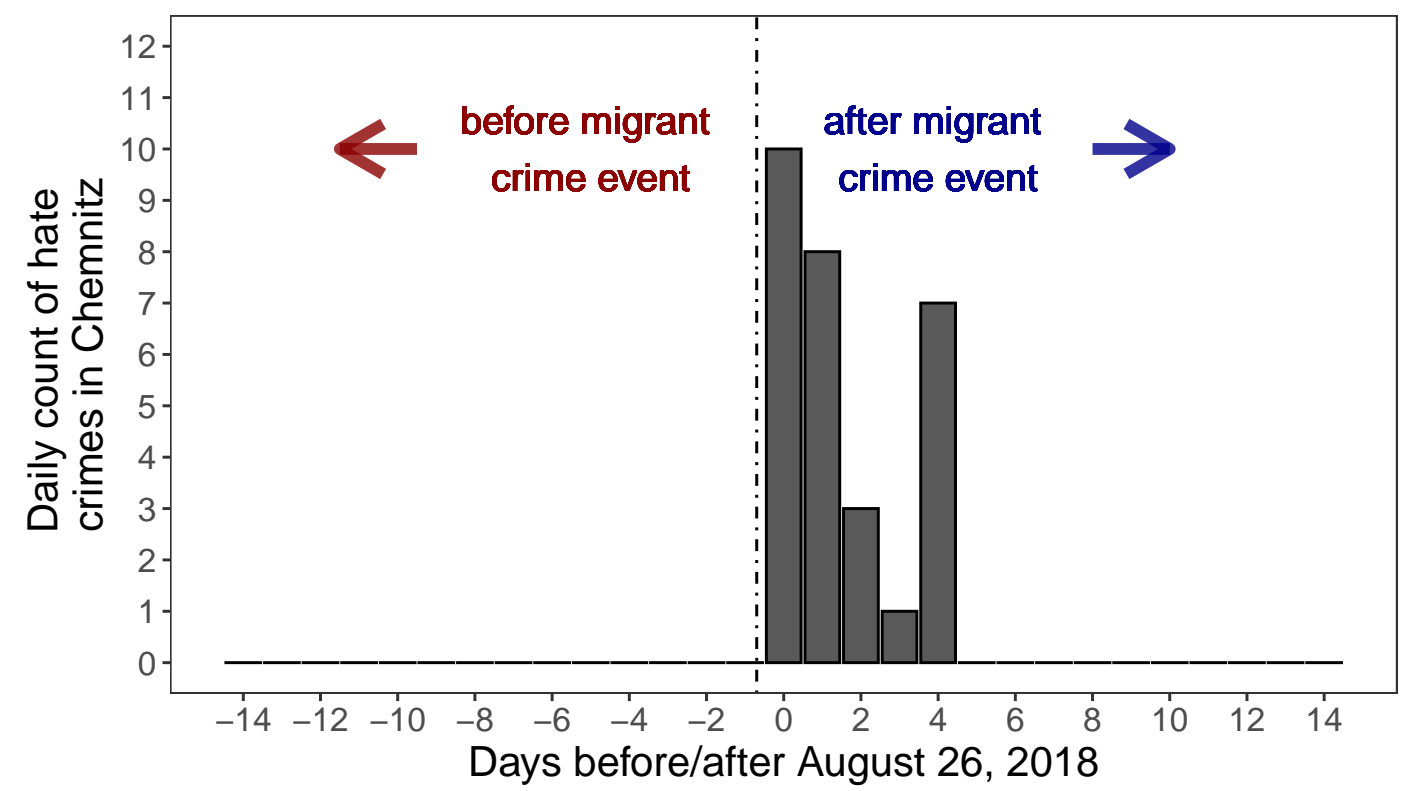

Note: The figure illustrates the transformation of event-level data to the data we use for the RDiT design. We use the example of a stabbing that occurred in the East-German city of Chemnitz on August 26, 2018. The running variable is the time in days relative to an immigrant-attributed crime event. We consider the two-week period before and after each crime event. For this illustration, we discard the possibility of partial overlap between events (see section SI.2.7).

crime event and determines the treatment assignment. Counties are considered treated when an immigrant crime occurred, i.e. $T_{i, t, c}=1$ if $P_{i, t, c}>=0$. We provide details on how we deal with (partially) overlapping event periods in section SI.2.7. At 5,332 events, the effective sample size we use within the optimal bandwidth is substantially smaller than our baseline sample. We systematically investigate and discuss the differences between the two samples in figure SI 9. We find that our effective sample is generally representative for the larger sample of events in the refcrime database. It contains a slightly higher share of violent crime events compared to the full refcrime data. We also note that crime events are more likely to overlap in large cities or West Germany, where the share of the foreign-born population is higher.

We estimate a sharp regression discontinuity design in which the treatment assignment is a deterministic function of the time period as formalized in equation 1. We follow the standard practice in regression discontinuity designs and approximate the regression function $E\left[Y_{i, t, c} \mid P_{i, t, c}=p\right]$ by fitting local polynomials on each side of the treatment assignment cutoff. In a nutshell, we model the daily rate of hate crimes right before and after migrant crime events using a polynomial function. This allows us to estimate the local average treatment effect on 
the treated:

$$
\tau=E\left[Y_{i, t, c}(1)-Y_{i, t, c}(0) \mid P_{i, t, c}=0\right]
$$

Unless otherwise noted, we use a local linear polynomial to reduce the sensitivity of our results. In all presented analyses, we use robust bias-corrected standard errors and use a triangular kernel function as recommended by Cattaneo, Idrobo, and Titiunik (2019). For our main analyses, we do not use clustered standard errors. However, in a supplementary robustness test we establish that our results remain unchanged when we cluster at different levels (see Figure SI 27). The choice of the bandwidth in days $h$ involves a bias-variance trade-off. For our main results, we use an optimal bandwidth selection algorithm to minimize the MSE of our treatment effect estimates. Across a multitude of robustness checks, we demonstrate that our results hold using different functional forms of the regression function and varying bandwidths around the treatment assignment cutoff (see section SI.6). We provide more details on local polynomial estimation and optimal bandwidth selection in RD designs in section SI.4.

Identification rests on the standard assumptions of RD designs, in particular continuity of the potential outcomes around the treatment assignment cutoff. This means that no other determinant of hate crimes systematically coincides with migrant crime events within small temporal bandwidths. We stress that because we exploit variance in the rate of hate crimes within a given county over time, all factors that are invariant within small temporal bandwidths are held constant by design (e.g. election results, local wages, unemployment, bureaucratic efficiency, etc.). While the propensity to report hate crimes or crimes attributed to immigrants might vary across counties, our design only requires that the propensity to report either crime is constant around the temporal cutoff before and after crimes attributed to immigrants (see also section $\mathrm{SI.3.3).}$

We provide additional evidence in support of our key identification assumption in section SI.6. In addition to a battery of robustness tests, we demonstrate that i) hate crimes do not predict migrant crime events (figure SI 21), ii) migrant crimes and hate crimes do not generally cluster on the same days of the week (figure SI 23), and iii) the days before and after migrant crime events are similar in terms of observable climatic characteristics (figure $\mathrm{SI} 28$ ). We also conduct an empirical test for spillover effects, where we demonstrate that crimes attributed 
to immigrants do not predict hate crimes in directly contiguous, or geographically proximate counties (see figure SI 18).

\section{Results}

Before moving on to our main results, we descriptively examine the association between migrant crime events and hate crimes in section SI.5 in the appendix. We begin by plotting the number of recorded migrant crime events against the number of hate crimes in a given county in a given month. We document a positive correlation between the two variables $(r=0.21)$. Next, we investigate the empirical relationship between immigrant-attributed crimes and hate crimes using a variety of standard panel models. Among other things, we conduct a first-difference analysis where we regress the change in the number of hate crimes in a given county in a given week on the change in the number of immigrant-attributed crimes in the same county in the same week (see table SI 5). Across a variety of model specifications we find a positive, statistically significant association between crimes attributed to immigrants and hate crimes recorded in a given county in a given week/month. Of course, other factors might drive this correlation. Most importantly, the analyses presented in section SI.5 do not precisely disentangle the temporal ordering of migrant crimes and hate crimes. We rely on our RDiT identification strategy described in section 3.2 to address concerns that this correlation - while robust across a variety of standard panel models - does not establish a causal relationship.

\subsection{Main findings}

In Figure 3, we plot the daily rate of hate crimes in the two-week period before and after an immigrant crime event occurred in a given county. We find a sharp spike in hate crimes in the immediate aftermath of crimes attributed to immigrants. After about four days, the likelihood of hate crimes reverts back to its pre-treatment level.

This descriptive pattern is mirrored in our main results from regression discontinuity in time regression models, which we present in table 1. We find a positive, statistically significant effect of immigrant-attributed crimes on the propensity of hate crimes across a variety of model specifications. Our results hold for both the binary and count measurement of hate 
Figure 3: RD Plot

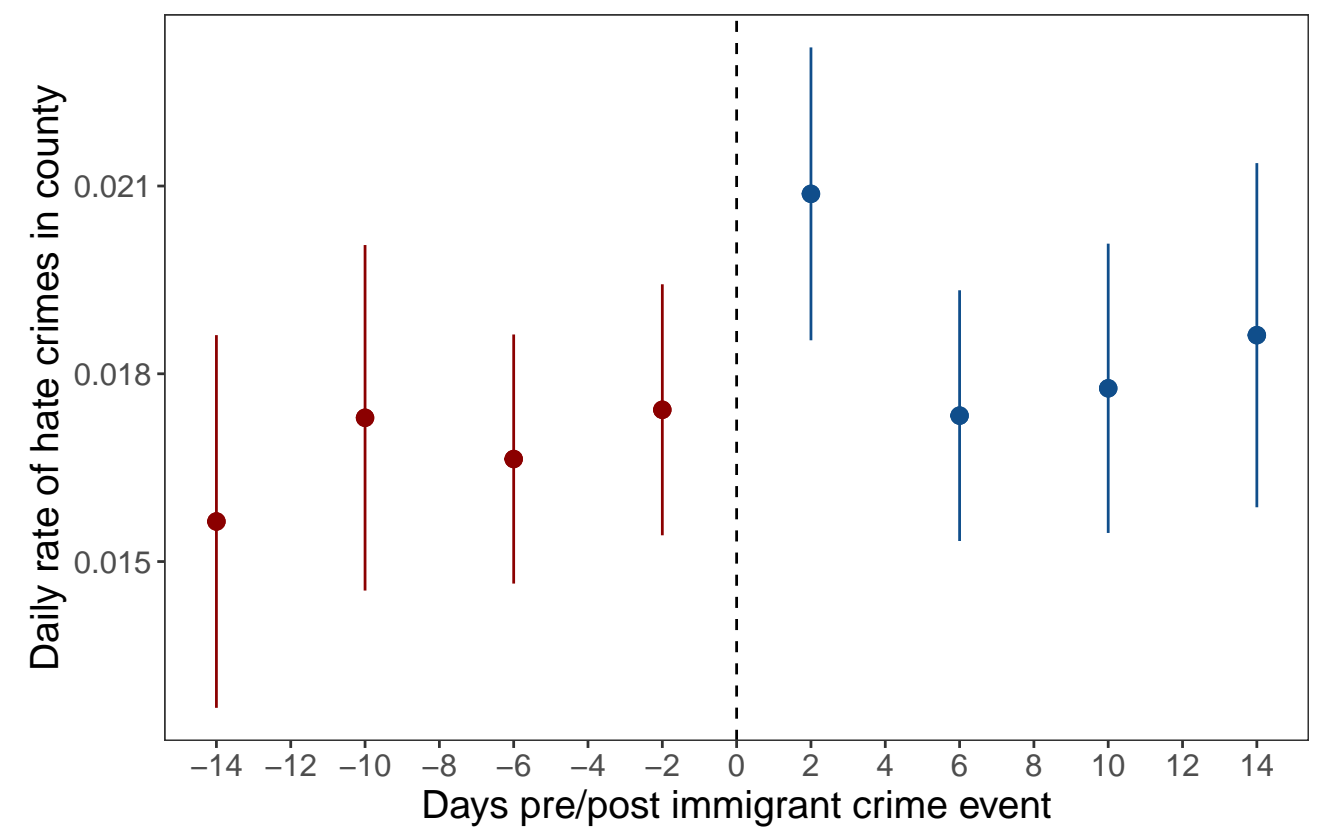

Note: The plot shows the daily rate of hate crimes in the two-week period before and after an immigrant crime event occurred. Error-bars indicate $95 \%$ confidence intervals. We show RD plots including a linear polynomial fit in section Sl.10.

crimes (see section 3.2), and for different functional forms of the local polynomial that we fit on both sides of the treatment assignment cutoff. In line with our theoretical expectations, these results are driven by violent crime events (e.g. stabbings, rape, etc.) that are most likely to generate perceived out-group threat. Based on the models using a binary outcome variable, we estimate that the daily probability of a xenophobic hate crime in a county increases by $1-2$ percentage points in the immediate aftermath of an immigrant crime event. The magnitude of the effect estimates varies moderately across model specifications, with larger estimates when we use a quadratic rather than linear functional form.

While the baseline probability of a hate crime occurring in a given county on a given day is low, the estimated treatment effects are sizable. In relative terms, an increase of 1- 2 percentage points in the daily probability of hate crimes in a given county corresponds to a $65 \%-130 \%$ increase relative to the pre-treatment baseline. A back-of-the-envelope calculation on the basis of our findings suggests that about 500 additional hate crimes occurred because of the 17,600 migrant crime events we observe. ${ }^{9}$ This is a lower-bound estimate of the total net effect of

${ }^{9}$ We arrived at this estimate by multiplying the effect estimate from model 1 in table 1 (count 
Table 1: Main results

\begin{tabular}{lllllll}
\hline$\hat{\tau}$ & p-value & Crime Subset & DV & Bandwidth & Polynomial & $N$ \\
\hline $0.015^{* *}$ & 0.01 & Full sample & Count & 2 & Linear & 26,131 \\
$0.024 * *$ & 0.03 & Full sample & Count & 3 & Quadratic & 36,215 \\
$0.011^{* *}$ & 0.03 & Full sample & Binary & 2 & Linear & 26,131 \\
$0.021 * *$ & 0.04 & Full sample & Binary & 3 & Quadratic & 36,215 \\
$0.010 * *$ & 0.047 & Violent crime & Count & 3 & Linear & 33,349 \\
-0.005 & 0.55 & Non-violent crime & Count & 4 & Linear & 16,482 \\
\hline
\end{tabular}

Notes: The table shows the results from regression discontinuity analyses. The outcome variable are hate crimes measured at the county-day level (see section 3.2). The first column shows the local average treatment effect estimates $(\hat{\tau})$. The number of daily observations that fall within the bandwidth is shown in the last column $(N)$. Because we use an optimal bandwidth selection algorithm, the bandwidth differs across samples and model specifications. Results for manual bandwidths are presented in figure SI 17. We use linear or quadratic polynomials for estimation (see also section SI.4). For the results shown in rows five and six, we subset to violent/non-violent immigrant crime events prior to data transformation (see section SI.2.8 for more details). We use robust bias-corrected standard errors for all analyses. ${ }^{* * *} \mathrm{p}<.01$; ${ }^{* *} \mathrm{p}<.05 ;{ }^{*} \mathrm{p}<.1$.

immigrant-attributed crimes on hate crimes since our data source does not cover the entirety of crimes attributed to immigrants. To further put the magnitude of our findings into perspective, we estimated the share of variance in hate crimes across counties that can be accounted for by different covariates in fixed effects OLS regressions (see figure SI 14). We find that our effect size estimates are larger compared to other covariates (e.g. native unemployment) that prior research has identified as important determinants of hate crime.

Do immigrant-attributed crime events increase the rate of hate crimes through processes of cognition (shifting attitudes), affect (emotional reactions), or both? (see section 2) While we cannot conclusively answer this question, we view the temporal persistence of our effects as suggestive evidence in this regard. As noted above, we observe a surge in the rate of hate crimes in the immediate aftermath of crime events attributed to immigrants. After about four days, the likelihood of hate crimes reverts back to its pre-treatment level. We argue that the short-term effects we identify speak in favor of affect as a central driver of our results. If attitude shifts were the primary mechanism driving our results, we would expect a more persistent shift in

outcome measure, linear polynomial) by the total number of refcrime events attributed to Muslim/African perpetrators (17,600) for a bandwidth of 2 days. 
the rate of hate crimes rather than a temporary, short-term surge. Accordingly, we interpret our results as evidence that out-group crime events act as an emotional 'trigger' for individuals who already hold negative anti-immigrant attitudes.

In section SI.6 we present the results from a battery of additional tests we conducted to ensure the robustness of our results. We demonstrate that our results are robust to (1) different choices of the bandwidth in days, (2) jackknife resampling at the county/state level, (3) excluding events that are not substantiated by official police press releases, (4) leveraging the full sample of more than 17,600 events, regardless of partial overlap between events, and (5) conducting a simple difference in means comparison around the cutoff (see table SI 6). We also address the possibility of spillover effects, reverse causality, and time-varying confounders through a number of additional tests, which we discuss in detail in section SI.6. Notably, we do not find evidence for spillover effects: migrant crimes do not predict hate crime events in neighboring counties (see Figure SI 18). This suggests that the effects we identify are highly localized and thus distinct from the focusing events studied in prior research.

\subsection{Moderators and mechanisms}

We now turn to investigating the mechanisms that drive our results. In section 2, we argued that migrant-attributed crimes leads to cognitive and affective reactions based on perceived threat. Unfortunately, we cannot test these mechanisms directly: perpetrators of hate crimes are a small population that is difficult to sample. However, we can derive and test observable implications for key mechanisms. We proceed in three steps.

First, we analyze what types of migrant-attributed crimes drive our results. As we outlined in section 2, we would expect that violent migrant-attributed crimes (e.g. stabbings, rape, etc.) present a greater threat to the ingroup and should thus be more likely to lead to hate crimes. To test this, in Table 1 we re-estimate our main model for two different subsets of our data: violent crimes and non-violent crimes. ${ }^{10}$ In line with our theoretical expectations, we find that our results are driven by violent migrant-attributed crime events, which are most likely to engender outrage among natives (Couttenier et al. 2019). We find smaller, statistically

${ }^{10}$ We provide more details on the classification of crime events in section SI.2.8. 
insignificant treatment effect estimates for the subset of non-violent crimes such as traffic offenses, fare evasion, and other minor offenses.

Table 2: Placebo tests, non-refugee perpetrator groups

\begin{tabular}{llllll}
\hline$\hat{\tau}$ & p-value & Perpetrator Subset & Crime subset & BW & $N$ \\
\hline 0.004 & 0.45 & European perp. & Full sample & 3 & 30,732 \\
-0.003 & 0.62 & European perp. & Violent crime & 3 & 26,594 \\
0.002 & 0.78 & European perp. & Non-violent crime & 5 & 20,022 \\
0.002 & 0.62 & Nationality unknown & Full sample & 5 & 65,794 \\
-0.004 & 0.34 & Nationality unknown & Violent crime & 3 & 42,221 \\
-0.006 & 0.47 & Nationality unknown & Non-violent crime & 4 & 16,719 \\
0.003 & 0.58 & Excluding Muslims/Africans & Full sample & 3 & 31,352 \\
-0.005 & 0.47 & Excluding Muslims/Africans & Violent crime & 3 & 27,221 \\
0.0004 & 0.95 & Excluding Muslims/Africans & Non-violent crime & 5 & 20,670 \\
\hline
\end{tabular}

Notes: The table shows the results from regression discontinuity analyses. The outcome variable is the number of hate crimes measured at the county-day level. The first column shows the local average treatment effect estimates $(\hat{\tau})$. The number of daily observations that fall within the optimal bandwidth is shown in the last column $(N)$. We subset to (i) crimes committed by European perpetrators, (ii) cases for which the nationality of the perpetrator is unknown, and (iii) all perpetrator nationalities except Muslim-majority and African countries (see also section SI.2.9). We use a linear polynomial and robust bias-corrected standard errors for all analyses. ${ }^{* * *} p<.01 ;{ }^{* *} p<.05 ;{ }^{*} p$ $<.1$.

In addition, we also expect backlash to be less likely in reaction to crimes committed by perpetrators that are neither Muslim nor African. Following our theoretical framework, crimes committed by Eastern Europeans, for instance, should not result in xenophobic violence against refugees (see also section 3.1). To test this observable implication, we re-estimate our main specifications for crimes in which (i) at least one perpetrator was reported to be from a European country, (ii) crimes where no group-relevant information on the perpetrator was given, and (iii) crimes attributed to perpetrators of any nationality except Muslim-majority or African countries. We present the results in Table 2. We do not find a backlash effect for either of these perpetrator groups. These findings suggest that we are indeed identifying group-based vicarious retribution dynamics against refugees. Perceived threat generated by out-group crime leads to xenophobic backlash.

Next, we test whether our results are driven by regions in which the share of potential perpetrators who could be triggered by immigrant-attributed crimes is high, or where relevant group dynamics might be more likely. We measure far-right mobilization potential using two 
complementary proxy measures: i) the county-level vote share of the AfD in the 2017 federal election, and ii) state-level AfD membership (Niedermayer 2020).

We find that our results are driven by localities in which the potential for far-right mobilization is high (see figure 4). We find large, statistically significant effect estimates in the subset of counties in which electoral support for the AfD is high, and many individuals supported the AfD not just in elections but as active party members. Xenophobic backlash against immigrant crimes is most likely to occur in localities where the radical right enjoys deep-rooted local support. In contrast, we find small, statistically insignificant effect estimates when we subset to localities where the potential for far-right mobilization is low. We interpret this as evidence supporting the hypothesis that out-group crimes are more likely to trigger hate crimes when local group dynamics and norms are more permissive of hate crimes, and when a substantial numeric reservoir of potential hate crime perpetrators exists (see section 2). ${ }^{11}$

We also test whether the mere local number of and increase in migrants - a proxy for potential threat perceptions - increases the probability of backlash. We find that hate crimes in reaction to migrant-attributed crimes are more likely in areas where there has been a significant demographic change over a short time span, that is where there has been a large proportional increase in the foreign-born population in recent years. Vicarious retribution is if anything more likely in areas with few foreigners. A recent increase in the immigrant population, not their absolute number, appears to create a context of out-group threat conducive to backlash. This finding aligns with prior research on the importance of over-time changes in the immigrant population as a determinant of attitudes and perceptions (Hopkins 2010; Newman and Velez 2014). ${ }^{12}$

${ }^{11}$ We note that formal tests of the statistical significance of the treatment-moderator interactions in the RDiT setup require additional assumptions about the covariance between LATE estimates across subsets. We elaborate on this point in section SI.11 in the SI, where we conduct significance tests for the results presented in Figure 4.

${ }^{12}$ In section SI.7 in the SI, we conduct supplementary analyses for additional moderator variables, including local economic conditions, and East/West Germany; these additional analyses do not show clear patterns of effect heterogeneity. 
Figure 4: Effect heterogeneity, local far-right mobilization potential

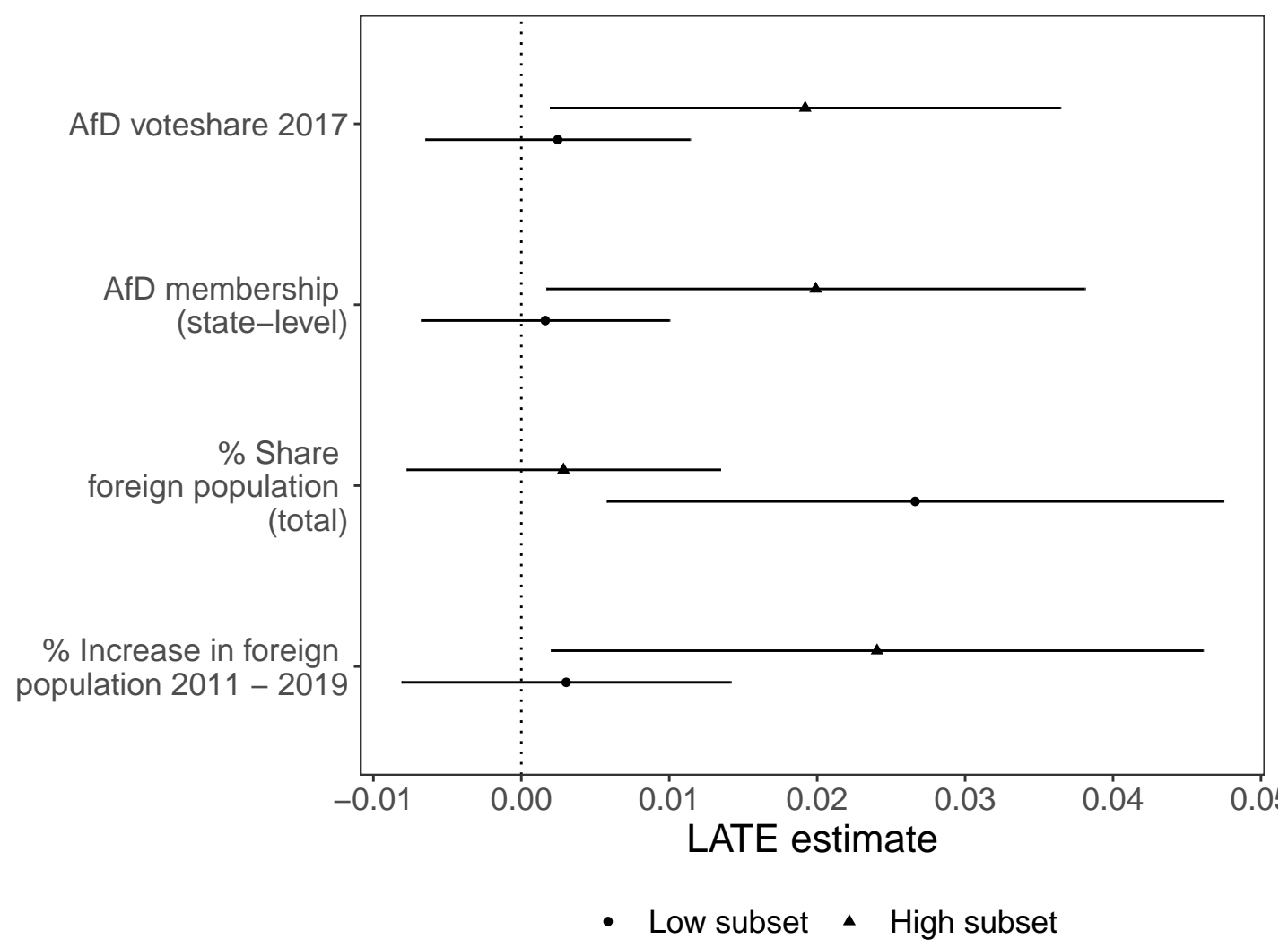

Note: Local average treatment effect on the treated estimates from RDiT models. To test for effect heterogeneity, we re-estimate the same model as for our main results in different subsets of the data. We created the subsets by first dichotomizing each moderator variable using a median split. We then subset our data to a 'low' subset in which the moderator variable takes on values below its median value and a 'high' subset in which the moderator lies above its median value. Error-bars indicate $95 \%$ confidence intervals. We note that this analysis is similar to the estimation of interaction effects in standard OLS models.

Finally, we provide additional evidence on the broader social effects of migrant-attributed crime at the aggregate level. We draw on nation-wide public opinion data to examine attitudes towards immigration before and after two of the most salient migrant crime events we discussed previously: the events in Chemnitz and the sexual assaults in Cologne on New Year's Eve 2015-2016. These data do not show any meaningful public opinion shifts in the aftermath of these salient crime events. If anything, we find that natives, on average, are increasingly concerned about xenophobic violence against minorities during periods of intergroup conflict (for detailed results, see appendix SI.8). We interpret this as suggestive evidence that outgroup threats do not appear to increase the legitimacy of xenophobic hate crimes in the broader population. We stress that our analysis focuses on averages across representative samples of the German population - perceived out-group threats might of course increase the legitimacy 
of xenophobic acts in some segments of the electorate. Moreover, we cannot rule out the possibility that perceptions of the legitimacy of vicarious retribution shift among potential perpetrators - regardless of the true shift in public opinion in the aftermath of crimes attributed to immigrants.

In sum, the evidence we find aligns with our theoretical account that treats out-group threat as a mobilizing event among already radicalized individuals. This account also aligns with anecdotal evidence from prominent cases such as the events in Chemnitz described in the introduction, where individuals with preexisting prejudice against minorities were triggered to commit hate crimes. We do not find evidence for broader legitimization of hate crimes in the aftermath of crimes attributed to immigrants. However, it is of course possible that perceptions of hate crime legitimacy shift among radicalized potential perpetrators, rather than objective indicators of legitimacy itself. We caution against a conclusive interpretation of our evidence on the individual-level mechanisms driving our results, as hate crimes are a rare phenomenon and perpetrators are generally not identifiable in public opinion surveys. It is possible that other mechanisms might be relevant in the context of our study.

\section{Conclusion}

A growing literature notes that salient national events drive negative attitudes towards minorities (e.g., King and Sutton 2013; Frey 2020; Devine 2020). Our research adds a local intergroup perspective: localized threatening acts committed by out-group members - here approximated with crimes attributed to immigrants - can lead to a temporary surge in the rate of hate crimes. Using unique geocoded data on hate crimes and crime attributed to immigrants, we estimate the causal effect of such 'migrant crime' on hate crimes using a regression discontinuity in time design. We find a clear increase in the rate of hate crimes against refugees immediately after crimes attributed to immigrants from Muslim-majority or African countries. We also provide indicative evidence that the most plausible mechanism underlying this effect is one of a trigger for action among already radicalized individuals. Thus, the surge in hate crimes is clearer for violent acts attributed to immigrant perpetrators. Moreover, we find suggestive evidence that the extent to which immigrant-attributed crimes are seen as threatening matters, 
as the increase in hate crimes is greater where there has been a larger proportional increase in foreigners in recent years. In addition, in-group legitimization and dynamics may matter, as we find a greater retributive reaction in areas where there are more radicalized individuals, as measured by radical-right party strength. Recent research also indicates that hate crimes may in turn foster radical right support (Eger and Olzak 2022). We also find suggestive evidence that vicarious retribution does not emerge from a change in attitudes towards foreigners among the broader native population, but rather stems from those who already hold strong negative prejudice towards immigrants and refugees.

Are our findings generalizable to other cases? We view it as plausible that the vicarious retribution dynamics we document in this paper might also apply in other countries and time periods. As we outlined in section SI.1, the German case is a typical case in many ways, particularly in that (i) Germany hosts a large and growing immigrant population, (ii) immigration was a salient policy issue during our study period, and (iii) hate crimes against minorities have surged in recent years. The AfD is now an established radical-right party, making Germany much less exceptional in the European context. Against this background, we view Germany as a typical and 'most likely case' - at least since the so called 'refugee crisis'. At the same time, more research is needed to better understand how political and societal contextual conditions moderate the mechanisms we lay out in this paper.

Naturally the fact that migrant-attributed crime leads to hate crimes in no way legitimizes these acts. Instead, our findings are consistent with studies that show that perceived immigration-based threats have a galvanizing effect on those already predisposed towards negative attitudes, rather than a broader persuasive effect (Sniderman, Hagendoorn, and Prior 2004). Importantly, our findings do not provide support for an account where two clearly defined social groups oppose each other, as would be the case for more broad-based ethnic tension and violence. Instead, crimes attributed to migrants - themselves a diffuse group - appear to trigger a narrow set of ingroup members to commit hate crimes against (usually uninvolved) out-group members. This dynamic is not one that fits a simple story of community-based ethnic conflict, even if those who perpetrate hate crimes may see it that way. Interestingly, there is evidence that hate crimes in turn facilitate jihadi recruitment (Mitts 2019); these terrorist sympathizers are of course just as unrepresentative of the out-group as hate crime perpetrators 
are of the ingroup.

While our study advances existing research by providing a local perspective on hate crimes and vicarious retribution, it comes with several limitations that future research might be able to address. First, questions about the mechanisms underlying local vicarious retribution dynamics remain. For data privacy reasons, we are unable to identify the perpetrators of hate crimes, and thus cannot complement our quantitative work with in-depth interviews to tease apart the individual-level motives of offenders. We view this as a general gap in the literature on hate crimes: research on the motivations of hate crime perpetrators is rare, as offenders generally remain anonymous for data privacy reasons. We note, however, that those selected studies that have analyzed perpetrators cite 'retaliatory motives' as an important driver of hate crimes (McDevitt, Levin, and Bennett 2002; Byers and Crider 2002). ${ }^{13}$ Nevertheless, qualitative or quantitative data on the characteristics and motivations of hate crime perpetrators in our setting could help clarify the individual-level mechanisms driving our results.

We also want to highlight the possibility of measurement error in both our treatment and outcome variables. While we conducted a variety of robustness tests to verify that our results are not driven by systematic measurement error, underreporting remains a key challenge for the study of crime and hate crime specifically. Recent research by the EU Agency for Fundamental Rights suggests that as many as nine out of ten hate crimes remain unreported and hence practically invisible to researchers (FRA 2021).

Finally, more research is needed on the policy implications of our findings. At first sight, one might conclude that media outlets should not report on migrant crimes or, at the very least,

${ }_{13}^{13}$ CDevitt, Levin, and Bennett (2002) for example draw on police records for about 160 hate crimes in Boston and identified a retaliatory motive in about $8 \%$ of cases. In a unique qualitative study of hate crime offenders, Byers and Crider (2002) identify similar motives driving hate crimes against the Amish. In a series of narrative interviews of eight hate crime offenders, perpetrators frequently justified their actions on the grounds of 'deservingness', "either because of something that a specific Amish person had done to them, or for behaviors that the Amish, as a whole engage in which the offender found disturbing" (Byers and Crider 2002: p. 124). 
avoid the use of language that conveys the out-group status of perpetrators (Couttenier et al. 2019). While it is perhaps uncontroversial that news outlets should refrain from descriptions such as "[...] a dark-skinned man with thick lips, speaking broken German [...]"14, this is not a conclusion necessarily to be drawn only from our research. The advice that journalists should refrain from stereotypical, racist descriptions does not depend on the consequences of such reporting. Indeed, to the extent that natives hold biased beliefs about the relative frequency of native vs. immigrant perpetrators of crime, omitting (factual) identifying information from news articles might instead perpetuate biased beliefs about the prevalence of migrant crime and political slant in media reporting. More research is needed to understand how media outlets can disseminate information about salient local events - including crimes committed by both natives and immigrants - without facilitating the dynamics of prejudice and hate we have identified in this study.

\section{References}

Allen, Johnie J, Craig A Anderson, and Brad J Bushman. 2018. "The general aggression model." Current opinion in psychology 19: 75-80.

Anderson, Craig A, Brad J Bushman et al. 2002. “Human aggression." Annual review of psychology 53 (1): $27-51$.

Balcells, Laia, Lesley-Ann Daniels, and Abel Escribà-Folch. 2016. "The determinants of lowintensity intergroup violence: The case of Northern Ireland." Journal of Peace Research 53 (1): 33-48.

BAMF. 2016. “Antrags-, Entscheidungs- und Bestandsstatistik 2016.".

URL: https://fragdenstaat.de/files/foi/62265/HKL_Kontinentkum.pdf? down load

BAMF. 2017. “Pressemitteilung: 280.000 Asylsuchende im Jahr 2016." https://www . bmi . bund.

14“Dunkelhäutig, wulstige Lippen, er sprach gebrochenes Deutsch” (HNA 2017). 
de/SharedDocs/pressemitteilungen/DE/2017/01/asylantraege-2016.html. Accessed: 2021-08-25.

Benček, David, and Julia Strasheim. 2016. "Refugees welcome? A dataset on anti-refugee violence in Germany." Research \& Politics 3 (4).

Bischof, Daniel, and Markus Wagner. 2019. “Do Voters Polarize When Radical Parties Enter Parliament?" American Journal of Political Science 63 (4): 888-904.

Blumer, Herbert. 1958. "Race prejudice as a sense of group position." Pacific sociological review $1(1): 3-7$.

Byers, Bryan D, and Benjamin W Crider. 2002. "Hate crimes against the Amish: A qualitative analysis of bias motivation using routine activities theory." Deviant Behavior 23 (2): 115-148.

Cattaneo, Matias D, Nicolás Idrobo, and Rocío Titiunik. 2019. A practical introduction to regression discontinuity designs: Foundations. Cambridge University Press.

Christensen, Love, and Jakob Enlund. 2019. "Echoes of Violent Conflict.".

Colussi, Tommaso, Ingo E Isphording, and Nico Pestel. 2021. “Minority salience and political extremism." American Economic Journal: Applied Economics 13 (3): 237-71.

Couttenier, Mathieu, Sophie Hatte, Mathias Thoenig, and Stephanos Vlachos. 2019. “The logic of fear-populism and media coverage of immigrant crimes.".

Czymara, Christian S, and Alexander W Schmidt-Catran. 2016. "Wer ist in Deutschland willkommen?" KZfSS Kölner Zeitschrift für Soziologie und Sozialpsychologie 68 (2): 193-227.

Czymara, Christian S, and Alexander W Schmidt-Catran. 2017. "Refugees unwelcome? Changes in the public acceptance of immigrants and refugees in Germany in the course of Europe's 'immigration crisis'." European Sociological Review 33 (6): 735-751.

Dancygier, Rafaela, and Donald P Green. 2010. "Hate crime." In The SAGE handbook of prejudice, stereotyping, and discrimination, ed. JF Dovidio, M. Hewstone, Glick P, and VM Esses. Sage pp. 294-311. 
Dancygier, Rafaela M. 2010. Immigration and conflict in Europe. Cambridge University Press.

Devine, Daniel. 2020. "Discrete Events and Hate Crimes: The Causal Role of the Brexit Referendum." Social Science Quarterly p. (forthcoming).

Di Stasio, Valentina, Bram Lancee, Susanne Veit, and Ruta Yemane. 2021. “Muslim by default or religious discrimination? Results from a cross-national field experiment on hiring discrimination." Journal of Ethnic and Migration Studies 47 (6): 1305-1326.

Dinas, Elias, and Joost van Spanje. 2011. "Crime Story: The role of crime and immigration in the anti-immigration vote." Electoral Studies 30 (4): 658-671.

Disha, Ilir, James C. Cavendish, and Ryan D. King. 2011. "Historical Events and Spaces of Hate: Hate Crimes against Arabs and Muslims in Post-9/11 America." Social Problems 58 (1): 21-46.

Eger, Maureen A, and Susan Olzak. 2022. "The Polarizing Effect of Anti-Immigrant Violence on Radical Right Sympathies in Germany." International Migration Review p. 01979183221126461.

Enos, Ryan D. 2014. "Causal effect of intergroup contact on exclusionary attitudes." Proceedings of the National Academy of Sciences 111 (10): 3699-3704.

FRA. 2021. "Hate crime reporting infographic.".

URL: https://fra. europa.eu/en/publications-and-resources/infographics/ hate-crime-reporting-infographic

Frey, Arun. 2020. “'Cologne Changed Everything'-The Effect of Threatening Events on the Frequency and Distribution of Intergroup Conflict in Germany." European Sociological Review pp. 1-16.

Godefroidt, Amelie. 2021. “How Terrorism Does (and Does Not) Affect Citizens Political Attitudes: A Meta-Analysis." American Journal of Political Science .

Green, Donald P., and Amber D. Spry. 2014. "Hate Crime Research: Design and Measurement Strategies for Improving Causal Inference." Journal of Contemporary Criminal Justice 30 (3): 228-246. 
Green, Donald P, Jack Glaser, and Andrew Rich. 1998. “From Lynching to Gay Bashing: The Elusive Connection Between Economic Conditions and Hate Crime." Interpersonal Relations and Group Processes 75 (1): 82-92.

Green, Donald P, Laurence H Mcfalls, and Jennifer K Smith. 2001. “Hate Crime: An Emergent Research Agenda." Annual Review of Sociology 27 (1): 479-504.

Grunert, Johannes. 2018. "Der Abend, an dem der Rechtsstaat aufgab." ZEIT Online, https://www.zeit.de/gesellschaft/zeitgeschehen/2018-08/chemnitz-rechtedemonstration-ausschreitungen-polizei.

Guyer, Joshua J, and Leandre R Fabrigar. 2015. "Attitudes and behavior." In International Encyclopedia of the Social and Behavioral Sciences, 2nd edition, ed. James D Wright. Elsevier pp. 183-189.

Hanes, Emma, and Stephen Machin. 2014. "Hate Crime in the Wake of Terror Attacks: Evidence From 7/7 and 9/11." Journal of Contemporary Criminal Justice 30 (3): 247-267.

Hangartner, Dominik, Elias Dinas, Moritz Marbach, Konstantinos Matakos, and Dimitrios Xefteris. 2019. "Does Exposure to the Refugee Crisis Make Natives More Hostile?" American Political Science Review 113 (2): 442-455.

Hausman, Catherine, and David S. Rapson. 2018. “Regression Discontinuity in Time: Considerations for Empirical Applications." Annual Review of Resource Economics 10 (1): 533-552.

Hestermann, Thomas. 2019.

URL: https://mediendienst-integration. de/fileadmin/Expertise_Hestermann_ Herkunft_von_Tatverdaechtigen_in_den-Medien.pdf

HNA. 2017. "23-jaehrige Frau in Kassel vergewaltigt und mit Messer verletzt." https://www.hna.de/kassel/23-jaehrige-frau-in-kassel-vergewaltigt-undmit-messer-verletzt-9459385.html. Accessed: 2021-08-25.

Hopkins, Daniel J. 2010. “Politicized places: Explaining where and when immigrants provoke local opposition." American Political Science Review 104 (1): 40-60. 
Ivandic, Ria, Tom Kirchmaier, and Stephen J Machin. 2019. “Jihadi attacks, media and local hate crime." IZA Institute of Labor Economics, https://www.iza.org/publications/dp/12352/ jihadi-attacks-media-and-local-hate-crime.

Jäckle, Sebastian, and Pascal D. König. 2018. “Threatening events and anti-refugee violence: An empirical analysis in the wake of the refugee crisis during the years 2015 and 2016 in Germany." European Sociological Review 34 (6): 728-743.

Jungkunz, Sebastian, Marc Helbling, and Carsten Schwemmer. 2019. "Xenophobia before and after the Paris 2015 attacks: Evidence from a natural experiment." Ethnicities 19 (2): 271-291.

Kam, Cindy D, and Donald R Kinder. 2007. "Terror and ethnocentrism: Foundations of American support for the war on terrorism." The Journal of Politics 69 (2): 320-338.

Kampf, Lena, Sebastian Pittelkow, and Katja Riedel. 2019. “Chatprotokolle zeigen Verabredung zu Hetzjagden in Chemnitz." Süddeutsche Zeitung.

Karapin, Roger. 2002. “Antiminority riots in unified Germany: Cultural conflicts and mischanneled political participation." Comparative Politics pp. 147-167.

King, Ryan D., and Gretchen M. Sutton. 2013. “High times for hate crimes: Explaining the temporal clustering of hate-motivated offending." Criminology 51 (4): 871-894.

Krueger, Alan B. 2007. What Makes a Terrorist. Princeton: Princeton University Press.

Krueger, Alan B, and Jörn-Steffen Pischke. 1997. “A statistical analysis of crime against foreigners in unified Germany." Journal of Human Resources pp. 182-209.

Legewie, Joscha. 2013. "Terrorist events and attitudes toward immigrants: A natural experiment." American journal of sociology 118 (5): 1199-1245.

Lickel, Brian, Norman Miller, Douglas M Stenstrom, Thomas F Denson, and Toni Schmader. 2006. "Vicarious retribution: The role of collective blame in intergroup aggression." Personality and social psychology review 10 (4): 372-390. 
Liebe, Ulf, and Nicole Schwitter. 2021. "Explaining Ethnic Violence: On the Relevance of Geographic, Social, Economic, and Political Factors in Hate Crimes on Refugees." European Sociological Review . jcaao55.

McDevitt, Jack, Jack Levin, and Susan Bennett. 2002. “Hate crime offenders: An expanded typology." Journal of social issues 58 (2): 303-317.

Meuleman, Bart, Koen Abts, Koen Slootmaeckers, and Cecil Meeusen. 2019. “Differentiated threat and the genesis of prejudice: group-specific antecedents of homonegativity, Islamophobia, anti-Semitism, and anti-immigrant attitudes." Social Problems 66 (2): 222-244.

Mitts, Tamar. 2019. "From isolation to radicalization: anti-Muslim hostility and support for ISIS in the West." American Political Science Review 113 (1): 173-194.

Müller, Karsten, and Carlo Schwarz. 2020. “Fanning the Flames of Hate: Social Media and Hate Crime." Journal of the European Economic Association . jvaao45.

Newman, Benjamin J, and Yamil Velez. 2014. 'Group size versus change? Assessing Americans' perception of local immigration." Political Research Quarterly 67 (2): 293-303.

Niedermayer, Oskar. 2020. “Parteimitglieder in Deutschland: Version 2020.".

Nussio, Enzo. 2020. “Attitudinal and Emotional Consequences of Islamist Terrorism. Evidence from the Berlin Attack." Political Psychology 41 (6): 1151-1171.

Nussio, Enzo, Vincenzo Bove, and Bridget Steele. 2019. “The consequences of terrorism on migration attitudes across Europe." Political Geography 75: 102047.

Peffley, Mark, Marc L Hutchison, Michal Shamir et al. 2015. "The impact of persistent terrorism on political tolerance: Israel, 1980 to 2011." American political science review 109 (4): 817-832.

Reuters Institute. 2018. “Digital News Report 2018.".

URL: https://reutersinstitute.politics.ox.ac.uk/sites/default/files/ digital-news-report-2018. pdf 
Romarri, Alessio. 2020. "Do far-right mayors increase the probability of hate crimes? Evidence from Italy." SSRN Working Paper, https://papers. ssrn.com/sol3/papers.cfm?abstract_ $i d=3506811$.

Smångs, Mattias. 2016. “Doing violence, making race: Southern lynching and white racial group formation." American Journal of Sociology 121 (5): 1329-1374.

Smångs, Mattias. 2017. "The lynching of African Americans in the US South: A review of sociological and historical perspectives." Sociology compass 11 (8): e12500.

Sniderman, Paul M, Louk Hagendoorn, and Markus Prior. 2004. “Predisposing factors and situational triggers: Exclusionary reactions to immigrant minorities." American political science review pp. 35-49.

Statistisches Bundesamt. 2019. "Schutzsuchende - Ergebnisse Des Ausländerzentralregisters 2020.".

Valentino, Nicholas A, Stuart N Soroka, Shanto Iyengar, Toril Aalberg, Raymond Duch, Marta Fraile, Kyu S Hahn, Kasper M Hansen, Allison Harell, Marc Helbling et al. 2019. “Economic and cultural drivers of immigrant support worldwide." British Journal of Political Science 49 (4): $1201-1226$.

van Um, Eric, Michael Huch, and Mathias Bug. 2015. “Lokale Kriminalitätsberichterstattung: Abbild oder Zerrspiegel von Kriminalität?" DIW Wochenbericht 82 (12): 288-294.

Walters, Mark Austin. 2011. "A general theories of hate crime? Strain, doing difference and self control." Critical Criminology 19 (4): 313-330.

Weaver, Michael. 2019. "Judge Lynch in the court of public opinion: Publicity and the delegitimation of lynching." American Political Science Review 113 (2): 293-310.

Zeitzoff, Thomas. 2014. "Anger, Exposure to Violence, and Intragroup Conflict: A "Lab in the Field" Experiment in Southern Israel." Political Psychology 35 (3): 309-335. 
Supporting Information:

Out-group Threat and Xenophobic Hate Crimes:

Evidence of Local Intergroup Conflict Dynamics between Immigrants and Natives 


\section{SI Supporting Information}

\section{Contents}

Sl.1 The case: Germany, 2015-2019 _ . . . . . . . . . . . . . . . . . . . . SI 3

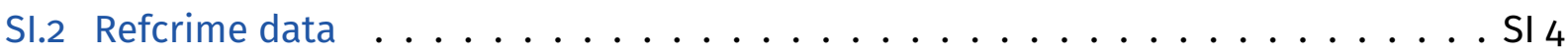

SI.2.1 Summary statistics . . . . . . . . . . . . . . . . . SI 4

SI.2.2 Data quality ............................... 5

SI.2.3 Additional details: validation by hand-coding . . . . . . . . . . . SI 6

SI.2.4 Sources cited on refcrime . . . . . . . . . . . . . . . . . . SI 10

SI.2.5 Police information in local news outlets . . . . . . . . . . . . . SI 12

SI.2.6 Correlates of refcrime event counts . . . . . . . . . . . . . . . SI 13

Sl.2.7 Overlapping events . . . . . . . . . . . . . . . . . . SI 14

SI.2.8 Classification of violent and non-violent crimes . . . . . . . . . . . . . SI 17

SI.2.9 Country classification . . . . . . . . . . . . . . . . SI 18

SI.3 Hate crime data . . . . . . . . . . . . . . . . . . . . . . . SI 19

SI.3.1 Descriptive statistics . . . . . . . . . . . . . . . . . . SI 19

SI.3.2 Data source. . . . . . . . . . . . . . . . . . . . . SI 21

SI.3.3 Validation ................................ SI 22

SI.3.4 Cross sectional predictors of hate crime . . . . . . . . . . . . SI 22

SI.3.5 Variance explained by other covariates . . . . . . . . . . . . . SI 24

SI.4 Additional information regarding the empirical strategy $\ldots \ldots \ldots$. . . . . . SI 25

SI.4.1 Local polynomial estimation . . . . . . . . . . . . . . . . SI 25

SI.4.2 Optimal bandwidth selection . . . . . . . . . . . . . . SI 26

Sl.5 Panel analysis . . . . . . . . . . . . . . . . . . . . . SI 27

Sl.6 Robustness . . . . . . . . . . . . . . . . . . . . . . . . SI 31

SI.7 Heterogeneity for additional moderators . . . . . . . . . . . . . . . . SI 40

SI.8 Nation-wide public reaction to salient migrant crime events . . . . . . . . . . SI 41

Sl.9 Public opinion about immigration . . . . . . . . . . . . . . . . . SI 45

Sl.10 RD Plots with linear fit . . . . . . . . . . . . . . . . . . . SI 47

Sl.11 Test of statistical significance for treatment-moderator interactions . . . . . . SI 49 


\section{SI Supporting Information}

\section{Sl.1 The case: Germany, 2015-2019}

During the time period we study, Germany experienced similar demographic and political trends as many other Western European countries. First, both in Germany and other European democracies, the immigrant population has sharply increased in recent years. Between 1990 and 2020, the foreign-born population has risen from $9.2 \%$ to $20 \%$ in Sweden, from $2.5 \%$ to $10.2 \%$ in Italy, and from $7.5 \%$ to $16.3 \%$ in Germany OECD (2021); World Bank (2022). In addition, Germany experienced a sharp influx of refugees starting in 2015 , comparable in per-capita magnitude to countries like Sweden and Austria. By 2018, the total refugee population in Germany had risen to 1.78 million more than $2 \%$ of the country's total population.

Second, immigration was a highly salient policy issue during our study period. Between mid-2014 and 2019, the refugee influx and immigration more generally was by far the most salient political issue in Germany (see Figure $\mathrm{SI} 34$ in the $\mathrm{SI}$ ). In late 2015, almost $90 \%$ of Germans viewed immigration as the most important political issue facing the country. The crime-immigration nexus is a central component of public attitudes towards immigration during our study period. To illustrate this, we draw on a survey fielded in Germany in 2018. More than $40 \%$ of respondents expressed concerns that migration would lead to an increase in crime and terrorism (see figure $\mathrm{SI} 33$ in the $\mathrm{SI}$ ). Worries about immigrant crime and terrorism were much more widespread than worries about labor market competition (15.7\%), or potential fiscal costs (32.7\%). Moreover, a large proportion of respondents expressed worries about precisely the violence dynamics we describe in this study: migrant crime, hate crimes against immigrants, and the overall polarization of society.

Third, while Germany had been one of the few European countries without a radical right party in the federal parliament for decades, this changed after the Alternative für Deutschland entered the Bundestag in 2017. Prior research suggests that radical right parties can lead to a change of social norms concerning the legitimacy of xenophobia Bischof and Wagner (2019); Bursztyn, Egorov, and Fiorin (2020). Similar concerns have been raised for Germany: the Alternative für Deutschland frequently links immigrants to crime, violent crime such as homicides in particular Hestermann and Hoven (2020).

Finally, it is plausible that localized events matter in Germany. For one, about one in two Germans consumed local news - either online or in print - on a weekly basis during our study period Reuters Institute (2018). Such news may also spread in various ways through local social networks, such as in online and offline interpersonal discussion. Moreover, reporting on crime is a central facet of German local news, with one study - a quantitative analysis across 31 German local newspapers - showing that one-third of local news articles are about crime, while violent crimes such as homicides and sexual assaults receive disproportionate attention compared to their overall relative frequency van Um, Huch, and Bug (2015). News on crime tends to feature the nationality or region of origin of the perpetrator Hestermann (2019).

In these aspects, the German case is likely comparable to other Western European countries. Given the salience of the migration 'crisis' and the emergence of the AfD during our study period, our setting can be characterized as particularly conducive to the type of intergroup violence dynamics we study here. We will return to a discussion of the generalizability of our findings to other contexts in the conclusion in section 5 . 


\section{SI.2 Refcrime data}

\section{SI.2.1 Summary statistics}

Table SI 1: Summary statistics, refcrime data

\begin{tabular}{lrrrrrr}
\hline Variable & Mean & Median & S.D. & N & Min & Max \\
\hline City (Stadtkreis) & 0.47 & 0 & 0.50 & 17651 & 0 & 1 \\
Hour of day (o-24) & 13.37 & 15 & 7.34 & 8824 & 0 & 24 \\
Year & 2017.11 & 2017 & 1.06 & 17651 & 2015 & 2019 \\
Violent crime (o/1) & 0.77 & 1 & 0.42 & 17651 & 0 & 1 \\
East Germany (o/1) & 0.17 & 0 & 0.38 & 17651 & 0 & 1 \\
Perpetrator from African country & 0.23 & 0 & 0.42 & 17651 & 0 & 1 \\
Perpetrator from Muslim country & 0.94 & 1 & 0.24 & 17651 & 0 & 1 \\
\hline
\end{tabular}

Notes: Summary statistics for the refcrime data. We subset to the set of cases where at least one suspected perpetrator was either from a Muslim-majority or African country. We provide more details on how we classified countries in section SI.2.9. Some events contain multiple perpetrators, i.e. the binary indicators for Muslim/African origin of the perpetrator are not mutually exclusive. We provide more details on our classification of violent and non-violent immigrant-attributed crimes in section SI.2.8.

Figure SI 1: Temporal distribution of refcrime events

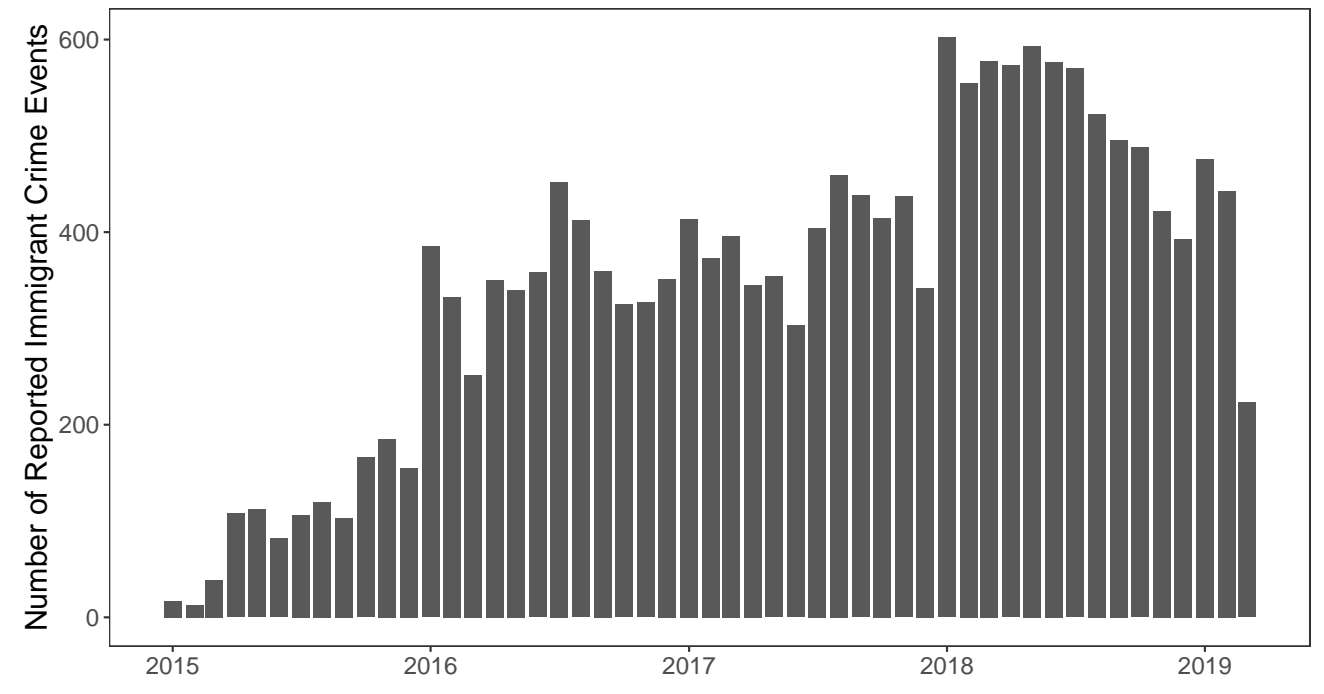

Note: The figure shows the monthly number of reported migrant crime events between 2015 and 2019. We subset to the set of cases where at least one suspected perpetrator was either from a Muslim-majority or African country. 


\section{SI Supporting Information}

\section{SI.2.2 Data quality}

We implemented a number of quality checks of the immigrant crime data to ensure that the reported information is accurate and reporting is not systematically biased.

We first asked five research assistants to independently validate the information reported on the website (see section SI.2.3 for more details). In total we asked our RAs to code 600 randomly drawn events reported by refcrime. Out of these 50 events were coded by all coders. This allows us to estimate the intercoder reliabiliy across the five coders which is high across all coding tasks we assigned (e.g. Cronbach's $\alpha=0.87$ for the verification whether or not the crime was conducted by a migrant according to the source materials).

We then rely on the fact that the refcrime website lists an original source for each reported event (see section SI.2.3 for concrete examples). We find that in virtually all cases, the reporting by refcrime is in line with the listed sources. We find only few instances in which the date (1.63\%), location (1.25\%), or nationality of the perpetrator $(5.51 \%)$ - if listed - is not in line with the source material. Furthermore, in most cases, "migrant crimes" are based on press releases by the local police authorities. In few instances, they are based on reporting by local news outlets. The source material used by refcrime appears to be reliable and, thus, constitutes a credible source to obtain event-level information about crimes attributed to immigrants. We note that the date and time we observe in the recrime data is generally the date when the crime incident occurred.

As an additional step, we also examine the face validity of the migrant crime data by examining the correlation between the number of events reported at the county level with the size of foreign population in the same county. We assume that there should be a correlation between the amount of migrants living in county and the number of crimes committed. As expected, the bivariate correlation between the number of foreigners in a county and the number of reported migrant crimes in our sample is strong at $r=0.55$ (see figure $\mathrm{SI}$ 2).

Figure SI 2: Crimes attributed to immigrants and foreign-born population

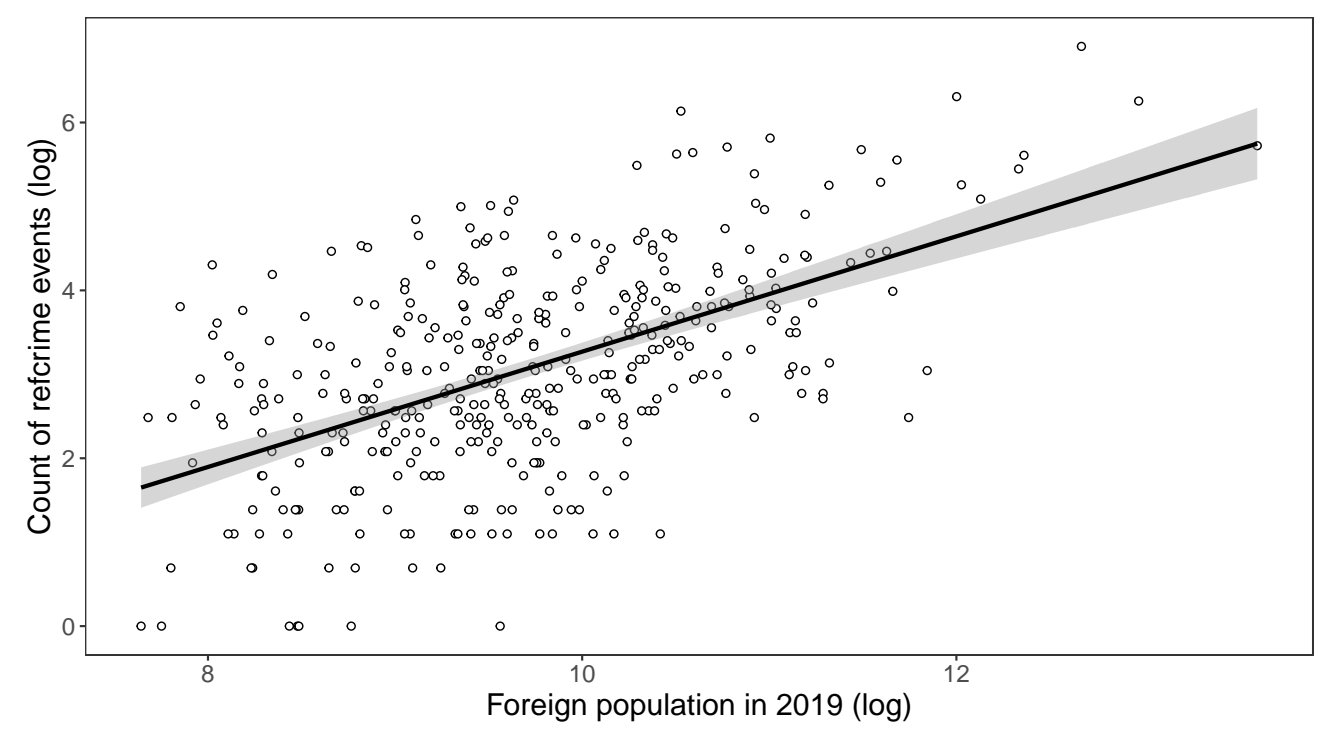

Note: The plot shows the bivariate relationship between the total foreign population (as of 2019) and the total number of migrant crime events recorded in the refcrime data during our study period. Both variables are log-transformed. Each observation represents one county. The Pearson correlation between the two measures is $r=0.546$.

We also verify that refcrime reporting is not simply determined by pre-existing anti-immigrant attituides at the local level. We examine the correlation between the number of recorded migrant crime events and support for the anti-immigrant party Alternative fuer Deutschland (AfD) in the 2017 federal election at the county level. We do not find a relationship between the two variables (see figure $\mathrm{SI} 3$ ).

Importantly, we do not assume that the refcrime data comprehensively covers all crimes committed by 
Figure SI 3: Crimes attributed to immigrants and AfD support

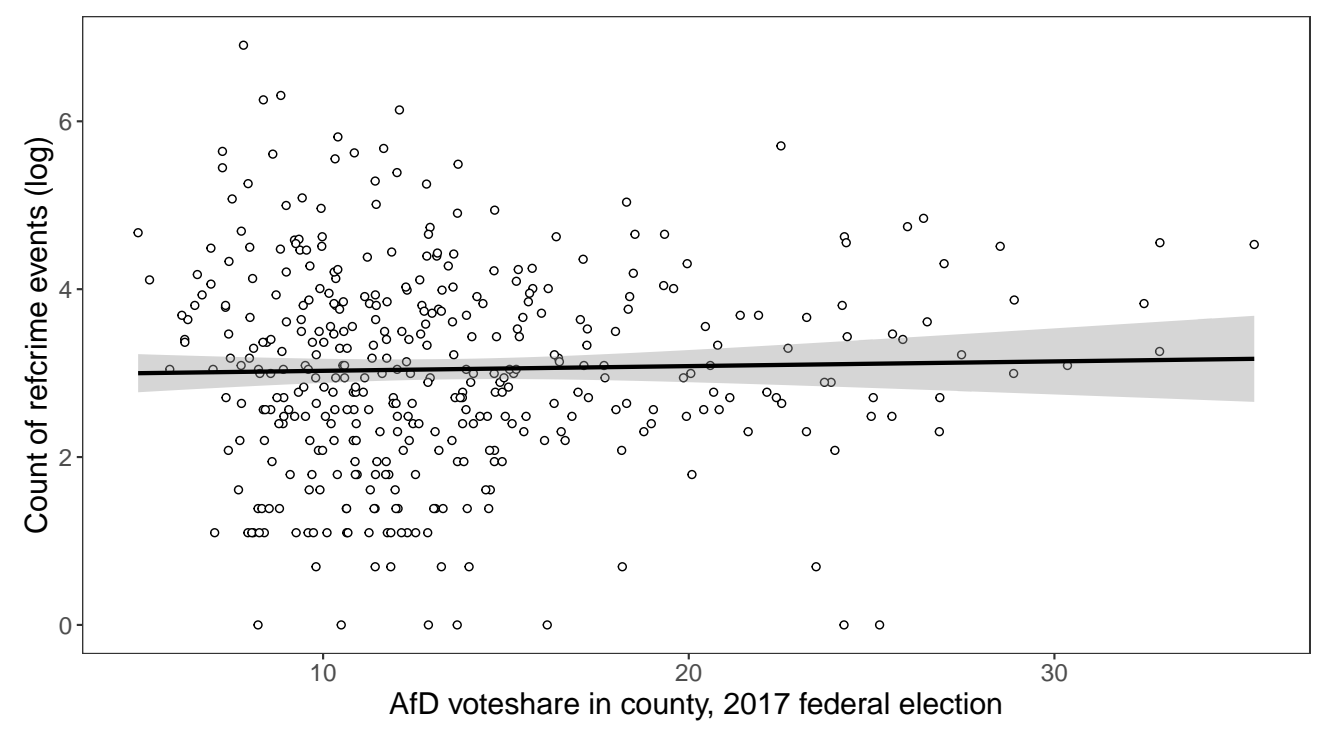

Note: The plot shows the bivariate relationship between the vote share for the Alternative fuer Deutschland (AfD) in the 2017 federal election and the total number of migrant crime events recorded in the refcrime data. The number of crime events is log-transformed. Each observation represents one county. The Pearson correlation between the two measures is $r=0.02$.

immigrants across Germany. Instead, for our purposes the dataset needs to provide a good approximation to migrant crime events that received most attention in the local news media, or right-wing networks. In other words, the dataset covers those incidents that natives were most likely to be aware of.

\section{SI.2.3 Additional details: validation by hand-coding}

We asked five of our research assistants to handcode information on the crime events data we use in this paper. The key reason for doing so is to validate the migrant crime data we scraped from refcrime. Luckily refcrime reports for each crime event the sources from which the information on the crime is retrieved from.

This allows us to validate whether or not the information reported by refcrime is accurate according to the sources used by refcrime. Given the political leaning (conservative/far right) by refcrime we have good reason to assume that refcrime overreports migrant crime. The webpage has been created with the goal to report the "true" amount of "migrant crime" in Germany. This already suggests that the information publicly available is false to some extent. Also the webpage allows everyone to report crimes. This might again result in overreporting of fake events by far right agitators. Yet, fortunately for us, $93 \%$ of the reported events are substantiated by official police press releases. Below we provide three concrete examples: 


\section{SI Supporting Information}

Figure SI 4: Example 1: theft on February 27, 2019 (Gundelsheim), attributed to an Iraqi immigrant

Gundelsheim/Neckarsulm: Zweimal in einer Nacht

Gleich zweimal in einer Nacht ging ein mutmaßlicher Dieb ins Netz der Polizei. Gegen 1 Uhr wurde von einem Zeugen gemeldet, dass ein Mann im Stadtgebiet Gundelsheim an geparkten Autos hantiere. Offensichtlich teste er, ob die Fahrzeuge verschlossen sind. Als er einen solchen Wagen fand, setzte er sich hinein und steckte Münzgeld, das er in der Mittelkonsole fand, ein. Dann ging er weiter zur Schillerstraße, wo er von einer Zivilstreife der alarmierten Polizei gestellt wurde. Er gab zu, mehrere unverschlossene Autos gefunden zu haben, Beute habe er aber nur in einem gemacht. Nach dem Abschluss der Maßnahmen auf dem Polizeirevier Neckarsulm wurde er wieder auf freien Fuß gesetzt. Kurz darauf sah ein Polizeibeamter, der sich auf dem Nachhauseweg befand, den Iraker bei einem Neckarsulmer Autohaus in der Heilbronner Straße. Da er sich bei den dort stehenden PKW aufhielt, wurde er erneut kontrolliert. Er hatte einen 100 Euro-Schein bei sich, den er auf dem Polizeirevier sicher nicht hatte. Auf Frage meinte er, er habe den Schein in der Heilbronner Austraße, nahe der dortigen Asylbewerberunterkunft, gefunden. Da dies zeitlich überhaupt nicht möglich war, wurden erneute Ermittlungen eingeleitet. Diese ergaben den dringenden Verdacht, dass er sich schon wieder an Autos zu schaffen machte und das Geld in dem unverschlossenen PKW eines Österreichers fand.

Source: https://www.presseportal.de/blaulicht/pm/110971/4204514

Figure SI 5: Example 2: robbery on February 25, 2019 (Giessen), attributed to a refugee from Somalia

26.02.2019-15:07

Polizeipräsidium Mittelhessen - Pressestelle Gießen

POL-GI: Pressemeldungen vom 26.02.2019: Festnahme nach Einbruch+++Gleich zwei Räder entwendet+++Heizöl auf Wiese geschüttet

\section{$f y$ (i) $x$ in}

Gießen (ots)

Gießen: Festnahme bei Einbruch

Schnell geschnappt war ein 25 - Jähriger am Montagabend in der Georg-Elser-Straße in Gießen. Gegen 22.40 Uhr wurde in der Drogerie ein Einbruchalarm ausgelöst. Mehrere Streifen waren schnell dort und konnten feststellen, dass offenbar eine Tür eingeschlagen wurde. Bei der Durchsuchung des Marktes konnten die Beamten dann den mutmaßlichen Täter, einen Asylbewerber aus Somalia, widerstandslos festnehmen. Offenbar hatte der Verdächtige mit einem Hammer die Scheibe eingeschlagen und bereits mehrere Waren eingesteckt. Bei den ersten Ermittlungen stellte es sich heraus, dass er zuvor zu tief ins Glas geschaut hatte. Ein Test ergab einen Wert von 1,51 Promille. Die Ermittlungen dauern an. Hinweise bitte an die Kriminalpolizei in Gießen unter der Rufnummer 0641 - 70062555.

Source: https://www . presseportal.de/blaulicht/pm/43559/4203847 


\title{
SI Supporting Information
}

Figure SI 6: Example 3: sexual assault on February 26, 2019 (Stuttgart), attributed to a Pakistani immigrant 27.02.2019-14:37

Polizeipräsidium Stuttgart

\author{
POL-S: Staatsanwaltschaft und Polizei Stuttgart geben \\ bekannt: Sexuelle Nötigung - Tatverdächtiger festgenommen
}

\section{$f y$ (c) $x$ in $M$}

Stuttgart-Vaihingen (ots)

\begin{abstract}
Polizeibeamte haben am Dienstagabend (26.02.2019) an der S-Bahn-Haltestelle Rohr einen 22 Jahre alten Mann festgenommen, der zuvor seine 20-jährige ehemalige Partnerin sexuell genötigt, verletzt und bedroht haben soll. Die 20-Jährige hatte die Wohnung des Tatverdächtigen in StuttgartRohr am Abend zu einer Aussprache aufgesucht. Während des Gesprächs küsste der Tatverdächtige die Frau gegen ihren Willen. Zudem packte er sie mehrfach am Hals, würgte sie und berührte sie an der Brust und im Intimbereich. Die Frau rief um Hilfe und wehrte sich, schließlich ließ der Verdächtige von ihr ab. Anschließend verließen sie gemeinsam die Wohnung. Nachdem die Frau den Verdächtigen dazu bewegen konnte, getrennt weiter zu gehen, rief sie die Polizei. Alarmierte Polizeibeamte nahmen den Tatverdächtigen kurze Zeit später, gegen 21.00 Uhr, fest. Der 22-jährige Pakistani wird am Mittwoch (27.02.2019) mit Antrag der Staatsanwaltschaft auf Erlass eines Haftbefehls dem zuständigen Richter vorgeführt.
\end{abstract}

Source: https://www presseportal. de/blaulicht/pm/110977/4204920

To systematically assess the accuracy of the information recorded on refcrime, we randomly draw 175 events from our data for each RA (in total 600 unique events). We made sure that out of the 175 events, 50 events are the same for all three RAs. This allows us to test the reliability of the handcoding conducted by our three RAs (see more details below).

\section{Instructions for our coders}

The goal of the handcoding is to validate the data we retrieved from refcrime. To do so we ask you to double-check a range of informations reported in the data and outlined below. By double-checking we mean that you 1) open the excel provided to you and 2) check if the information we report in the excel can be retrieved by the sources reported in the first column of the excel. As you will see for each variable the excel contains three columns. The first column is the information as we retrieved it from refcrime the second and third columns are for you to be filled.

The coding is simple, if the information reported in our data is in line with the information you find in the source material you code ' 1 ' into the second column (called *_true), otherwise ' $O$ '. Whenever you code ' $\mathrm{o}$ ' in *_true - meaning that the information reported by refcrime is not in line with the information in the source material - you will need to report the information you found in the source material in the third column called *_source. In case you code ' 1 ' in *_true - meaning that the information reported by refcrime is in line with the information in the source material - please leave *_source empty.

Please double-check the following information in the Excel provided to you:

1. date of the event

2. location of the event

3. gender of the victim

4. gender of the perpetrator(s)

5. origin of the perpetrator(s) only as MENA o/1 and Africa o/1

6. crime type 


\section{SI Supporting Information}

7. migrant_yn Is there clear information provided suggesting that the perpetrator(s) are of "migrant origin"? - 1 = Yes, there is clear information that the perpetrator(s) are of "migrant origin".

- $\mathrm{o}=$ unclear information.

- $-1=$ No, there is no information even suggesting that the perpetrator(s) are of "migrant origin".

E.g. what makes the crime a migrant one? Which information is provided about the perpetrator(s) citizenship/naturalization status? 


\section{SI Supporting Information}

\section{SI.2.4 Sources cited on refcrime}

Coders on refcrime report an external reference for all crime events listed on the website. In most cases, these are official police press statements which are released online. For a subset of about 12,000 cases, we directly observe the local news outlet that reported on the crime. We extracted the original news sources from these URLS, which we list below. We note that in this subsection, we rely on the full refcrime dataset of about 60,000 events rather than focusing exclusively on those events that were attributed to perpetrators from African and/or Muslim-majority countries.

We find that refcrime draws on information from over 400 unique sources. Most of these are the online websites of local newspapers, but some events are also referenced on the websites of national newspapers, TV channels, or local radio stations. We note that some of the refcrime sources are only available online but not in print. For comparison, there were a total of 341 newspapers in Germany in 2021, according to the German association of newspaper publishers (BDVZ). Events reported on refcrime were also reported in outlets across the German media landscape.

\section{List of sources cited on refcrime}

112-magazin.de; 24vest.de; aachener-nachrichten.de; aachener-zeitung.de; abendzeitung-muenchen.de; agkblog.de; ak-kurier.de; alles-lausitz.de; allgaeuhit.de; allgemeine-zeitung.de; alsfelder-allgemeine.de; amp.infranken.de; amp.mz-web.de; auepost.de; augsburger-allgemeine.de; az-online.de; az-web.de; azonline.de; baden-tv.com; badische-zeitung.de; bamberger-onlinezeitung.de; banews.de; bayerndepesche.de; bayern-freizeitparks.de; bayernwelle.de; bayregio-eichenau.de; bayregio-fuerstenfeldbruck.de; bayregio-garmisch-partenkirchen.de; bayregio-germering.de; bayregio-landsberg.de; bayregioschongau.de; bayregio-weilheim.de; bayregio.de; bbglive.de; bbv-net.de; berlin.de; berliner-kurier.de; berliner-zeitung.de; berlinonline.de; bgland24.de; bild.de; bkz-online.de; bkz.de; blick-aktuell.de; blick.de; blickpunkt-nienburg.de; bo.de; borkenerzeitung.de; boyens-medien.de; br.de; braunschweigerzeitung.de; bremerhavennews24.de; brigitte.de; brk-kurier.de; bsaktuell.de; buerstaedter-zeitung.de; butenunbinnen.de; bz-berlin.de; cellesche-zeitung.de; chiemgau24.de; come-on.de; compact-online.de; da-imnetz.de; derwesten.de; deutscheopfer.de; deutschlandfunk.de; dewezet.de; die-glocke.de; dieharke.de; dnn.de; donauzfm.de; donaukurier.de; dorstenerzeitung.de; dortmund24.de; dortmundecho.org; dubisthalle.de; dueren-magazin.de; durlacher.de; echo-online.de; echo24.de; edlive.de; ehrenmord.de; eifelzeitung.de; ejz.de; emma.de; epochtimes.de; ers-hameln.de; esslingerzeitung.de; eurotransport.de; express.de; extra-tipp-krefeld.de; feuerwehr-kutenholz.de; ffh.de; fnp.de; focus.de; fr-online.de; fr.de; frankenpost.de; freiburg-nachrichten.de; freiepresse.de; fudder.de; fuldaerzeitung.de; gea.de; general-anzeiger-bonn.de; generalbundesanwalt.de; gera.otz.de; giessener-allgemeine.de; giessener-anzeiger.de; gifhorner-rundschau.de; gmuender-tagespost.de; gn-online.de; halleon.de; halloherne.de; hamburg.de; hanauer.de; haolam.de; harburg-aktuell.de; harlinger.de; hasepost.de; haz.de; heidelberg24.de; hellwegeranzeiger.de; helmstedter-nachrichten.de; hersfelder-zeitung.de; hessenschau.de; hildesheimer-allgemeine.de; hitradio-rtl.de; hna.de; huffingtonpost.de; idowa.de; ikz-online.de; in-und-um-schweinfurt.de; infranken.de; ingolstadt-today.de; innsalzach24.de; input-aktuell.de; insuedthueringen.de; jenaer-nachrichten.de; juedische-allgemeine.de; jumpradio.de; ka-news.de; karlsruhe-insider.de; kassel-live.de; kirschenland.de; klartext-ne.de; knonline.de; kreis-anzeiger.de; kreisbote.de; kreiszeitung.de; krzbb.de; ksta.de; kurier-dachau.de; l-iz.de; lahrer-zeitung.de; lampertheimer-zeitung.de; landeszeitung.de; landtag.sachsen-anhalt.de; leonberger-kreiszeitung.de; live.goslarsche.de; In-online.de; lokalkompass.de; lokalo.de; lokalo24.de; lokalstimme.de; Ir-online.de; ludwigshafen24.de; Ivz.de; lz.de; m.bild.de; m.dnn.de; m.focus.de; m.haz.de; m.kn-online.de; m.lvz.de; m.maz-online.de; m.neuepresse.de; m.news.de; m.op-marburg.de; m.otz.de; m.swp.de; m.sz-online.de; m.tagesspiegel.de; m.wn.de; magdeburger-news.de; mainecho.de; main-spitze.de; mainpost.de; mangfall24.de; mannheim24.de; marbacher-zeitung.de; maz- 


\section{SI Supporting Information}

online.de; mdr.de; meetingpoint-brandenburg.de; meetingpoint-jl.de; mein-krefeld.de; merkur.de; migazin.de; mittelbayerische.de; mittelhessen.de; mmnews.de; mobil.mopo.de; mobil.nwzonline.de; mobil.recklinghaeuser-zeitung.de; mopo.de; morgenpost.de; morgenweb.de; moz.de; mrn-news.de; msl24.de; mt.de; muensterlandzeitung.de; muensterschezeitung.de; mv-online.de; mz-web.de; $n$ tv.de; ndr.de; neckar-chronik.de; neuepresse.de; neustadt-ticker.de; news.de; news.feed-reader.net; news38.de; news711.de; nh24.de; niederlausitz-aktuell.de; nnn.de; nnz-online.de; nokzeit.de; nordbayerischerkurier.de; nordbayern.de; nordbuzz.de; nordkurier.de; noz.de; np-coburg.de; nq-online.de; nrkurier.de; nrwz.de; nrz.de; nw.de; nwzonline.de; oberberg-aktuell.de; oberhessen-live.de; oberlahn.de; oberpfalzecho.de; onetz.de; op-marburg.de; op-online.de; osthessen-news.de; osthessenzeitung.de; ostsee-zeitung.de; ots.de; otz.de; ovb-online.de; owl24.de; oz-online.de; peiner-nachrichten.de; pfaelzischer-merkur.de; pfaffenhofen-today.de; pfalz-express.de; pnn.de; pnp.de; poessneck.otz.de; potsdamer-nachrichten.de; presse-augsburg.de; presse.sachsen-anhalt.de; presseportal.de; pressreader.com; pure-fm.de; pz-news.de; queer.de; radio-bamberg.de; radio-in.de; radio-oberland.de; radio8.de; radio912.de; radiochemnitz.de; radiodresden.de; radioerft.de; radioerzgebirge.de; radioguetersloh.de; radiohochstift.de; radiokiepenkerl.de; radiolausitz.de; radioleipzig.de; radioleverkusen.de; radiolippe.de; radiorur.de; radiovest.de; radiowaf.de; radiowestfalica.de; radiozwickau.de; rbb-online.de; rbb24.de; regenbogen.de; regio-news.de; region-muenchen.de; regionalbraunschweig.de; regionalgoslar.de; regionalpeine.de; regiotrends.de; report-k.de; reportsan.de; rhein-zeitung.de; rheinische-anzeigenblaetter.de; rheinneckarblog.de; rheinpfalz.de; rnf.de; rnz.de; rosenheim24.de; rostock-heute.de; rp-online.de; rtl.de; ruesselsheimer-echo.de; ruhr24.de; ruhrnachrichten.de; ruhrpott-schoten.de; rundblick-dortmund.de; rundblick-unna.de; rundschau-online.de; saarbrueckerzeitung.de; saarland.de; sachsen-depesche.de; sachsen-fernsehen.de; sachsenanhalt112.de; saechsische.de; salue.de; sauerlandkurier.de; sazbike.de; schaumburger-zeitung.de; schwaebische-post.de; schwaebische.de; schwarzwaelder-bote.de; sdp.fnp.de; shz.de; siegener-zeitung.de; siegerlandkurier.de; sn-online.de; soester-anzeiger.de; sol.de; solinger-bote.de; spiegel.de; sr.de; stadt-burg.de; stadt-kurier.de; starnberg24.de; stern.de; stimme.de; stuttgart-journal.de; stuttgarter-nachrichten.de; stuttgarter-zeitung.de; sueddeutsche.de; suedkurier.de; supertipp-online.de; svz.de; swp.de; swr.de; sz-online.de; t-online.de; t.haz.de; t.lvz.de; t.ostsee-zeitung.de; tag24.de; tagesspiegel.de; tah.delokales; tangrintler-medienhaus.de; taz.de; tegernseerstimme.de; tenoronline.de; thueringen24.de; thueringerallgemeine.de; tlz.de; tonkuhle.de; tsv-burgdorf-fussball.de; tvo.de; tz.de; ulm-news.de; unserradio.de; usinger-anzeiger.de; verlagshaus-jaumann.de; volksfreund.de; volksstimme.de; vorsprungonline.de; wa.de; wanga-press.de; wasserburg24.de; wasserburger-stimme.de; waz-online.de; waz.de; waz.m.derwesten.de; wdr.de; welt.de; werra-rundschau.de; werturteile.de; weser-kurier.de; wetterauerzeitung.de; wiesbadenaktuell.de; wiesbadener-kurier.de; winsen.de; wir-sind-mueritzer.de; wirsiegen.de; wlz-online.de; wn.de; wochenanzeiger.de; wochenspiegel-web.de; wochenspiegellive.de; wolfsburgernachrichten.de; wormser-zeitung.de; wp.de; wr.de; wuerzburgerleben.de; wuppertaler-rundschau.de; ww-kurier.de; www.stimme.de; wz-newsline.de; wz.de; wzonline.de; zdf.de; zeit.de; zeitbote-regional.de; zoll.de; zvw.de. 


\section{SI Supporting Information}

\section{SI.2.5 Police information in local news outlets}

In a second step, we verify that local news outlets base most of their crime reporting on information released by the police. Our goal here is to show that both (local) news outlets and refcrime draw on the same primary data source: police press releases about crime events. In fact, some newspapers (e.g. the Berliner Morgenpost) directly link to the police press releases on its website. While it is unlikely that local news reporters are retrieving information from the refcrime website, they are obtaining information from the same original source. As we argued earlier in the paper, the refcrime data contains the most salient crime events (stabbings, cases of rape, etc.) which at the same time contained out-group cues in the original press releases.

To provide evidence on how frequently local news reporting is based on police information, we hand-coded local newspaper articles from 123 unique outlets. Our sample of newspapers contains all newspapers that can be accessed through the Factiva database. The Factiva sample of news outlets covers all German states and a wide spectrum of the German media landscape. For each local newspaper, we retrieved all articles containing the key word "police (Polizei)" during the last month (July 2021).

We find that $92 \%$ of the newspapers in our sample published at least one article on crime that referenced police information over the last month. Furthermore, we find that explicit citations of police materials - such as police reports or direct cites - are common: only 5 newspapers (4\%) out of 123 newspapers we coded do not explicitly cite police reporting. We list the 123 outlets in our sample below:

BILD Berlin-Brandenburg; Lausitzer Rundschau; Maerkische Allgemeine Zeitung; Maerkische Allgemeine Zeitung Online; Maerkische Oderzeitung; Oranienburger Generalanzeiger; Baden-Wuerttemberg/RheinlandPfalz; BILD Stuttgart; Metzinger Uracher Volksblatt; Reutlinger Nachrichten; Schwarzwaelder Bote; Stuttgarter Nachrichten; Suedwest Presse; B.Z.; Berliner Kurier; Berliner Morgenpost; Berliner Morgenpost Online; Bremer Nachrichten; Kurier am Sonntag; Weser Kurier; Bergedorfer Zeitung; BILD Hamburg; Hamburger Abendblatt; Hamburger Abendblatt Online; ZEIT Hamburg; Abendzeitung Muenchen; Allgaeuer Zeitung; Bayerische GemeindeZeitung; Bayerische Staatszeitung; BILD Muenchen; Erlanger Nachrichten; Frankenpost; Fuerther Nachrichten; Neue Presse; Neumarkter Nachrichten; Nordbayerische Nachrichten; Nordbayerischer Kurier; Nuernberger Nachrichten; Passauer Neue Presse; tz Online; BILD Dresden; BILD Leipzig; Chemnitzer Morgenpost; Dresdner Morgenpost; Dresdner Neuste Nachrichten; Dresdner Neuste Nachrichten Online; Leipziger Volkszeitung; Leipziger Volkszeitung Online; Saechsische Zeitung; Wirtschaft in Sachsen; BILD Thueringen; Freies Wort; Meininger Tagblatt; Ostthueringer Zeitung; Suedthueringer Zeitung; Thueringer Allgemeine; Thueringische Landeszeitung; BILD Frankfurt Rhein-Main; BILD Rhein-Neckar; Darmstaedter Echo; Frankfurter Neue Presse; Giessener Anzeiger; Hanauer Anzeiger; Hersfelder Zeitung; Main-Spitze; Offenbach-Post; Waldeckische Landeszeitung; Werra Rundschau; Wetzlarer Neue Zeitung; Wiesbadener Kurier; Wiesbadener Tagblatt; Aller-Zeitung; Allgemeine Zeitung der Lueneburger Heide; BILD Hannover; Goettinger Tageblatt / Eichsfelder Tageblatt; Goettinger Tageblatt / Eichsfelder Tageblatt Online; Hannoversche Allgemeine Zeitung; Hannoversche Allgemeine Zeitung Online; HAZ-Wirtschaftszeitung; Hildesheimer Allgemeine Zeitung; Kreiszeitung Syke; Neue Presse; Neue Presse Online; NorwestZeitung; Peiner Allgemeine Zeitung; Peiner Allgemeine Zeitung Online; Schaumburger Nachrichten Online; Wolfsburger Allgemeine; Wolfsburger Allgemeine Online / Aller-Zeitung Online; BILD MecklenburgVorpommern; Nordkurier; Nordkurier Online; Ostsee-Zeitung; Ostsee-Zeitung Online; Aachener Nachrichten; Aachener Zeitung; BILD Duesseldorf; BILD Koeln; BILD Ruhrgebiet; Express; General Anzeiger; Koelner Stadt-Anzeiger; Koelnische Rundschau; Luedenscheider Nachrichten; Neue Westfaelische; Rheinische Post; Rheinische Post Online; Westfaelischer Anzeiger; Allgemeine Zeitung; Macher; Pfaelzischer Merkur; Trierischer Volksfreund; Wormser Zeitung; BILD Saarland; Saarbruecker Zeitung; BILD Halle; BILD Sachsen-Anhalt; Bergedorfer Zeitung; Kieler Nachrichten; Kieler Nachrichten Online; Luebecker Nachrichten; Luebecker Nachrichten Online; Segeberger Zeitung. 


\section{SI.2.6 Correlates of refcrime event counts}

Figure SI 7: Cross-sectional correlates of event counts in refcrime database

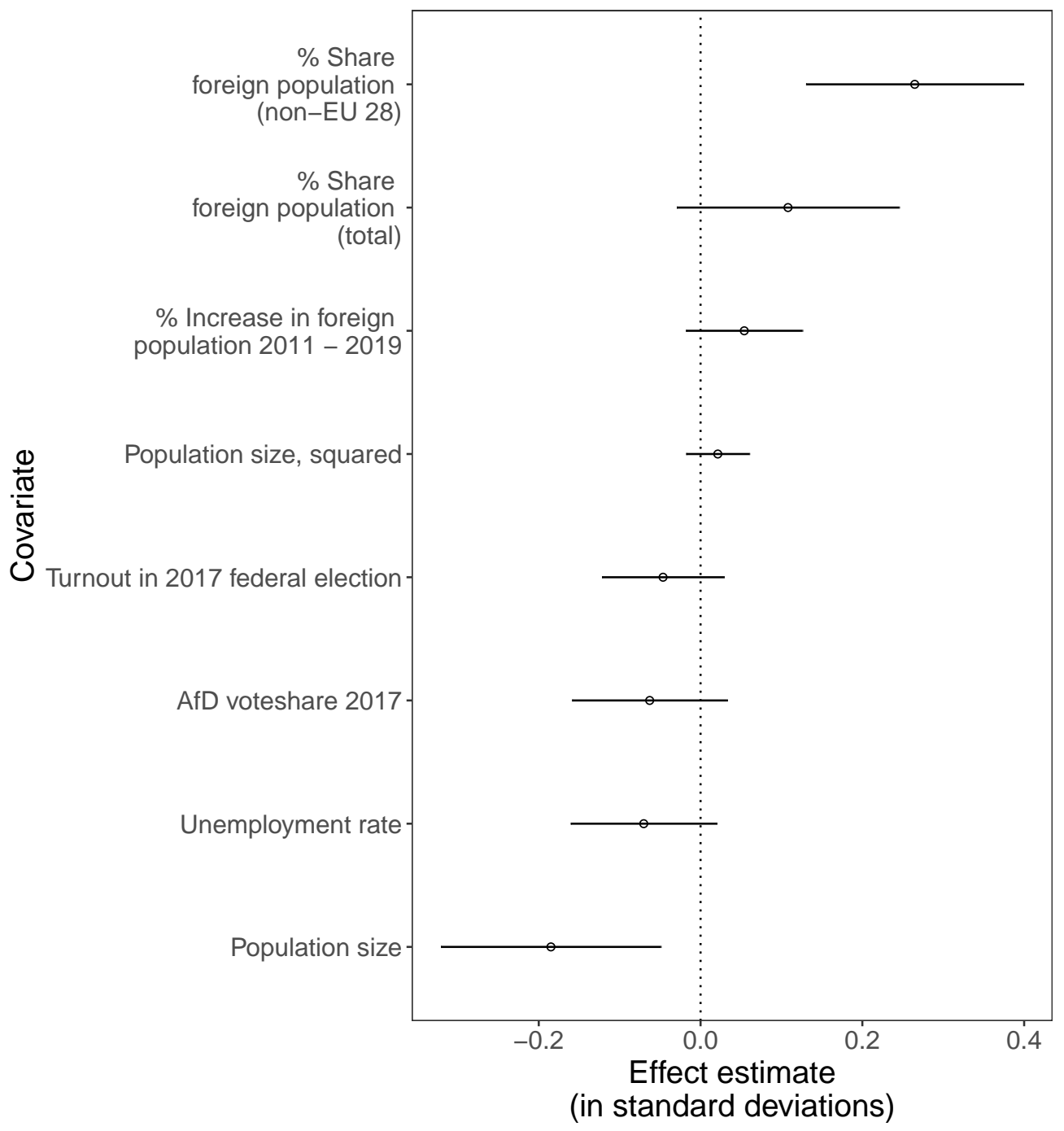

Note: The figure shows the coefficient estimates from a regression where the outcome is the total number of crime events recorded in the refcrime database in a given county in a given year, scaled by county population size. The analysis covers the time period 2015 to 2019. All covariates and the outcome were standardized prior to the analysis. The model includes state and year fixed effects. The horizontal bars indicate $95 \%$ confidence intervals. 


\section{SI Supporting Information}

\section{SI.2.7 Overlapping events}

We only retain a single immigrant crime event for each county on one single day. If multiple immigrant crime events occur on a single day in the same county, we retain only one single event.

- If another immigrant crime event occurs within the next 14 days after the treatment event $i$, we drop all observations of $Y_{i, t, c}$ after this next immigrant crime event (i.e. after the county is treated again).

- If another immigrant crime event occurred 28 to 14 days before the treatment event $i$, we only retain pre-periods that are at least 14 days apart from the most recent immigrant crime event. For instance: if an immigrant crime event occurred in the same county 20 days before the treatment event $i$, we only retain the pre-periods $P_{i, t, c} \in[-6,-1]$ and drop all other observations of $Y_{i, t, c}$.

- If another immigrant crime event occurred within 14 days before the treatment event, the county's treatment status in the pre-period is unclear. We drop all pre-treatment observations in such cases.

- For our main analysis, we only retain those events for which we 1) observe valid pre and post periods and 2) observe at least a total of 14 periods (days).

Figure SI 8: Valid observations by period

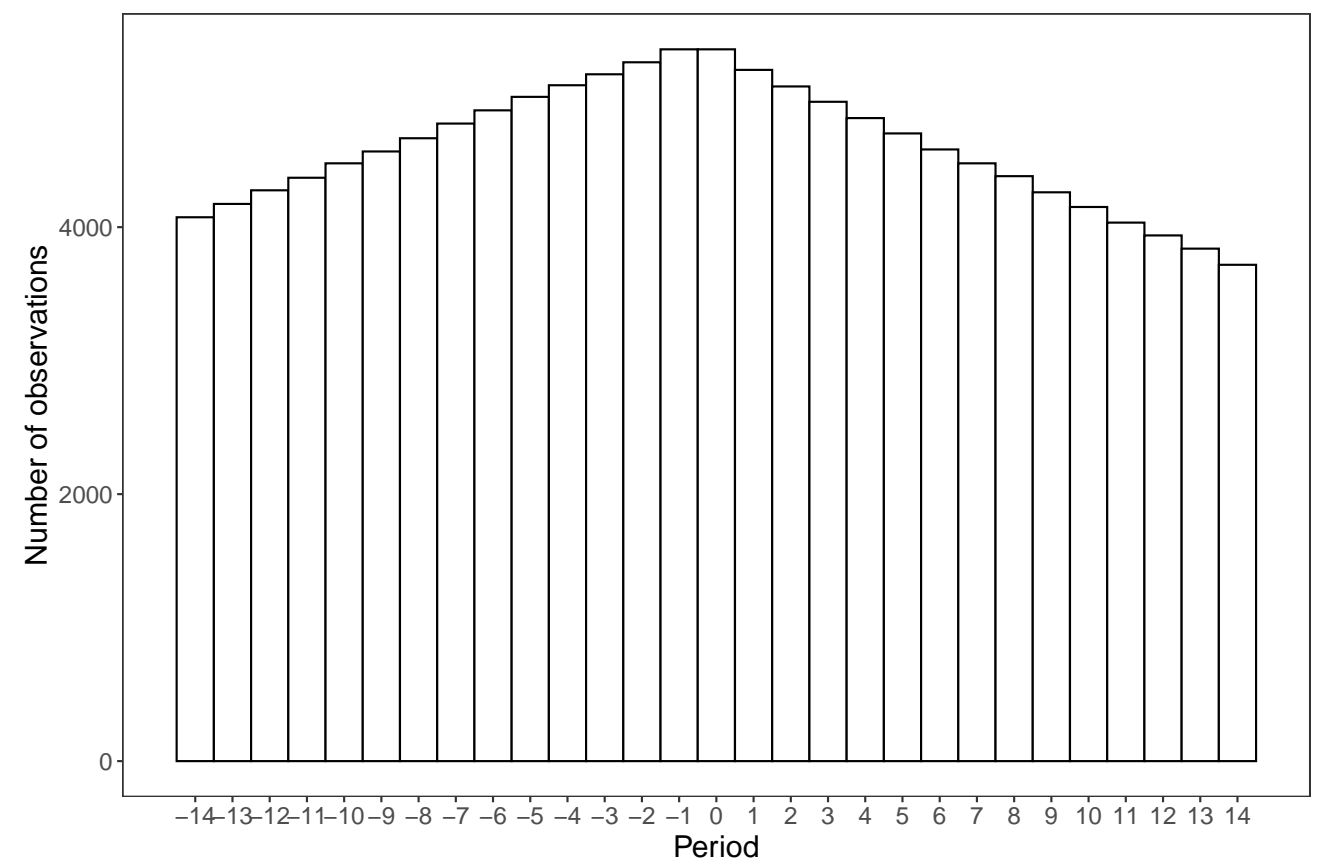

Note: The histogram shows the number of observations by period after recoding the migrant crime events as described in section SI.2.7.

As noted in section 3.1, we drop all refcrime events that are not attributed to perpetrators from African or Muslim-majority countries prior to data transformation. We do not take into account crimes attributed to Poles, for example, when we determine partial overlap between events.

The main reason why we drop some observations is because when out-group crimes cluster in time, the treatment status of a given county on a given day is ambiguous. Consider for example a case where crime events attributed to refugees occur on April 2, April 7, and April 15. For the purposes of our empirical strategy, counties are in the 'control' state prior to each crime event and in the 'treated' state after the crime event occurred. This works well for the first crime event: we can compare the rate of hate crimes before and after April 2. Accordingly, we would keep this event in our data set. However, for the second and third crime event in the same county, we 


\section{SI Supporting Information}

are essentially lacking valid control observations. It would be inaccurate to classify the period between April 3 and April 6 as 'pre-treatment' or 'control' for the second event, as another crime event occurred immediately before. The same reasoning applies to the hypothetical event on April 15, for which we would likewise lack an adequate baseline pre-treatment period.

The effective sample size of refcrime events we use within the optimal bandwidth is 5,332. We recognize that this is substantially smaller than our baseline sample size. However, our effective sample is generally representative for the larger sample of events in the refcrime database.

We systematically investigate the differences between the two samples in figure SI 9, where we use to compare the means in standard deviations for the full sample of refcrime events attributed to Muslims and/or African perpetrators and the effective sample of events we use in our RDiT analysis. All variables were standardized in the full sample prior to the analysis, hence the mean is fixed at o by definition for all variables in the full sample.

We find two primary differences between the two samples. First, the events in our effective sample for the RDiT tend to occur slightly earlier in time (about 2 months, or 0.2 standard deviations). Second, we have fewer events in cities (Stadtkreise) in our effective sample. This is unsurprising, since events are more likely to overlap in dense cities like Berlin, Hamburg, or Bremen, where the share of the foreign-born population is high. The same argument likely accounts for the slightly higher share of events in East-Germany vs. West-Germany in our effective sample. We also have a slightly higher share of violent migrant crime events in our effective sample (76\% vs. $82 \%)$. We do not find differences in terms of the time of the day when the event occurred.

Figure SI 9: Comparison of refcrime sample and effective RDiT sample

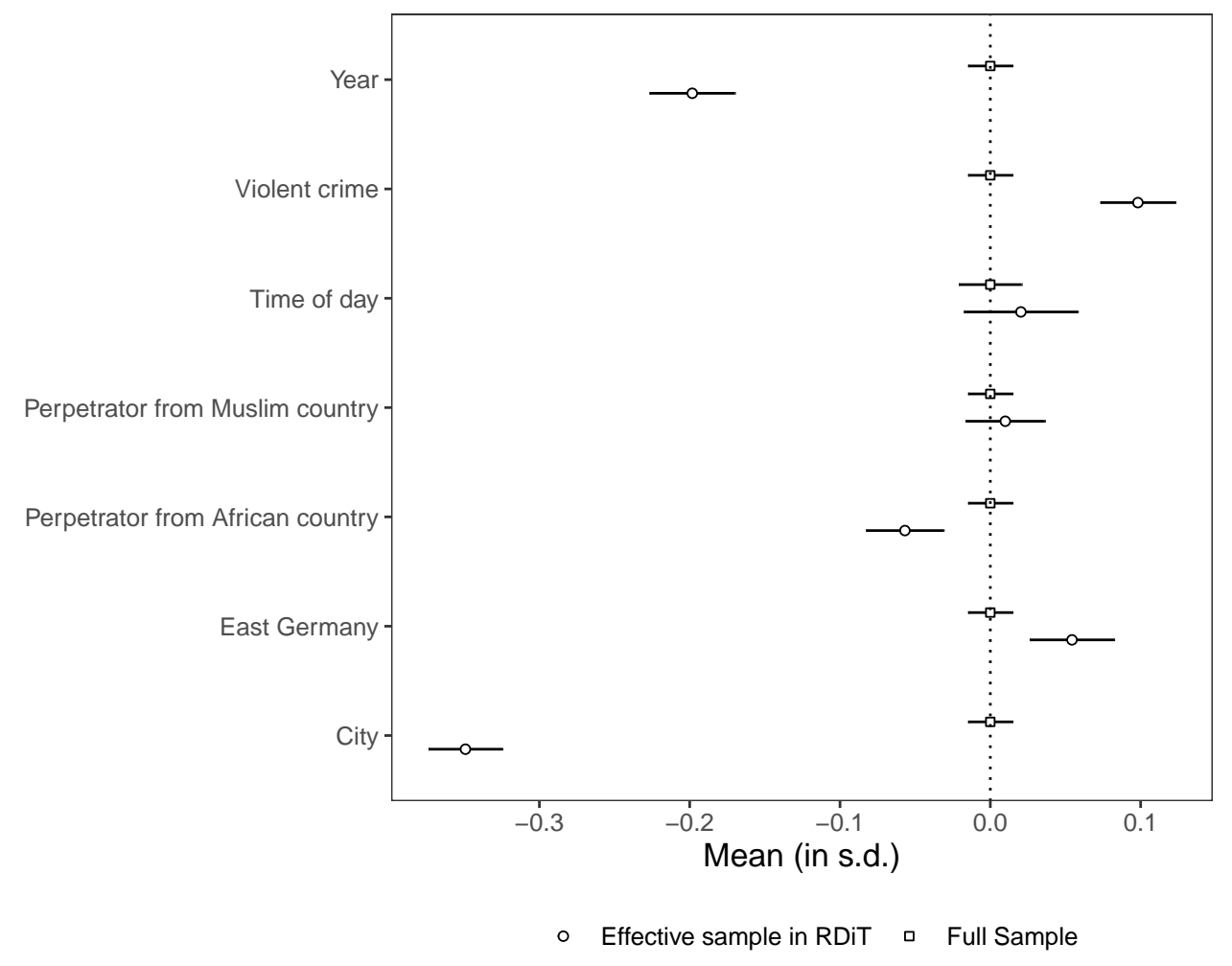

Note: The plot shows the means for different event-level variables in two samples: 1) the full sample of events in the refcrime database and 2) the effective sample of events we rely on in our main RDiT analysis. Horizontal lines indicate $95 \%$ confidence intervals around the mean. All variables were standardized in the full sample prior to the analysis.

Finally, we note that because of how we treat partial overlap between events, only a subset of events effectively contributes to increasing the bandwidth. In figure SI 10, we visualize the share of events in the RD data for which all periods are (validly) observed as a function of the bandwidth in days around the treatment assignment cutoff. 


\section{SI Supporting Information}

For example: for a bandwidth of three days, we observe the full set of periods, three days before and after the immigrant-attributed crime event, for about $90 \%$ of the events in the sample. As we increase the bandwidth, the share of events for which we observe all periods within the bandwidth decreases.

Figure SI 10: Share of events for which all periods are observed

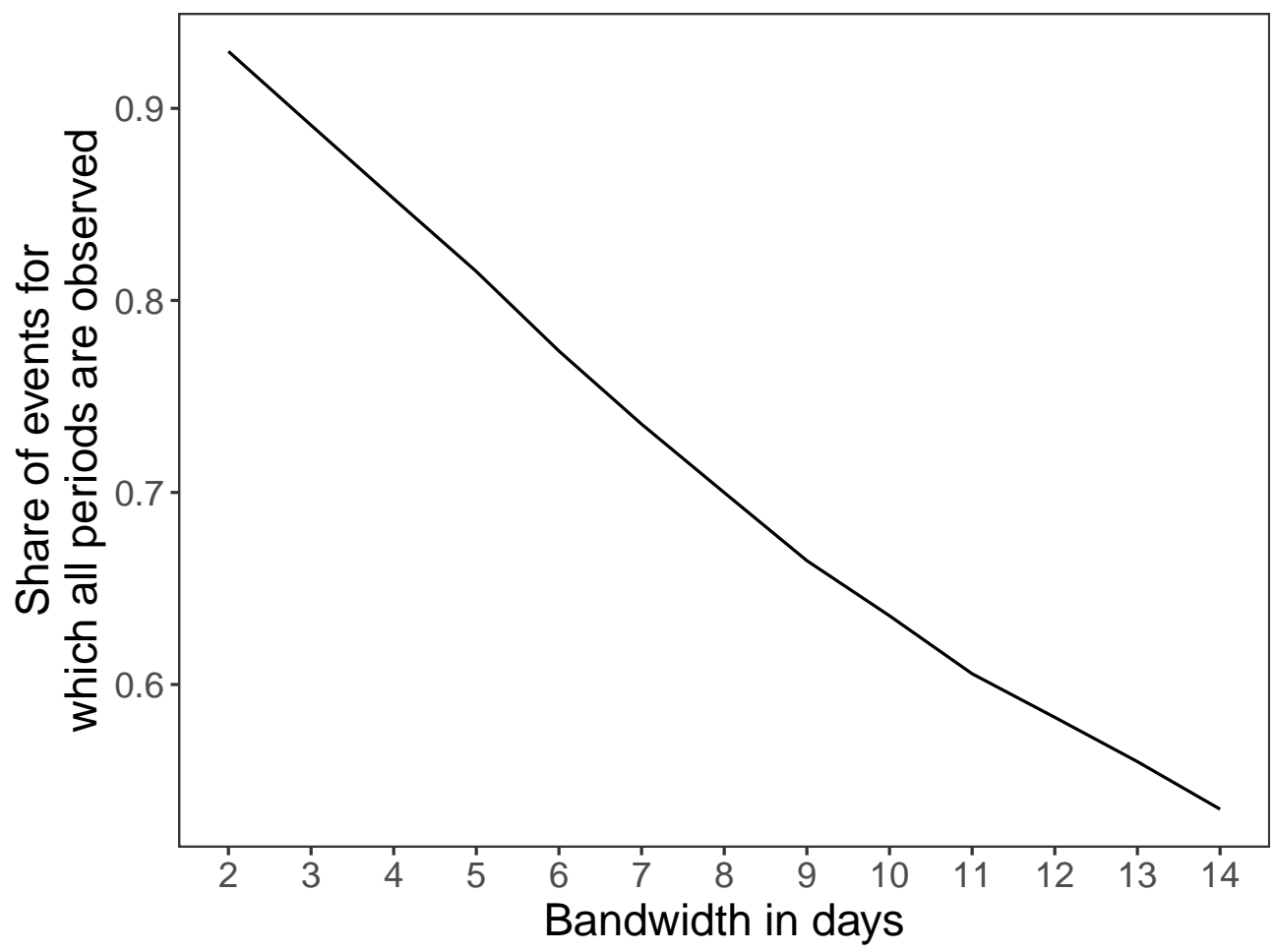

Note: The plot shows the share of events in the transformed RD data for which all potential periods are observed as a function of the bandwidth in days. 


\section{SI.2.8 Classification of violent and non-violent crimes}

We code the following categories as violent out-group crime events:

Battery; Burglary (attempted / completed); Forced prostitution; Hit and Run; Honor killing; Incendiary (intentional); Incendiary (negligent); Murder / Killing (attempted); Murder / Killing (completed); Other property crimes; Other sexual crimes; Other violent crimes; Physical sexual harassment; Rape (attempted); Rape (completed); Riot / Property damage; Robbery (attempted / completed); Sexual abuse in swimming pools; Stabing / Knife attack; Terrorism; Theft (attempted / completed); Threat / Insult / Miscellaneous; Violence against executory officers; violence in asylum shelters.

We code the following categories as non-violent crime events:

Confidence trick; Disturbing the peace; Driving without a license; Drugs; Drunkenness / drugs in traffic; Exhibitionism; Falsification of documents; Fare evasion; Illegal entry; Illegal stay; Illegal Possession of Firearms; Miscellaneous; Other frauds; Other traffic offenses; Receiving [stolen goods]; Smuggling of migrants; Social welfare fraud; Verbal sexual harassment. 


\section{SI Supporting Information}

\section{SI.2.9 Country classification}

We code the following countries as Muslim-majority and/or African countries:

Afghanistan; Albania; Algeria; Angola; Bahrain; Bangladesh; Benin; Bosnia and Herzegovina; Burkina Faso; Burundi; Cabo Verde; Cameroon; Central African Republic; Chad; Congo; Cote d'Ivoire; Egypt; Eritrea; Ethiopia; Gabon; Gambia; Ghana; Guinea; Guinea-Bissau; Iran; Iraq; Jordan; Kenya; Kosovo; Kuwait; Lebanon; Liberia; Libya; Madagascar; Malawi; Mali; Mauritania; Morocco; Mozambique; Namibia; Niger; Nigeria; Oman; Pakistan; Palestine; Rwanda; Saudi Arabia; Senegal; Sierra Leone; Somalia; South Africa; South Sudan; Sudan; Syrian Arab Republic; Tanzania; Togo; Tunisia; Turkey; Uganda; United Arab Emirates; Yemen; Zambia; Zimbabwe.

We note that we do not include Muslim-majority Southeast Asian (e.g. Indonesia, Malaysia, Brunei) or postSoviet countries (e.g. Tajikistan, Kazakhstan, Kyrgyzstan) in this list, as few refugees originate from these countries and they are generally not considered part of the same out-group as, for example, Syrian refugees.

We code the following countries as European:

Armenia; Austria; Belarus; Belgium; Bulgaria; Croatia; Serbia and Montenegro, Czechia; Denmark; Estonia; Finland; France; Georgia; Germany; Greece; Hungary; Iceland; Ireland; Italy; Latvia; Lithuania; Luxembourg; Moldova; Montenegro; Netherlands; Norway; Poland; Portugal; Republic of North Macedonia; Romania; Russian Federation; Serbia; Slovakia; Slovenia; Spain; Sweden; Switzerland; Ukraine; United Kingdom of Great Britain and Northern Ireland; Yugoslavia.

To create subsets, we always code whether at least one perpetrator from a given region was involved in a given crime. For example: if a crime is attributed to two perpetrators, one Romanian and one Syrian, this incident will be included in the main sample we analyze. 


\section{SI Supporting Information}

\section{Sl.3 Hate crime data}

\section{SI.3.1 Descriptive statistics}

Figure SI 11: Spatial distribution of hate crimes and migrant crimes

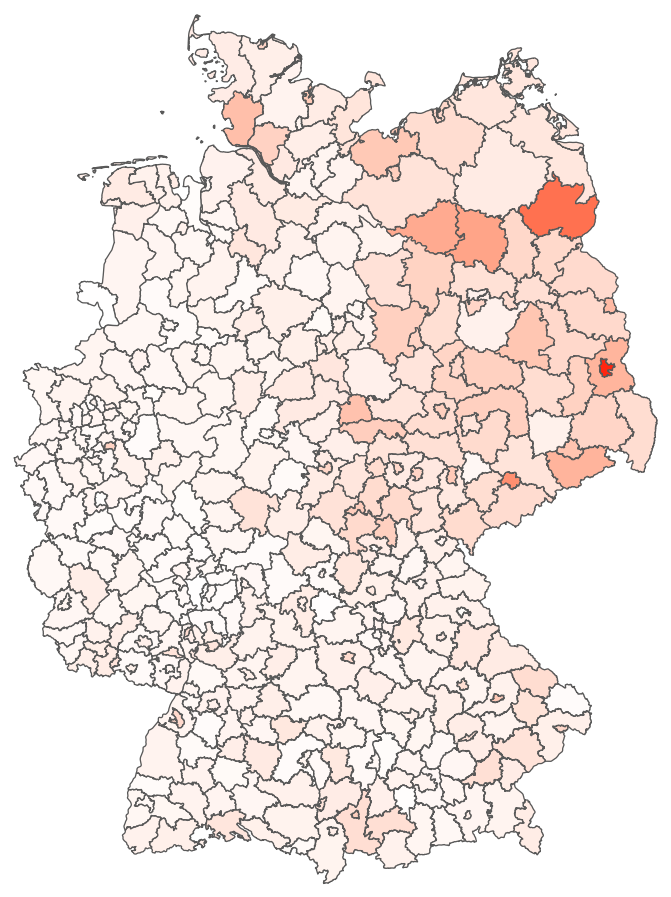

Hate crimes per 10,000 capita $(2015-2019)$

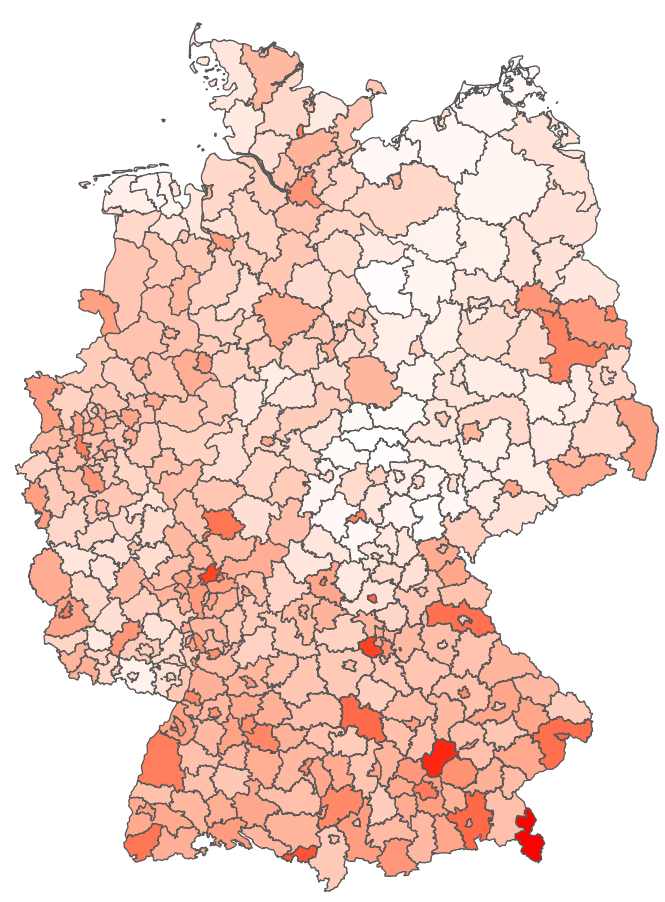

Share of foreigners among perpetrators $20 \quad 40 \quad 60$

Note: The left figure shows the spatial distribution of the total number of hate crime events that occurred between January 2015 and March 2019 across German counties. We scale the number of recorded events by county population size. The right figure shows the share of foreigners among all crime suspects identified by the German police in 2019 across German counties. The visualization on the right is based on official data provided by the German police (Polizeiliche Kriminalstatistik, PKS). 
Figure SI 12: Hate Crimes 2015 - 2019

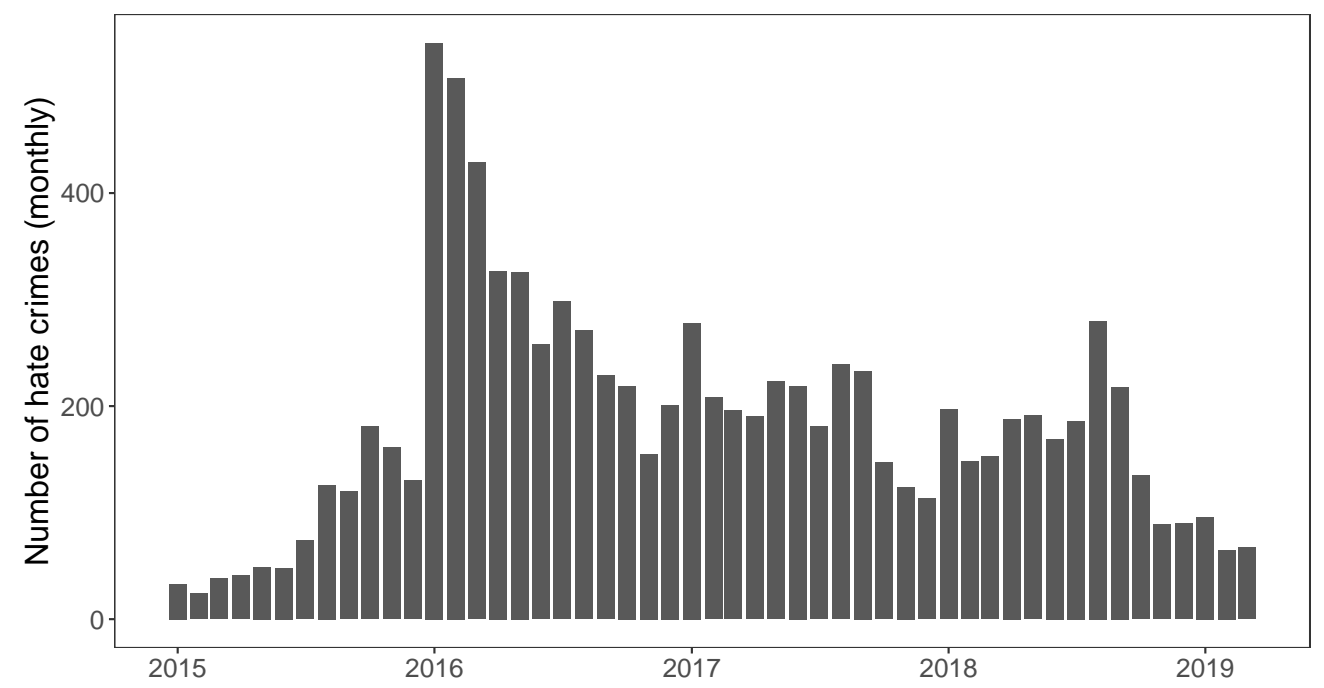

Note: The figure shows the number of hate crime incidents in Germany in each month between January 2015 and March 2019. 


\section{SI Supporting Information}

\section{SI.3.2 Data source}

The German police does not release event-level information on hate crimes. However, the German socialist party - Die Linke - inquires about hate crimes directed at refugees and refugee accommodations that occurred in Germany through quarterly 'parliamentary requests' ('kleine Anfrage'). The precise question wording in German is:

“Zu wie vielen Überfällen, Anschlägen, Sachbeschädigungen, tätlichen Angriffen auf a) Flüchtlingsunterkünfte oder von Flüchtlingen bewohnte Wohnungen, b) geplante bzw. im Bau befindliche Flüchtlingsunterkünfte, c) Flüchtlinge bzw. Asylsuchende außerhalb ihrer Unterkunft oder dezentralen Wohnungen und d) Einrichtungen, die sich unmittelbar für die Belange von Flüchtlingen bzw. Asylsuchenden einsetzen, kam es nach Kenntnis der Bundesregierung im ersten Quartal 2018 (bitte Fragen a bis d getrennt aufführen und nach Bundesländern, Orten, Ortsteil, Straße und Datum auflisten)?"

The federal government responds with a detailed list of hate crimes based on information from the German police and intelligence services. Along with a description of the law violated in each specific incident, we also have detailed information on the precise location and date of each event. Our comprehensive dataset covers all xenophobic hate crime incidents recorded by state agencies in Germany between January 2015 and March 2019.

As Marbach and Ropers (2019: Appendix A) discuss in detail, the general definition of 'hate crimes' covers a much broader range of incidents. In general, hate crimes include crimes motivated by Antisemitism and hatred against minorities more generally. We do not have information on all hate crimes recorded by the police, as they do not fall under the definition used by Die Linke in its parliamentary request. 


\section{SI Supporting Information}

\section{SI.3.3 Validation}

In this section, we systematically compare our hate crime data to the data on hate crime events released by Benček and Strasheim (2016). This 'arvig' dataset contains geocoded information on 6,918 xenophobic hate crime incidents and is based on information collected by two civil society organizations, the Amadeu Antonio Foundation and PRO ASYL. Because the time period covered in this alternative hate crime dataset is much shorter (up until November 2017), we do not use it for our main analysis.

We note that the definition of 'hate crimes' does not perfectly align across the two data sources. To make the two datasets more comparable, we exclude right-wing demonstrations from the arvig data because these incidents do not fall under the definition of our main data source (see section Sl.3.2). We also exclude events that the NGOs retrieved from the same original data source, i.e. parliamentary requests by Die Linke. This leaves us with 2,185 events in total.

We start by simply examining the correlation between the event counts across space. The correlation between the total number of events recorded by county in the two data sources stands very high at $r=0.92$. Next, we examine how many of the arvig events are also covered by our data source. To do this, we check whether for a given hate crime event recorded in arvig in a county on a given date, we also observe a hate crime in the same county on the exact same day in our main dataset. Reassuringly, we find that this is the case for $65.6 \%$ of the events in the arvig dataset.

Finally, we examine whether the discrepancies between the two data sources systematically vary across time and space. Specifically, we are concerned about a potentially confounding relationship between the rate of refcrime reporting and hate crime reporting by the police. Our empirical strategy requires that the probability of hate crime reporting by the police is constant before and after an immigrant crime event. We cannot directly test this assumption, because we cannot observe the complete set of all hate crime incidents in Germany independent of police reporting. However, we partially address this concern by using deviations between the arvig data and our main dataset as a proxy for bias in police reporting. To test whether this bias covaries with our refcrime data, we conduct the following empirical test:

1. For each event in the arvig dataset, we check whether it was also recorded in our main hate crime dataset. We code a binary indicator that equals one if the hate crime incident was also recorded in the same county on the same day in our main dataset.

2. For each arvig event, we merge the number of refcrime events that were recorded in the same county in the same calendar week.

3. We regress the binary indicator (as defined in step 1) on the number of refcrime events that were recorded in the same county in the same calendar week (as defined in step 2). We include county $\times$ year fixed effects in this regression. This means that we test whether within a given county in a given year, the likelihood that a given arvig event is also recorded in our main data source is higher (lower) in weeks when the number of recorded refcrime events was also high (low).

We present the results in Table SI 2. Reassuringly, we do not find a statistically significant relationship between the probability that a given arvig event is also recorded in our main data source and the number of refcrime events recorded in the same county in the same week. If anything, the correlation appears negative.

\section{SI.3.4 Cross sectional predictors of hate crime}

We investigate the cross-sectional correlates of hate crimes in figure SI 13, where we regress the total number of hate crimes in a given county on a variety of county-level covariates. 
Table SI 2: Validation of hate crime data

\begin{tabular}{lcc}
\hline & \multicolumn{2}{c}{ Event in both datasets $(0 / 1)$} \\
& $(1)$ & $(2)$ \\
\hline Numer of refcrime events in county & -0.014 & -0.018 \\
& $(0.014)$ & $(0.017)$ \\
$\mathrm{N}$ & 2185 & 2185 \\
Fixed effects & County $\times$ year & County $\times$ month \\
\hline
\end{tabular}

Notes: Results from OLS regressions. The sample are hate crime events recorded in the arvig dataset. The outcome is a binary indicator that equals one if the hate crime incident was also recorded in our main dataset. The independent variable is the count of refcrime events that were recorded in the same county in the same calendar week. Standard errors clustered at the county level are shown in parentheses. ${ }^{* * *} p<.01 ;{ }^{* *} p$ $<.05 ;{ }^{*} \mathrm{p}<0.1$

Figure SI 13: Cross-sectional correlates of hate crimes

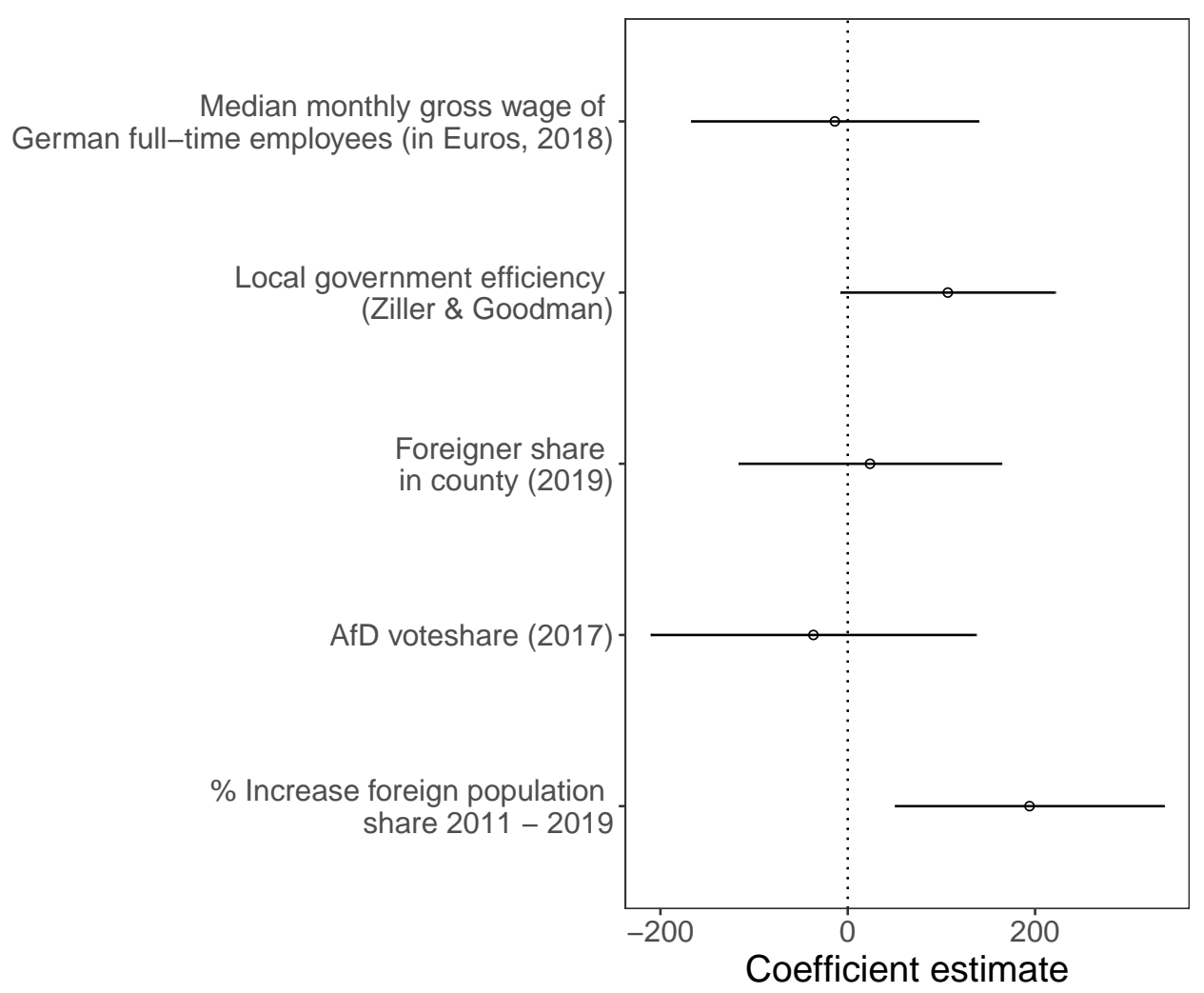

Note: The figure shows the coefficient estimates from a regression where the outcome is the total number of hate crimes recorded at the county-level between January 2015 and March 2019. The outcome was scaled by county population size (as of 2017). All covariates shown on the left hand-side were standardized prior to running the regression. Complete data was available for 392 out of 401 counties. The model includes state fixed effects. Error-bars indicate $95 \%$ confidence intervals. 
SI.3.5 Variance explained by other covariates

Figure SI 14: Variance in hate crimes explained by other covariates

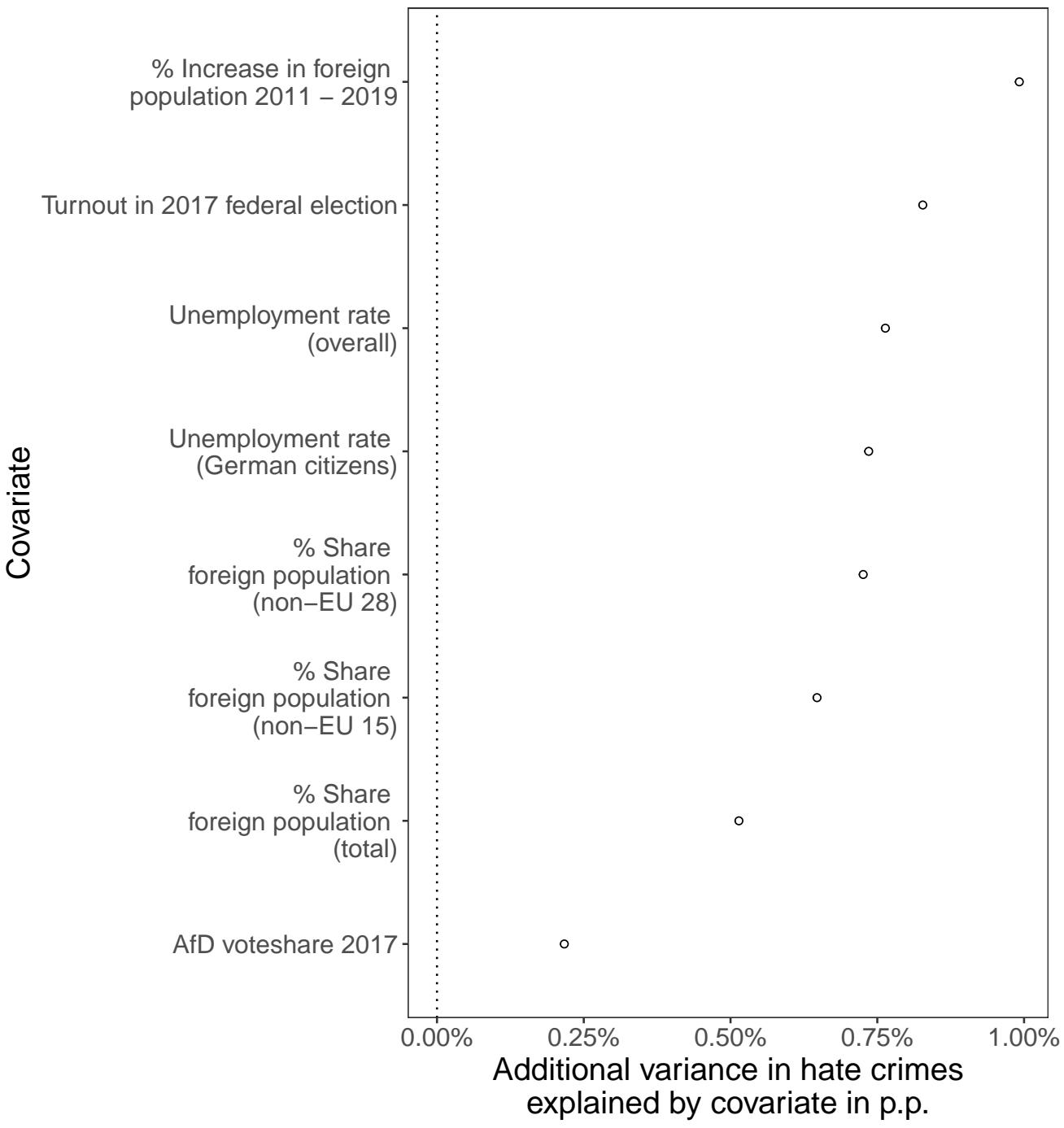

Note: The figure shows the share of variance in hate crimes explained by different county-level covariates. We estimate a baseline OLS model where the outcome is the number of hate crimes recorded in a given county in a given year scaled by county population. We exclude the year 2019 , because we do not observe hate crimes for the full year. The regressors in the baseline model are county population size, state fixed effects, and year fixed effects. For each covariate, we then estimate the same model and include the respective covariate. We compare the (unadjusted) $\mathrm{R}^{2}$ values of the two nested models. The difference in $\mathrm{R}^{2}$ between the two models is plotted on the $\mathrm{x}$-axis. We repeated this procedure separately for each covariate. 


\section{SI.4 Additional information regarding the empirical strategy}

In this section, we give a brief explanation of local polynomial estimation and optimal bandwidth selection in the sharp RD design. Our discussion heavily draws on the seminal work by Cattaneo, Idrobo, and Titiunik (2019).

\section{SI.4.1 Local polynomial estimation}

Our goal is to identify the increase in the rate of hate crimes immediately after a migrant crime event. The baseline is the period right before a migrant crime event. Formally, this difference in the rate of hate crimes at the treatment assignment cutoff is defined as $\tau=E\left[Y_{i, t, c}(1)-Y_{i, t, c}(0) \mid P_{i, t, c}=0\right]$.

To identify this difference, we have to use observations around the treatment assignment cutoff, which defines our bandwidth in days. We use these observations to estimate the rate of hate crimes right before and after migrant crime events.

The most straightforward way to do this is to simply calculate the difference in means before and after a migrant crime event within a given temporal bandwidth. This is precisely what we do for the results shown in rows 1-2 in table SI 6 . In the RD setup, this is equivalent to drawing two straight lines through the observations to the left and right of the treatment assignment cutoff separately. The treatment effect estimate in this setup is the level (intercept) difference between the two lines.

This approach imposes the assumption that there is no relationship between $E\left[Y_{i, t, c}\right]$ and the running variable (time in our setup). This is because the line fitted through the data on each side of the treatment assignment cutoff has a slope of zero by construction.

In the standard RD design, this assumption is relaxed by approximating $E\left[Y_{i, t, c}\right]$ to the left and right of the cutoff using polynomials of different orders. This approach builds on the insight that any sufficiently smooth function can be well approximated by a polynomial function up to an error term. Using a flexible functional form, the relationship between the running variable and outcome is modeled rather than assumed. In practice, this is done by fitting a weighted least-squares regression of the outcome $Y_{i, t, c}$ on a constant and $\left(P_{i, t, c}-\right.$ $c),\left(P_{i, t, c}-c\right)^{2}, \ldots,\left(P_{i, t, c}-c\right)^{k}$, where $k$ is the chosen polynomial order and $c=0$ is the treatment assignment cutoff. Observations closer to the treatment assignment cutoff receive larger weight in the weighted least squares regression.

The local average treatment effect estimate is the difference in the expected rate of hate crimes right before and after migrant crime events (i.e. right at the treatment assignment cutoff $c=0$ ). This difference is approximated by the (weighted) regression functions fitted left and right of the assignment cutoff.

Now, researchers can choose the order of the polynomial they want to use to approximate the expected value of the outcome to the left and right of the cutoff. Higher order polynomials are more flexible. However, it is generally advisable to use polynomials of order one or two (linear/quadratic). These functional forms are substantially less sensitive and more robust results compared to higher order polynomials (e.g. cubic). This is precisely what we do for the models shown in table 1.

Finally, we note that the regression function can be modified to include covariates (fixed effects). The weighted least squares regression then includes (i) a constant, (ii) a treatment indicator, iii) the p-order polynomial, and iv) the p-order polynomial on the running variable interacted with the treatment, and $\mathbf{v}$ ) the covariates $\mathbf{Z}$. However, we note that the inclusion of fixed effects generally involves strong assumptions about balance of the covariates around the treatment assignment cutoff. Similar to experimental settings, covariates in RD designs should generally be included in order to increase statistical power, not to fix imbalance around the treatment assignment cutoff. We refer to Cattaneo, Idrobo, and Titiunik (2019: p. 69-74) for a more detailed discussion of using covariates in RD designs. 


\section{SI Supporting Information}

\section{SI.4.2 Optimal bandwidth selection}

When we approximate the unknown function $E\left[Y_{i, t, c} \mid P_{i, t, c}\right]$ around the cutoff using a polynomial, the accuracy of the approximation can be improved by reducing the bandwidth. However, reducing the bandwidth also reduces the number of observations that are used for the estimation. The choice of the bandwidth in days $h$ hence involves a bias-variance trade-off in the estimation of $\hat{\tau}$.

For our main results, we follow the approach suggested by Cattaneo, Idrobo, and Titiunik (2019) and select $h$ in a data-driven, automatic way to limit researcher discretion. The optimal bandwidth selection algorithm seeks to minimize the MSE of the RD point estimator $(\hat{\tau})$ conditional on the choice of the polynomial and kernel weighting function. Cattaneo, Idrobo, and Titiunik (2019) derive an asymptotic approximation to the MSE of $\hat{\tau}$, optimize it with respect to $h$, and estimate unknown quantities in the formula to estimate the 'optimal' $h$ that minimizes the MSE.

In a nutshell, the bias of $\hat{\tau}$ depends on the curvature of the unknown regression function left and right of the cutoff. Holding the order of the polynomial used constant, the bias increases as the 'true' curvature of the unknown regression function increases. The intuition is that a quadratic function, for example, can only be imperfectly approximated using a linear polynomial. The variance of $\hat{\tau}$ mainly depends on the sample size within the bandwidth as well as the variance in the outcome around the cutoff. We refer to Cattaneo, Idrobo, and Titiunik (2019: p. 39 - 44) for a more detailed and complete discussion and derivation of the optimal bandwidth selection algorithm.

We demonstrate that our results are robust to using different, manually selected, bandwidths in figure SI 17. 


\section{SI Supporting Information}

\section{SI.5 Panel analysis}

In this section, we descriptively examine the association between migrant crime events and hate crimes. We use the same subset of refcrime events as for our main analysis, i.e. crimes attributed to perpetrators from African and Muslim-majority countries (see section 3.1). We begin by visually inspecting the relationship between the number of hate crimes and immigrant-attributed crime events reported in a given county in a given month in figure SI 15. We find a positive correlation between the two variables $(r=0.21)$.

Figure SI 15: Migrant crime and hate crimes, scatterplot

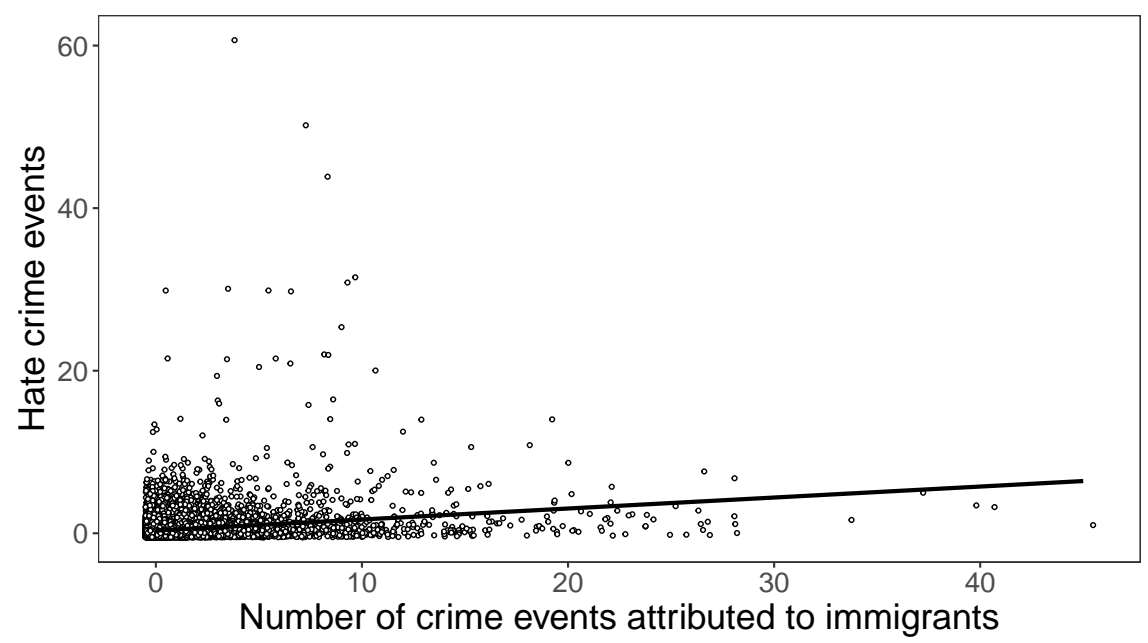

Note: The figure shows the bivariate relationship between the number of migrant-attributed crime events (as reported on refcrime) and the number of hate crime events we observe in our data. Each point represents one month in one county during our study period January 2015 to March 2019. For this visualization of two count variables, we slightly jitter the points on the graph - this jitter does not affect the OLS regression line of linear best fit. The raw bivariate correlation is $r=0.21$.

Table SI 3: Fixed effects panel analysis results

\begin{tabular}{|c|c|c|c|c|}
\hline & \multicolumn{4}{|c|}{ DV: Hate crimes } \\
\hline & (1) & (2) & (3) & (4) \\
\hline Migrant crimes & $\begin{array}{c}0.047^{* * *} \\
(0.011)\end{array}$ & $\begin{array}{c}0.036^{* * *} \\
(0.011)\end{array}$ & $\begin{array}{c}0.035^{* * *} \\
(0.010)\end{array}$ & $\begin{array}{c}0.033^{* * *} \\
(0.010)\end{array}$ \\
\hline County FE & Yes & Yes & Yes & Yes \\
\hline Year FE & No & Yes & Yes & No \\
\hline Month FE & No & No & Yes & No \\
\hline Year $\times$ Month FE & No & No & No & Yes \\
\hline $\mathrm{N}$ & 20451 & 20451 & 20451 & 20451 \\
\hline \multicolumn{5}{|c|}{$\begin{array}{l}\text { Notes: The outcome variable is the number of hate crimes recorded in a given } \\
\text { county in a given month. The effect size estimates relate to the independent } \\
\text { variable: the number of crime events attributed to immigrants (based on the } \\
\text { refcrime data) for the same county in the same month. The sample covers all } \\
\text { German counties from January } 2015 \text { to March } 2019 \text {. Standard errors are clustered } \\
\text { at the county level. }{ }^{* * *} p<.01 ;{ }^{* *} p<.05 ;{ }^{*} p<.1\end{array}$} \\
\hline
\end{tabular}

Next, we perform a standard fixed-effects panel analysis of the relationship between hate crimes and immigrant-attributed crimes reported in the refcrime database at the county-month level. Specifically, we 


\section{SI Supporting Information}

calculate the number of hate crimes and immigrant-attributed crimes for each county in each month during our study period from January 2015 to March 2019. This yields a total of 20,451 observations. We then run standard two-way fixed effects models where we regress the number of hate crimes reported for a given county in a given month on the number of immigrant-attributed crimes reported for the same county in the same month. We also include different combinations of county, year, and month fixed effects. The results are presented in table $\mathrm{SI} 3$. We find a positive, statistically significant relationship between our treatment and outcome variable. The results from fixed effects OLS regressions align with our main results using the RDiT design.

Next, we re-estimate the same fixed-effects specification as described above but now control for local right wing protests. We include a binary indicator variable for whether a right-wing 'PEGIDA' (Patriotic Europeans Against the Islamicisation of the Occident) demonstration occurred in a given county in a given month. We present the results in Table $\mathrm{SI}$ 4. Our conclusions remain unchanged: crimes attributed to immigrants predict the occurrence of hate crimes at the county-month level.

Table SI 4: Fixed effects panel analysis results, controlling for right-wing demonstrations

\section{DV: Hate crimes}

(1)

(2)

(3)

(4)

\begin{tabular}{lcccc}
\hline \hline Migrant crimes & $\begin{array}{c}0.050^{* * * *} \\
(0.013)\end{array}$ & $\begin{array}{c}0.037^{* * *} \\
(0.012)\end{array}$ & $\begin{array}{c}0.037^{* * *} \\
(0.012)\end{array}$ & $\begin{array}{c}0.035^{* * *} \\
(0.011)\end{array}$ \\
Right-wing demonstration $(\mathrm{o} / 1)$ & 0.689 & 0.622 & 0.614 & 0.542 \\
& $(0.650)$ & $(0.637)$ & $(0.637)$ & $(0.635)$ \\
$\mathrm{N}$ & 20451 & 20451 & 20451 & 20451 \\
County FE & Yes & Yes & Yes & Yes \\
Year FE & No & Yes & Yes & No \\
Month FE & No & No & Yes & No \\
Year $\times$ Month FE & No & No & No & Yes \\
$\mathrm{N}$ & 20451 & 20451 & 20451 & 20451 \\
\hline
\end{tabular}

Notes: The outcome variable is the number of hate crimes recorded in a given county in a given month. The effect size estimates relate to the independent variable: the number of crime events attributed to immigrants (based on the refcrime data) for the same county in the same month. The sample covers all German counties from January 2015 to March 2019. Standard errors are clustered at the county level. ${ }^{* * *} \mathrm{p}<.01 ;{ }^{* *} \mathrm{p}<.05 ;{ }^{*} \mathrm{p}<.1$

We also conduct a first-difference analysis of the relationship between immigrant-attributed crimes and hate crimes (see table SI 5). We regress the change in the number of hate crimes in a given county in a given week on the change in the number of immigrant-attributed crimes in the same county in the same/previous week. We also conduct the same analysis using a binary version of the treatment, where we code whether the week-to-week change in immigrant-attributed crime events at the county level was zero or greater than zero.

In this first-difference analysis, we hence conduct a comparison across counties. We ask: do hate crimes evolve differently in counties that experienced 'immigrant crime shocks' vs. those that did not? Again, we find a robust, statistically significant relationship between changes in immigrant-attributed crimes and hate crimes at the county-week level.

Finally, to examine long-run dynamic effects, we run another difference-in-differences specification including multiple lags of the treatment. We regress the change in the number of hate crimes in a given county in a given week on the change in the number of immigrant-attributed crimes in the same county in previous weeks. We now include multiple lags of the treatment, going back 10 weeks. We include all lags in the same OLS model. We present the result in figure SI 16. Again, we find a significant relationship between week to week changes in hate crimes and migrant crimes in the same week or immediately preceding week. With one exception, lags of the 
Table SI 5: First-difference estimation

\section{$\Delta$ Hate crimes (week to week)}

(1)

(2)

\begin{tabular}{ll}
\hline$\Delta$ Migrant crimes, same week & $0.014^{* * *}$ \\
& $(0.003)$ \\
$\Delta$ Migrant crimes, previous week & $0.018^{* * *}$ \\
& $(0.003)$
\end{tabular}

$\Delta$ Migrant crimes, same week (o/1)

$0.015^{* *}$

(0.006)

$\Delta$ Migrant crimes, previous week (o/1)

$0.017^{* * *}$

(0.006)

89022

$\mathrm{N}$

89022

Notes: The table shows the results from an OLS first-difference regression. The outcome is the change in the number of hate crimes observed at the county-week level. The treatment is the change in the number of immigrant-attributed crime events recorded in the refcrime database during the same or previous week in the same county. For the binary versions of the treatment, we code whether the week-to-week change in immigrant-attributed crime events at the county level was zero or greater than zero. The sample covers all German counties between January 2015 and March 2019. Standard errors are clustered at the county level. ${ }^{* * *} p<.01 ;{ }^{* *} p<.05 ;{ }^{*} p$ $<.1$

treatment that are more than 1 week removed do not predict changes in hate crimes. 


\section{SI Supporting Information}

Figure SI 16: First-difference model including additional lags of the treatment

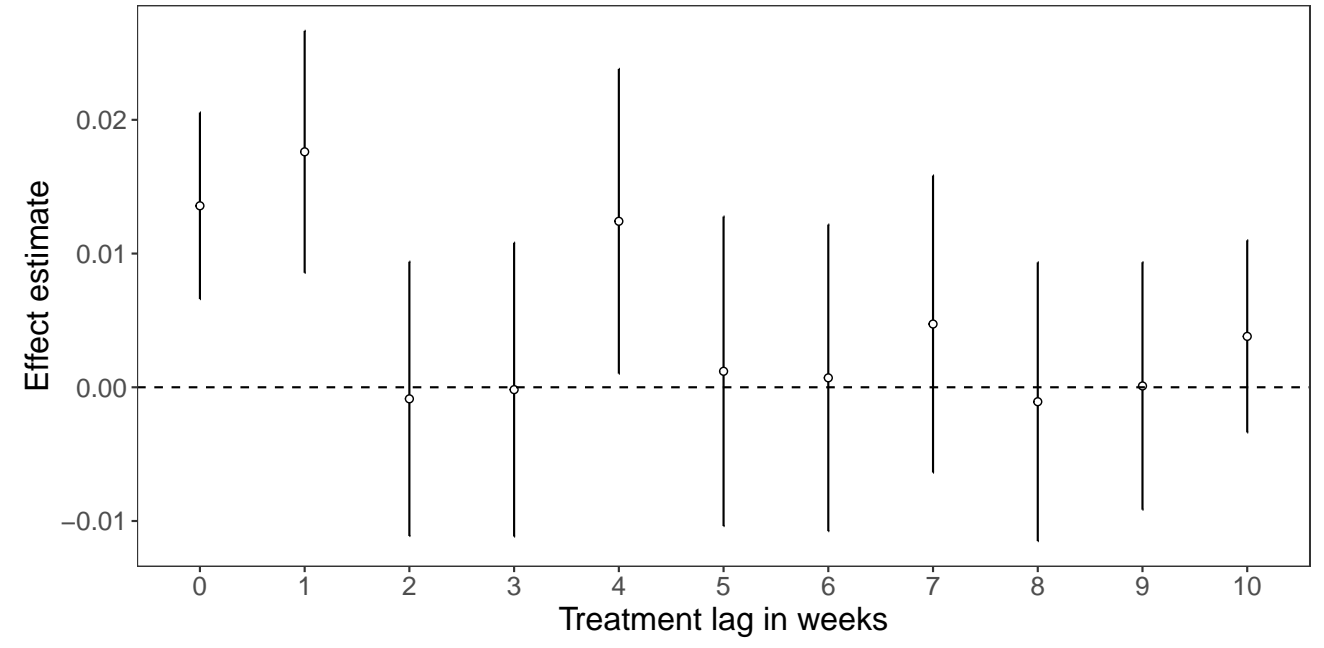

Note: The figure shows the results from an OLS first-difference regression. The outcome is the change in the number of hate crimes observed at the county-week level. The treatment is the week to week change in the number of immigrant-attributed crime events recorded in the refcrime database. We include 10 lags of the treatment in the model. A lag of zero corresponds to the case where we measure the change in the outcome and treatment for the same week. The sample covers all German counties between January 2015 and March 2019. Error-bars indicate $95 \%$ confidence intervals. 


\section{SI Supporting Information}

\section{SI.6 Robustness}

We conduct a series of tests to ensure the robustness of our main results.

First, one potential concern in RD studies is that the results might be sensitive to the choice of the bandwidth around the treatment assignment cutoff. To address this concern, we report the results from RDiT models using varying bandwidths in figure SI 17. The point estimates are stable and statistically significant across different bandwidths. Even for bandwidths as small as three days around the cutoff - for which our identification assumptions are most likely to hold - we find strong and statistically significant local average treatment effect estimates.

Figure SI 17: RD results for varying bandwidths

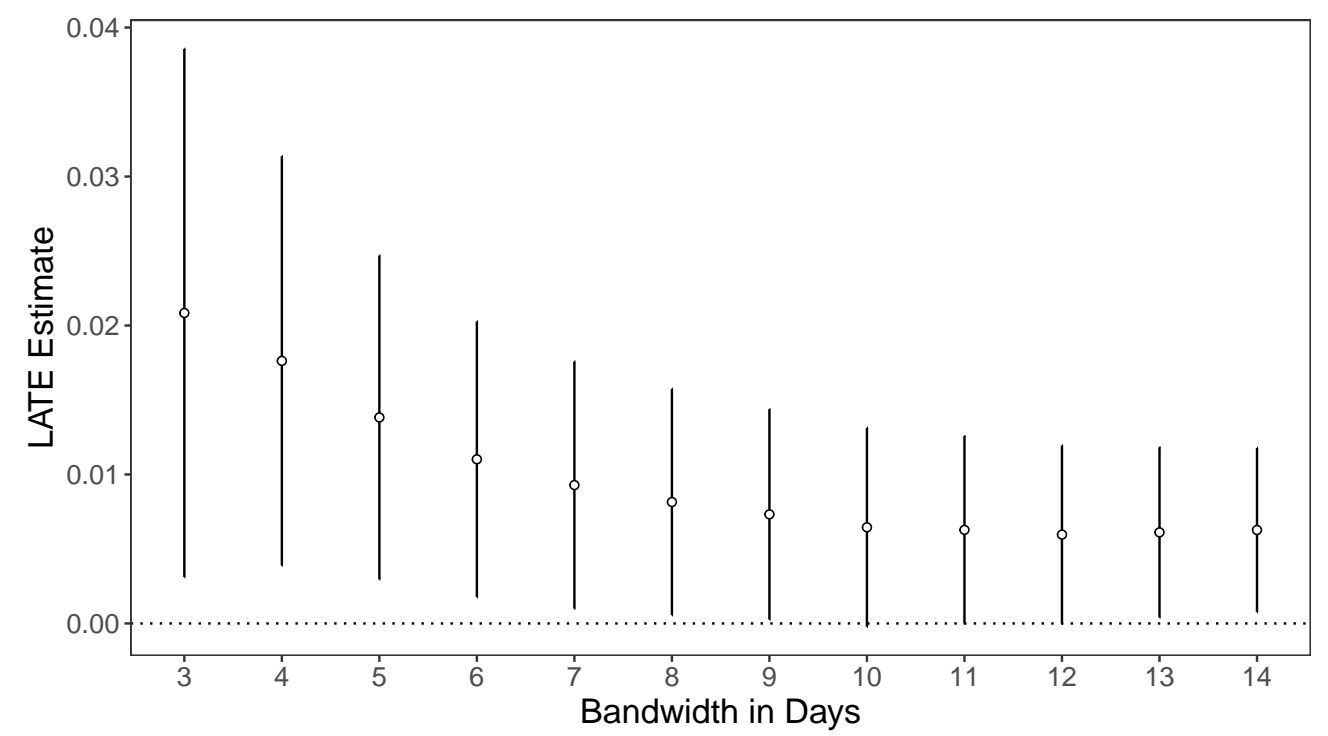

Note: Local average treatment effect on the treated estimates from RDiT models. We vary the bandwidth from 3 to 14 days on both sides of the cutoff. As for our main specification, we fit a local linear polynomial on both sides of the cutoff. Error-bars indicate $95 \%$ confidence intervals.

Second, spillover effects might be a concern in our study design if hate crimes are either subject to local clusters or if the occurrence of hate crimes leads to an increase of hate crimes in adjacent counties. To address this concern, we devised a test for spillover effects. Specifically, we repeat the same data transformation and RDiT analysis as for our main results but now examine whether immigrant crime events in a given county predict hate crimes in geographically proximate counties. We use two alternative ways to define proximity: i) direct border contiguity and ii) varying calipers for the distance between county centroids. We present the results in figure SI 18. We find no evidence for spillover effects: migrant crimes do not predict hate crime events in neighboring counties. This analysis can also be viewed as a placebo test: replacing the outcome of interest, i.e. hate crimes in the same community in which the migrant crime occurred, with a placebo outcome, we find no discontinuity at the treatment assignment cutoff. Note that our finding of no spillover effect is also of substantive interest (Romarri 2020), as it provides evidence that the local effect of migrant-attributed crime has a narrow geographic range. News of these crimes does not appear to travel, or at least it fails to elicit similar responses in neighbouring areas.

Third, we implement jackknife resampling to ensure that our results are not driven by a particular state or county. We implement two separate resampling strategies, by state and by county. We first run the same analysis as for our main results and one-by-one exclude one German county at a time (see figure SI 19). In a second step, we repeat the same procedure leaving out one of the sixteen federal states at a time (see figure $\mathrm{SI} 20$ ). Reassuringly, the RDiT effect size estimates appear stable across the different subsets.

Fourth, we conduct a placebo test for reverse causality. Specifically, we reproduce exactly the same data transformation procedure and RDiT analysis as for our main results but now switch the order of the outcome 


\section{SI Supporting Information}

Figure SI 18: Test for Spillover Effects

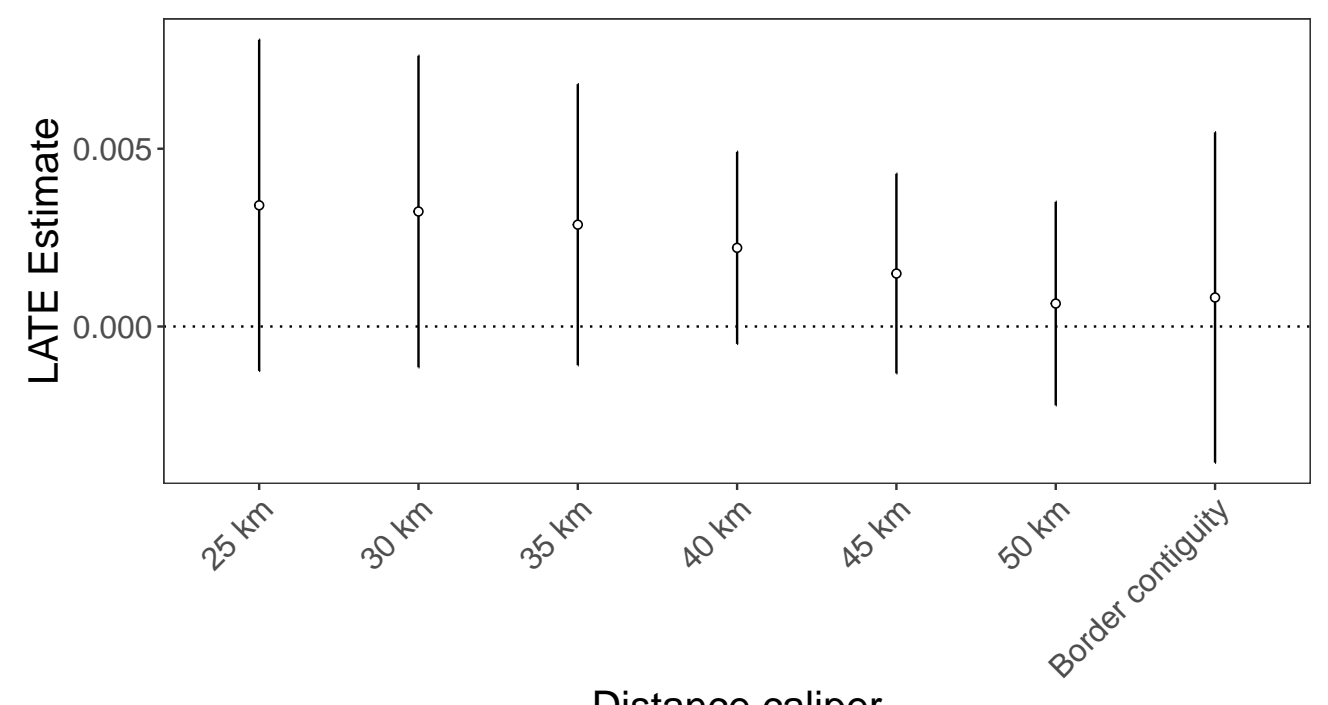

Distance caliper

Note: Local average treatment effect on the treated estimates from RDiT models. Here we estimate the effect of immigrant crime events on hate crimes in geographically proximate counties to test for spillover effects. We repeat exactly the same data transformation procedure as for our main results with one difference: we code the hate crimes outcome for geographically proximate counties. For the first set of tests, we define geographic proximity based on the distance between county centroids with a varying distance caliper. In addition, we run a specification where we define all contiguous counties (i.e. counties bordering the treated county directly) as 'proximate'. We compare the rate of hate crimes before and after the migrant crime event within each county that is geographically proximate to the treated county. Error-bars indicate $95 \%$ confidence intervals.

and treatment variables. We take hate crime events as the starting point, and examine the likelihood of migrant crime events in the two-week period before and after hate crime events. Reassuringly, we do not find evidence for reverse causality. The likelihood of migrant crime events does not increase after hate crime incidents (see figure SI 21).

Fifth, in our main analysis, we consider counties as treated starting on the day a migrant crime occurs. However, it may take a while until information about such events spreads to the native population. To account for this, we devise a test akin to the logic of a 'donut-RD' design. We use the fact that we observe the exact timing of a subset of migrant crimes in our dataset. We find that our results remain unchanged when we rely on the day of the migrant crime event only for those events that occurred very early in the morning (see figure $\mathrm{SI} 22$ ).

Sixth, we rule out that we simply identify temporal noise in the data. It might be the case, for instance, that migrant crimes and hate crimes cluster on similar days of the week. Figure SI 23 shows that both migrant crimes and hate crimes roughly approximate a uniform distribution over the days of the week. If anything, refcrime events are least likely to occur on Fridays, whereas hate crimes most frequently occur on Saturdays and Mondays.

Seventh, we address concerns about the quality of the refcrime data. In table SI 6, we show that our results hold when we subset to those immigrant-attributed crime events that are substantiated by official police reports (see table 1). About $93 \%$ of the events in the refcrime data are substantiated by official police press releases. We also perform an additional robustness check to demonstrate that the remaining $7 \%$ of cases are unlikely to drive our results. Specifically, we repeat our main analysis but randomly drop $7 \%$ of the events in the refcrime database. We repeat this procedure 100 times and report the results in figure $\mathrm{SI} 24$. We find that the effect size estimates appear largely stable when randomly pruning events from the refcrime data.

Eighth, we address the possibility that local right-wing activity might bias our results as a time-varying confounder that is correlated with immigrant-attributed crime. In table SI 6, we demonstrate that our results are robust to excluding migrant crime events in counties where a right-wing 'PEGIDA' (Patriotic Europeans Against the 


\section{SI Supporting Information}

Figure SI 19: RD results: jackknife resampling by county

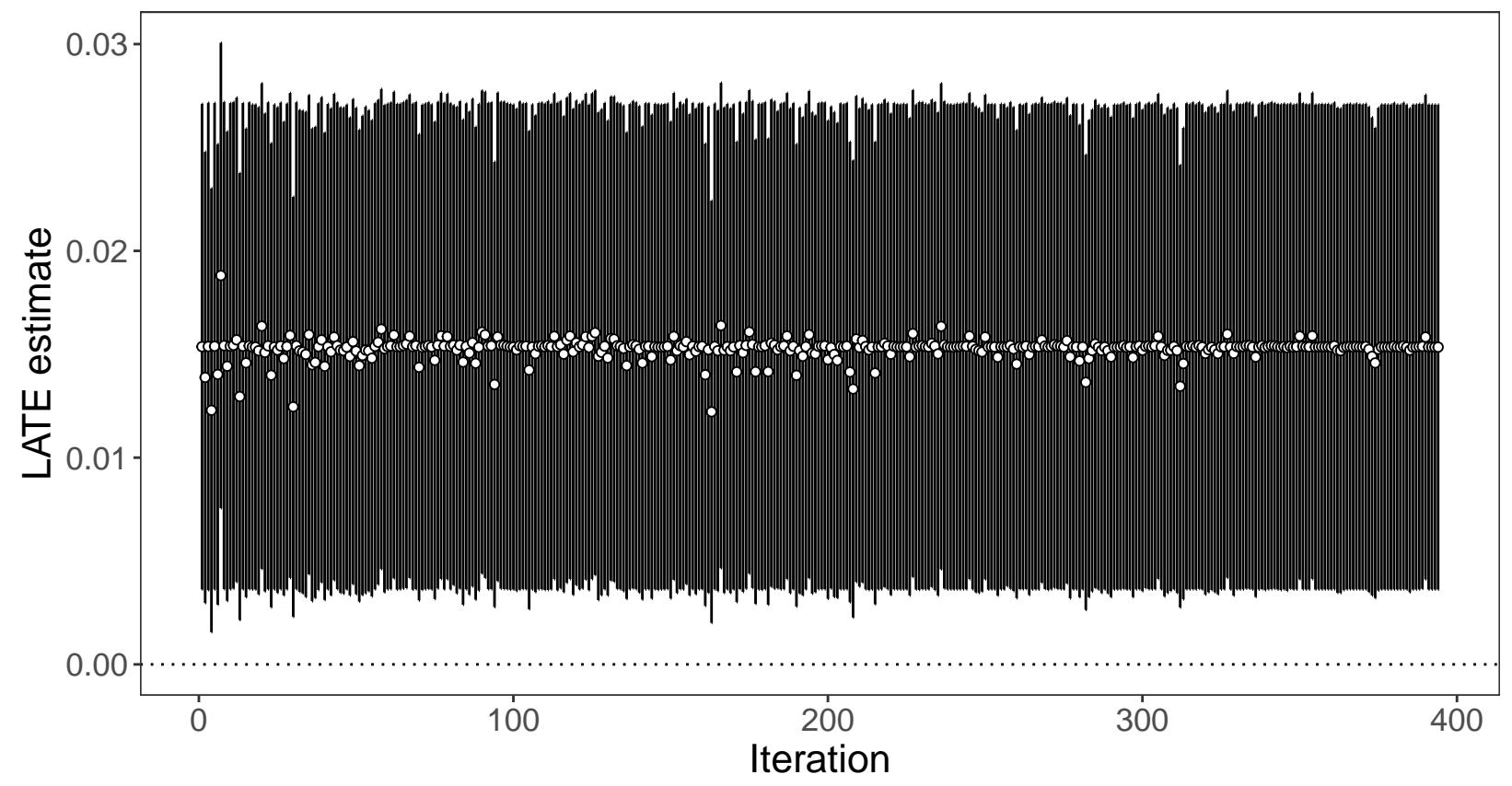

Note: Local average treatment effect on the treated estimates from RDiT models. Each iteration excludes one German county. Error-bars indicate $95 \%$ confidence intervals.

Islamization of the Occident) demonstration occurred during the same year. ${ }^{15}$

Ninth, we ensure that our results are sample selection due to our approach to dealing with overlapping events. For our main analysis, we opt for a conservative approach and drop refcrime events when we only observe few periods for which the unit's treatment status is unambiguous (see section SI.2.7). To ensure that this procedure does not introduce systematic bias into our results, we repeat exactly the same analysis with one difference: we retain all refcrime events in the sample, regardless of the number periods in which the unit's treatment status is unambiguous (see section SI.2.7). We also do not drop duplicate events that occur in the same county on the same day. This analysis hence relies on the full sample of about 17,600 events in the refcrime database. We present the results in figure SI 25. Reassuringly, our main results hold when we instead use the full sample including overlapping events. However, as the number of valid observed periods differs across refcrime events, leveraging all refcrime events might introduce covariate imbalance around the treatment assignment cutoff. We maintain that the main specification we presented in section 4.1 is more likely to yield an unbiased estimate of the local average treatment effect.

Tenth, we verify that our results are not driven by the inclusion of a specific perpetrator nationality in our sample (see also section SI.2.9 and section 3.1). We implement another jackknife analysis where we repeat our main RDiT analysis and, one by one, exclude one perpetrator nationality from the sample. We present the results in figure SI 26. Regardless of which nationality we exclude, we find a positive and statistically significant effect of immigrant crimes on the propensity of hate crimes.

${ }^{15}$ The data stem again from a parliamentary question by the 'Linke'. The government respondents by sharing all information the interior ministry has available on radical right protest. The ministry also provides a separate table about PEGIDA events only. We collected all this information with support from an RA. 


\section{SI Supporting Information}

Figure SI 20: RD results: jackknife resampling by state

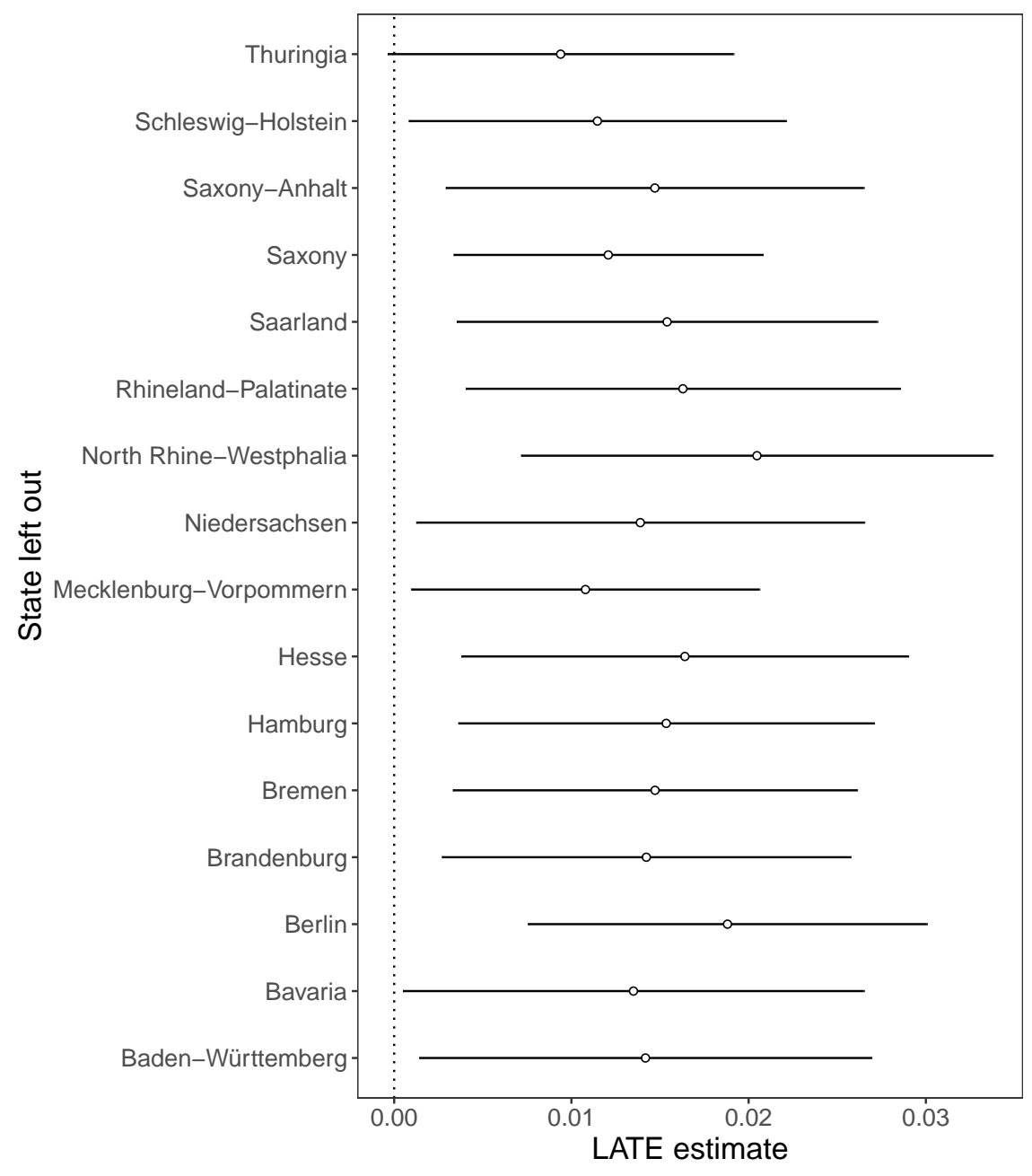

Note: Local average treatment effect on the treated estimates from RDiT models. Here we repeat the same analysis as for our main results seperately in different subsamples. Each subsample excludes one federal state at a time. Error-bars indicate $95 \%$ confidence intervals.

Eleventh, we replicate our main results using standard errors clustered at different levels: (1) the refcrime event, (2) county, (3) year $\times$ month, and (4) the date (Year-Month-Day) of a given observation in our data set. Clustering at the level of refcrime events (level of sampling) and the date of a given observation (treatment assignment) appear particularly sensible choices in our setting (Abadie et al. 2017). We present the results in Figure SI 27. Our main results remain unchanged when clustering at different levels.

Finally, we provide evidence that the days before and after migrant crime events are similar in terms of observable climatic characteristics. Drawing on daily rainfall data recorded on over 2,000 weather stations all across Germany, we show that rainfall recorded at the county-day level is constant around the treatment assignment cutoff (see figure SI 28). 
Figure SI 21: RD plot: effect of hate crimes on migrant crime

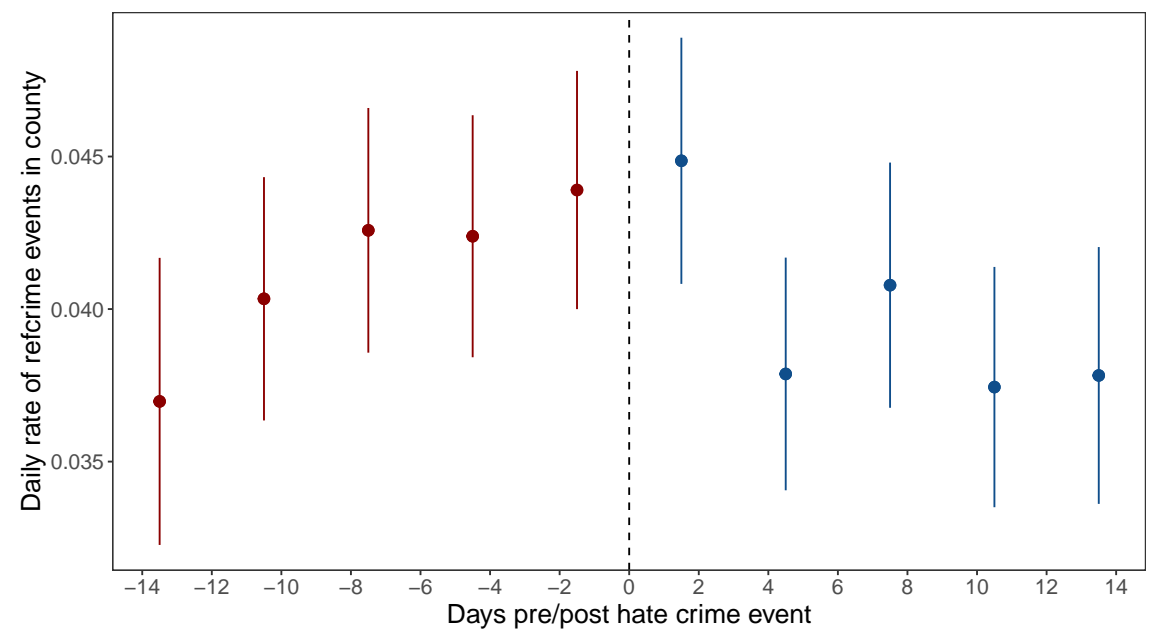

Note: RD plot where the outcome and treatment variable are reversed. We repeat exactly the same analysis as for our main results but treat hate crimes as the treatment event and the occurrence immigrant crimes as the outcome variable.

Figure SI 22: Excluding the first period

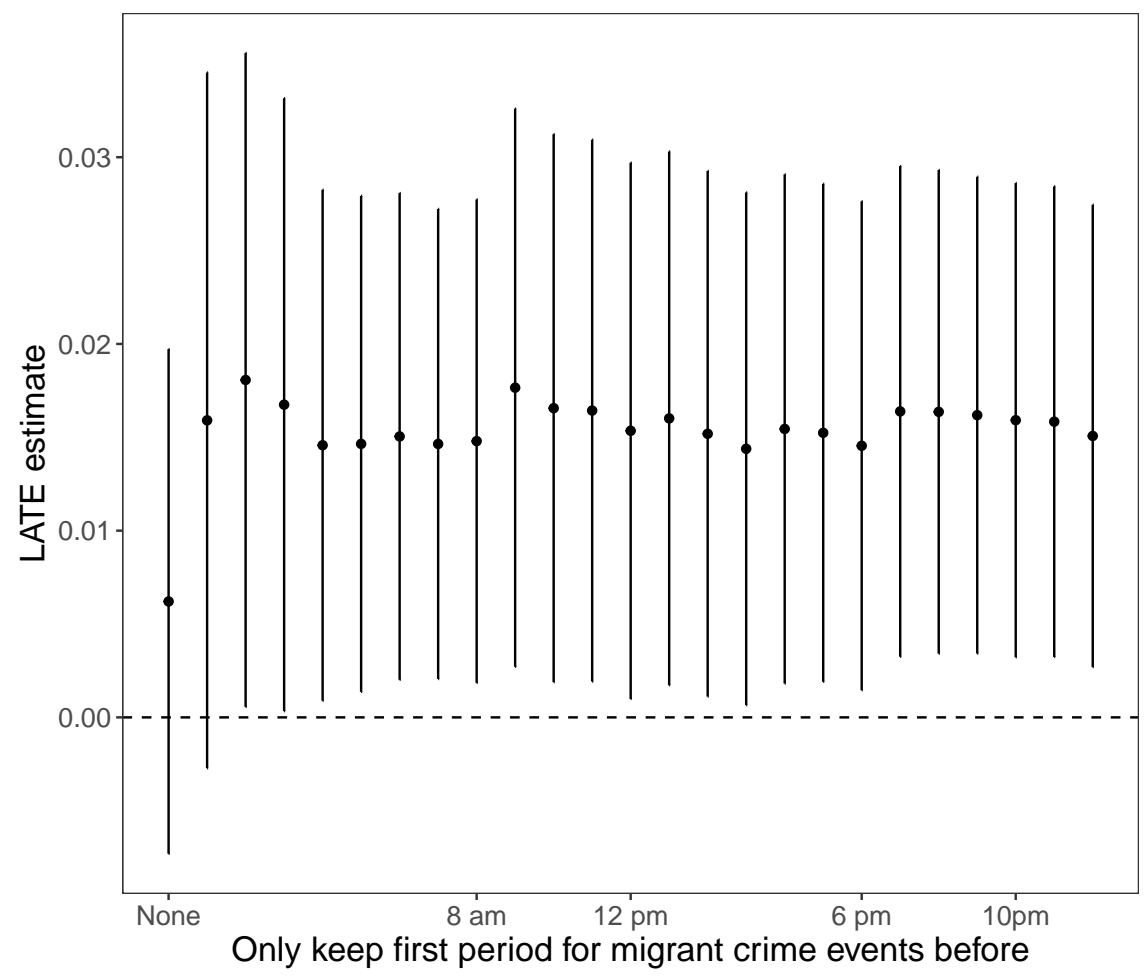

Note: The figure shows the LATE effect estimates from the regression discontinuity in time analsysis. We repeat the same analysis as for our main results but now exclude the day of the migrant crime event itself (period zero) for migrant crime events that occurred before a certain time of the day. We also exclude this period for those migrant crime events for which we do not observe the exact time at which they occurred. Error-bars indicate $95 \%$ confidence intervals. 


\section{SI Supporting Information}

Figure SI 23: Migrant crimes and hate crimes by day of the week

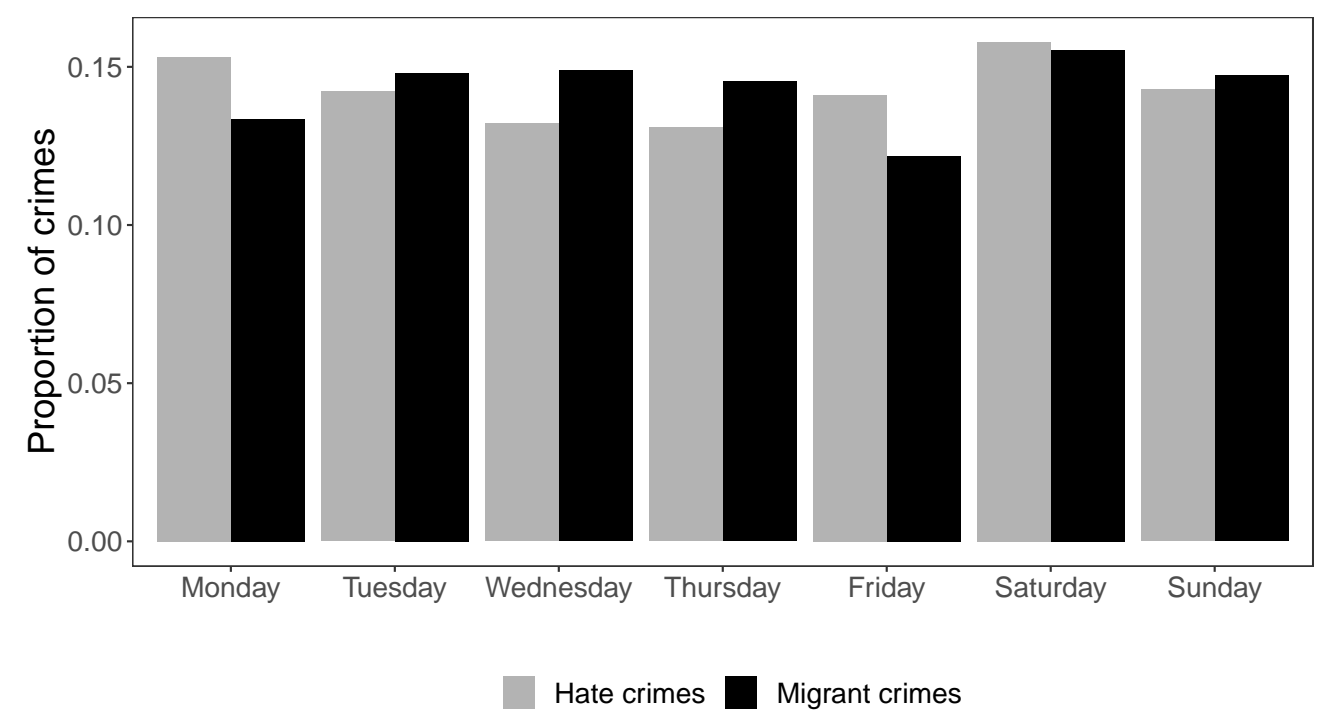

Note: The figure shows the proportion of all migrant crimes and hate crimes in our data set by day of the week.

Table SI 6: Additional results for different model specifications and subsets.

\begin{tabular}{|c|c|c|c|c|c|c|c|}
\hline$\hat{\tau}$ & p-value & Estimation & Subset & DV & $h$ & $p$ & $N$ \\
\hline $0.003 * *$ & 0.04 & Diff. in means & Main sample & Quant. & 4 & l & 46,095 \\
\hline 0.002 * & 0.07 & Diff. in means & Main sample & Quant. & 10 & l & 100,989 \\
\hline 0.0131 ** & 0.03 & RDiT & Police-reported crime & Quant. & 3 & 1 & 30,602 \\
\hline $0.023 * *$ & 0.047 & RDiT & Police-reported crime & Quant. & 3 & 2 & 30,602 \\
\hline $0.012 * * *$ & 0.009 & RDiT & $\begin{array}{l}\text { Exclude counties with } \\
\text { right-wing marches }\end{array}$ & Quant. & 3 & 1 & 34,707 \\
\hline $0.026 * * *$ & 0.009 & RDiT & $\begin{array}{l}\text { Exclude counties with } \\
\text { right-wing marches }\end{array}$ & Quant. & 3 & 2 & 34,707 \\
\hline
\end{tabular}

Notes: The outcome variable is the daily rate of hate crimes at the county-day level. The first two rows show the results from a simple difference in means comparison before and after immigrant crime events. For these models, we manually choose a bandwidth of four or ten days before and after the treatment events. Rows three to six show results from regression discontinuity in time analyses using optimal bandwidth selection and robust bias-corrected standard errors (see also section SI.4). For the specification in three and four, we subset our main dataset to migrant crime events based on official police press releases. For the specification rows five and six, we exclude counties that experienced a right-wing march (PEGIDA) during the same year in the same county. The first column shows the local average treatment effect estimate. The number of observations that fall within the bandwidth in days $(h)$ is shown in the last column $(N)$. The polynomial order is denoted by $p$, where $p=1$ indicates a linear polynomial. ${ }^{* * *} p<.01 ;{ }^{* *} p<.05$; $^{*} \mathrm{p}<.1$. 


\section{SI Supporting Information}

Figure SI 24: Excluding 7\% of the sample at a time

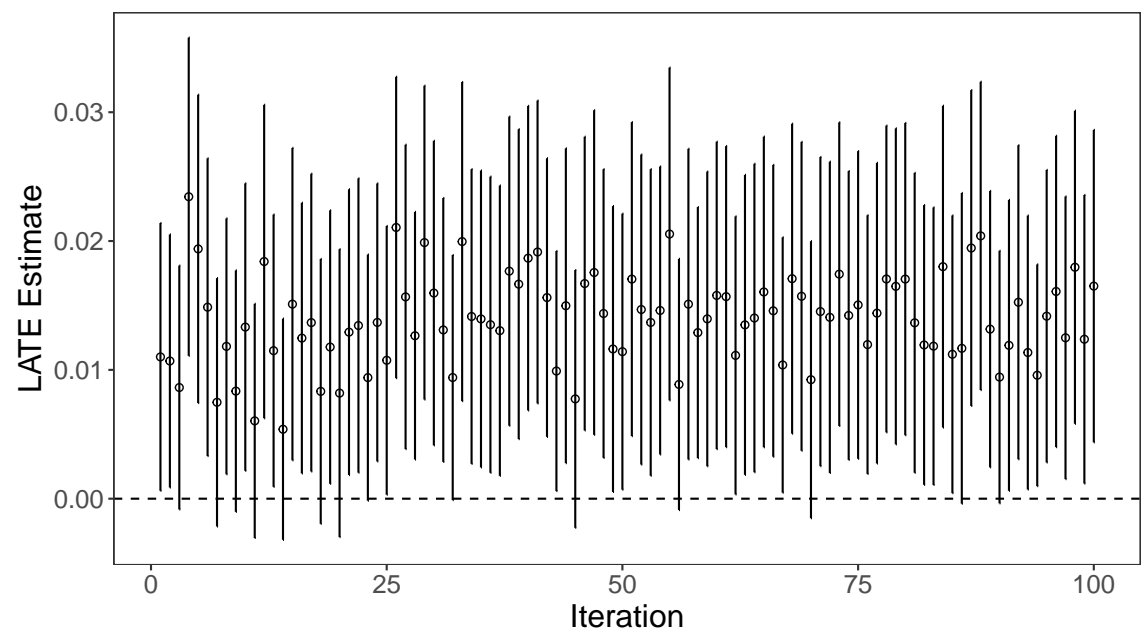

Note: The figure shows the LATE effect estimates from regression discontinuity in time analyses. We repeat the data transformation and RDiT analysis as for our main results but now randomly exclude $7 \%$ of the events reported in the refcrime database (prior to data transformation). We repeat this analysis 100 times. Each effect size estimate corresponds to one iteration. Error-bars indicate $95 \%$ confidence intervals.

Figure SI 25: RD results, full sample

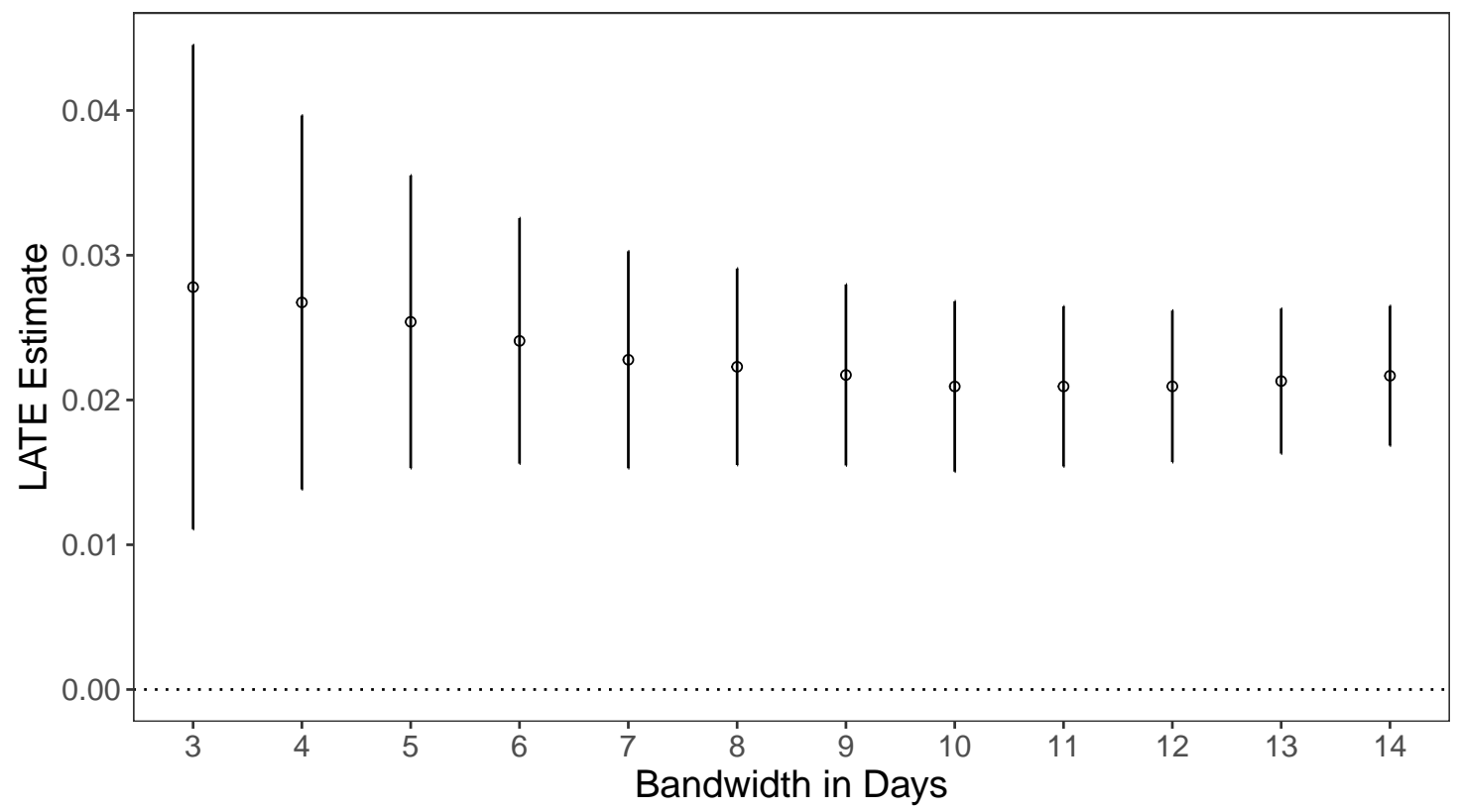

Note: Local average treatment effect on the treated estimates from RDiT models. We vary the bandwidth from 3 to 14 days on both sides of the cutoff. Error-bars indicate $95 \%$ confidence intervals. We repeat exactly the same data transformation procedure as for our main results with one difference: for this analysis, we do not drop any events due to partial overlap (see section SI.2.7). This analysis hence relies on the full sample of about 17,600 events in the refcrime database attributed to Muslim/African perpetrators. 


\section{SI Supporting Information}

Figure SI 26: Excluding perpetrator nationalities one by one

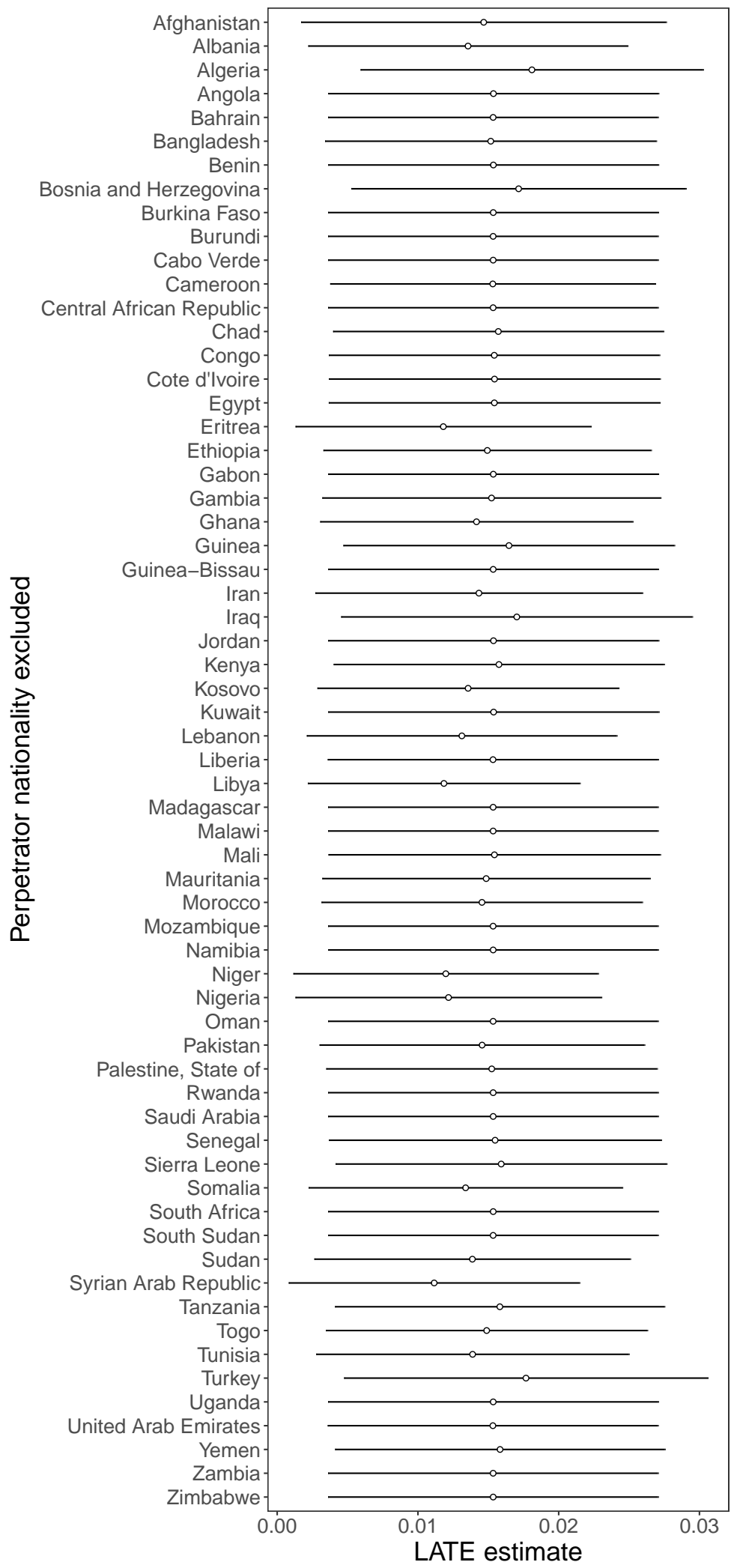

Note: The figure shows the LATE effect estimates from regression discontinuity in time analyses. We repeat the same data transformation and RDiT analysis as for our main results. After data transformation, we one by one exclude one perpetrator nationality from the data set. For each model, the excluded nationality is shown on the $y$-axis. Error-bars indicate $95 \%$ confidence intervals. 


\section{SI Supporting Information}

Figure SI 27: Clustered standard errors

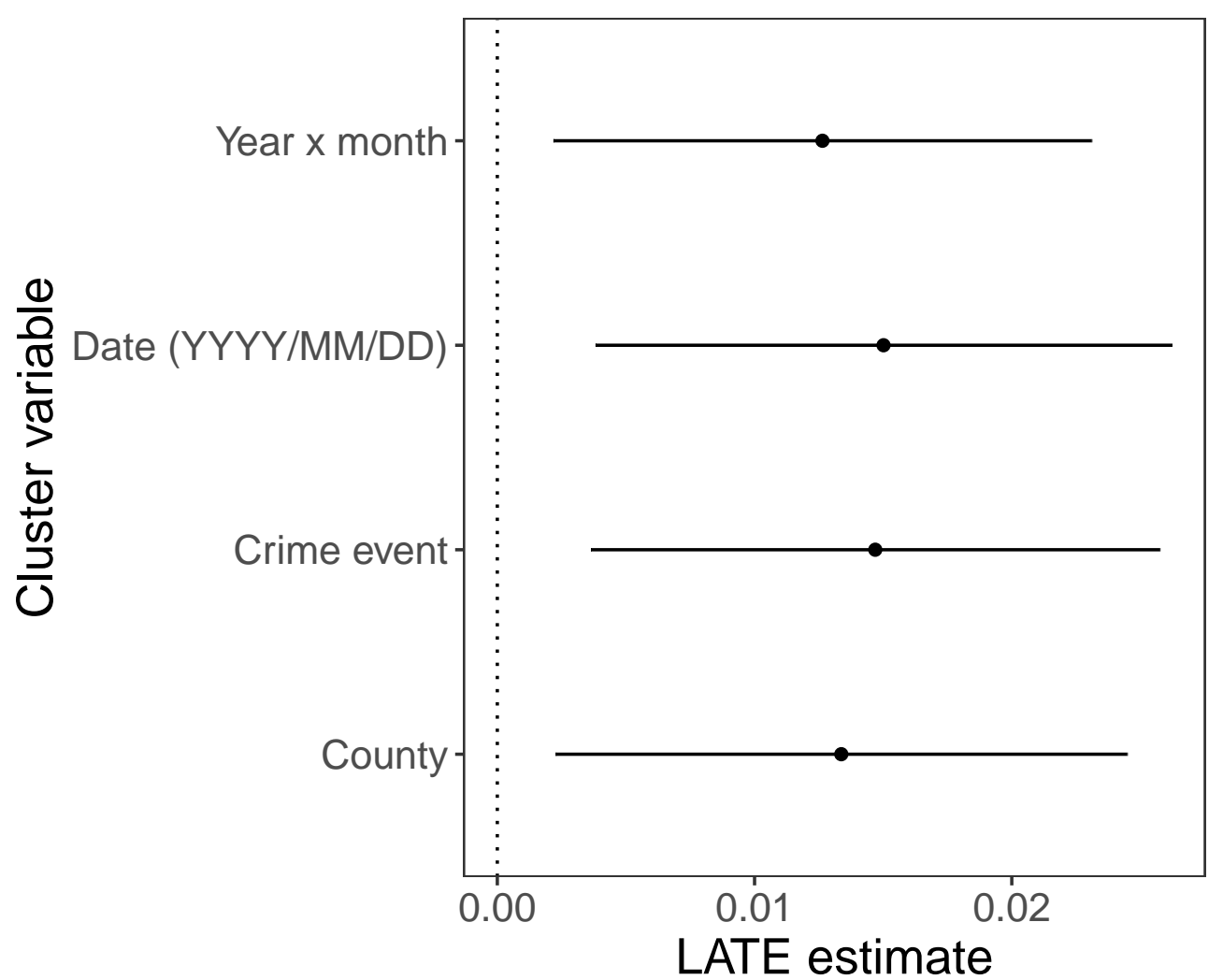

Note: Local average treatment effect on the treated estimates from RDiT models. Analogous to our main specification, the outcome variable is the count of hate crimes in a given county on a given day. We use a local linear polynomial fitted separately on both sides of the cutoff using rdrobust. We use standard errors clustered at different levels: (1) the refcrime event, (2) county, (3) year $\times$ month, and (4) the date (Year-Month-Day) of a given observation in our data set. Error-bars indicate $95 \%$ confidence intervals.

Figure SI 28: RD plot: rainfall

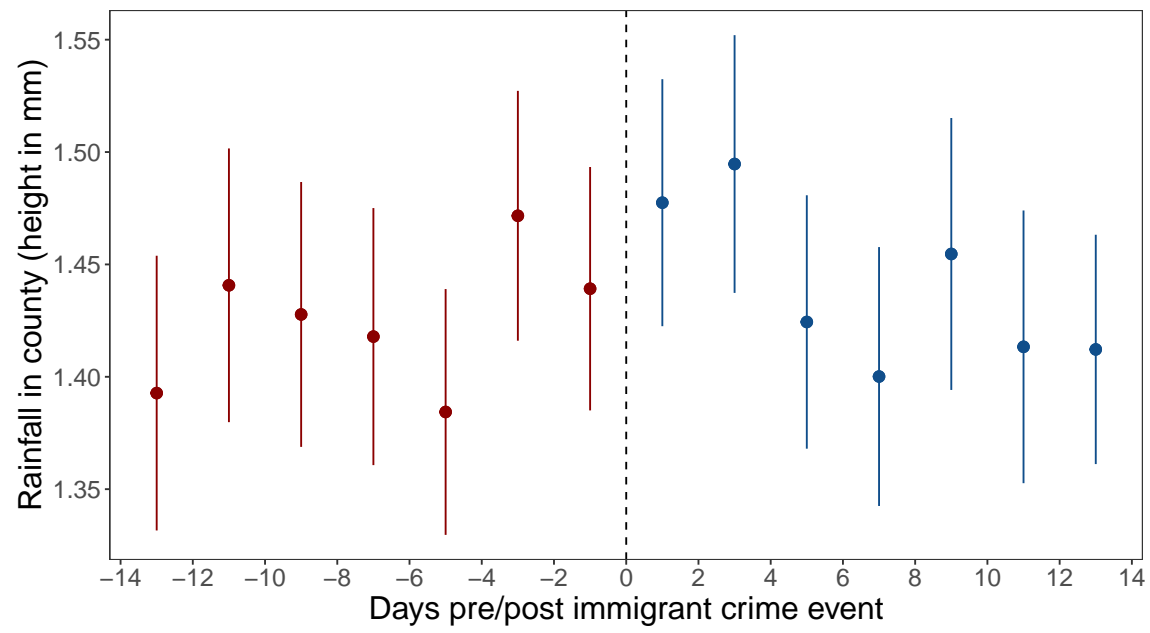

Note: RD plot where the outcome variable is the precipitation height in millimeters observed by county-day. We obtained data from all weather stations in Germany from the Climate Data Center of Germany's National Meteorological Service. Our raw data can be found under the variable code RS-MNoo6. We aggregated this data to the county level by geocoding all weather stations and calculating the median precipitation measured on all stations located within a given county by day. We exclude extreme outliers above the 97.5 percentile of the rainfall distribution. 


\section{SI Supporting Information}

\section{SI.7 Heterogeneity for additional moderators}

A key question emerging from our main finding is whether and how the dynamic of hate is potentially moderated by structural characteristics of a locality (see also section 2). The occurrences of hate crimes in Germany, of course, varies across municipalities. Consistent with prior research, we find clear cross-sectional patterns in our data (see Figures SI 11 and SI 13). Most notably, the level of hate crimes is much higher in East Germany than in West Germany. However, here the key question is whether migrant-attributed crime is more likely to lead to hate crimes in some contexts than in others.

In figure SI 29 we test for effect heterogeneity with respect to additional potential moderators: (i) the size of the local immigrant population (the proportion of the total population that are non-EU28 foreigners) (ii) unemployment among German natives, and (iii) East vs. West Germany.

We test for heterogeneity by repeating our analysis in different subsets of the data created by dichotomizing each moderator variable using a median split. We also run separate analyses for counties in East- and West Germany. This analysis is similar to estimating treatment-moderator interactions using standard OLS.

Figure SI 29: Effect heterogeneity in different subsets

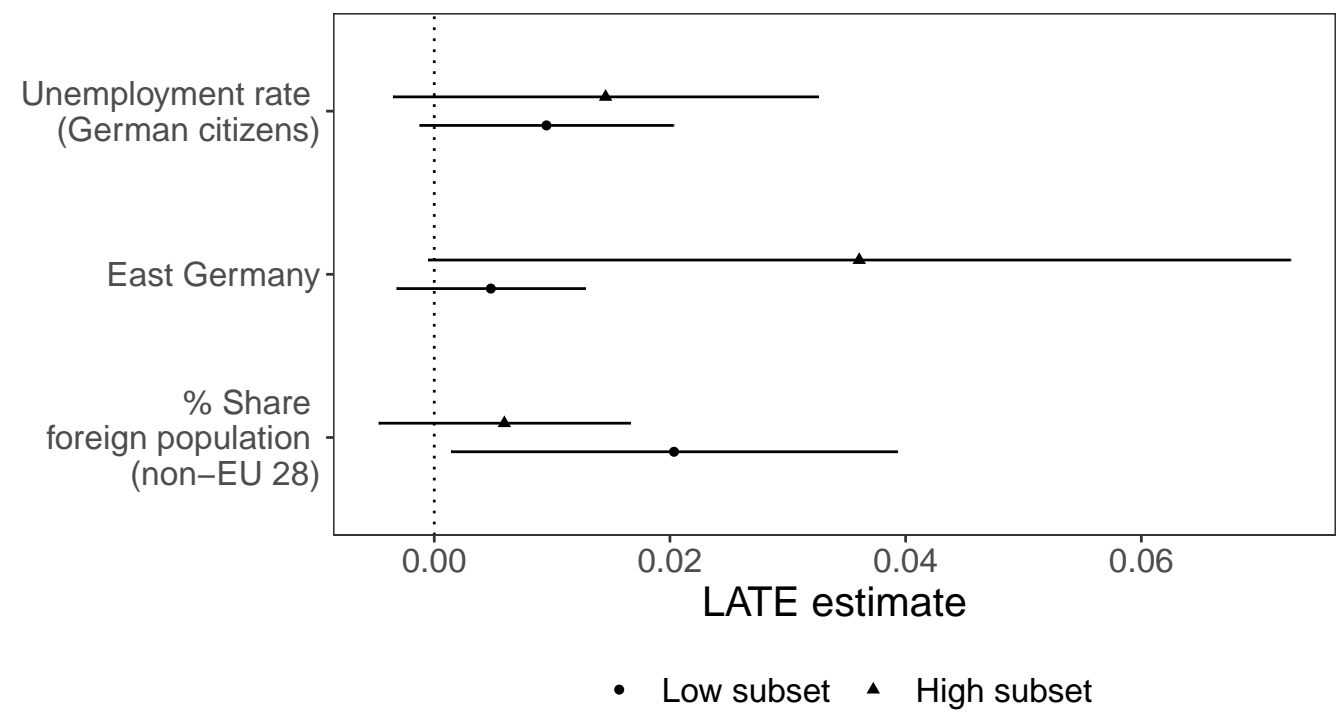

Note: Local average treatment effect on the treated estimates from RDiT models. Here we re-estimate the same model as for our main results in different subsets of the data. Error-bars indicate $95 \%$ confidence intervals. 


\section{SI Supporting Information}

\section{SI.8 Nation-wide public reaction to salient migrant crime events}

In the main body of our manuscript, we established a causal relationship between migrant-attributed crimes and subsequent hate crimes. Such hate crimes are clearly an extreme response to migrant behavior whose perpetrators already hold strong xenophobic attitudes. Thus, the fundamental question is how these attitudes are activated and result in xenophobic violence.

As outlined in our theoretical section, migrant-attributed crimes may lead potential perpetrators to see vicarious retribution as being more legitimate in the eyes of the general public, which may reduce inhibitions to commit hate crimes. We cannot test directly for such shifts in perceptions among potential perpetrators.

However, in this section, we test whether there is a legitimization effect among the general public; this might make shifts in perceptions of legitimacy among potential perpetrators more likely. A broad societal reaction to migrant-attributed crime is plausible. Public opinion surveys suggest that $40 \%$ of the German population links migrants to an increase of crime and terrorism (see figure SI 33 in the SI). The share is even higher among the sub-sample of more nationally-minded citizens, who are arguably ideologically closest to perpetrators of xenophobic hate crimes.

To test the effect of nationally salient migrant crime events, we turn to representative public opinion data from the German socio-economic panel (SOEP v.35), which includes some questions on migration along with questions about key current concerns. In addition, we draw on data from the German Longitudinal Election Study (GLES online). The GLES surveys (waves 29-32) were fielded online between September 2015 and June 2016. Using these surveys, we examine whether attitudes towards migrants shifted nationally after the two migrant crime events that arguably attracted most attention nationwide in Germany: the events in Chemnitz described in the introduction, as well as the sexual assaults in Cologne on New Year's Eve 2015-2016. These events allow us study how public attitudes are affected by migrant crimes gaining national attention.

Figures SI 30 and $\mathrm{SI} 32$ show that there is no evidence that natives generally became less supportive of immigration in the aftermath of nationally salient migrant crimes such as the events described in Chemnitz. The general public seems rather unresponsive to salient migrant crime events (see also: Nussio 2020). If anything, we find that natives, on average, are increasingly concerned about xenophobic violence against minorities during periods of intergroup conflict. Importantly, these results remain unchanged when analyzing a subset of respondents who hold negative attitudes towards migration even before these events (see figure SI 31).

Our survey evidence does not indicate that legitimization of hate crime follows migrant-attributed crime, at least at the national level. These findings also align with previous research on the stability of attitudes towards migration (Kustov, Laaker, and Reller 2019). We interpret these findings as evidence that a small subset of natives with pre-existing xenophobic attitudes is activated by local events with no broader effects on society in general. 
Figure SI 30: Attitudes towards migration before and after Chemnitz (SOEP)
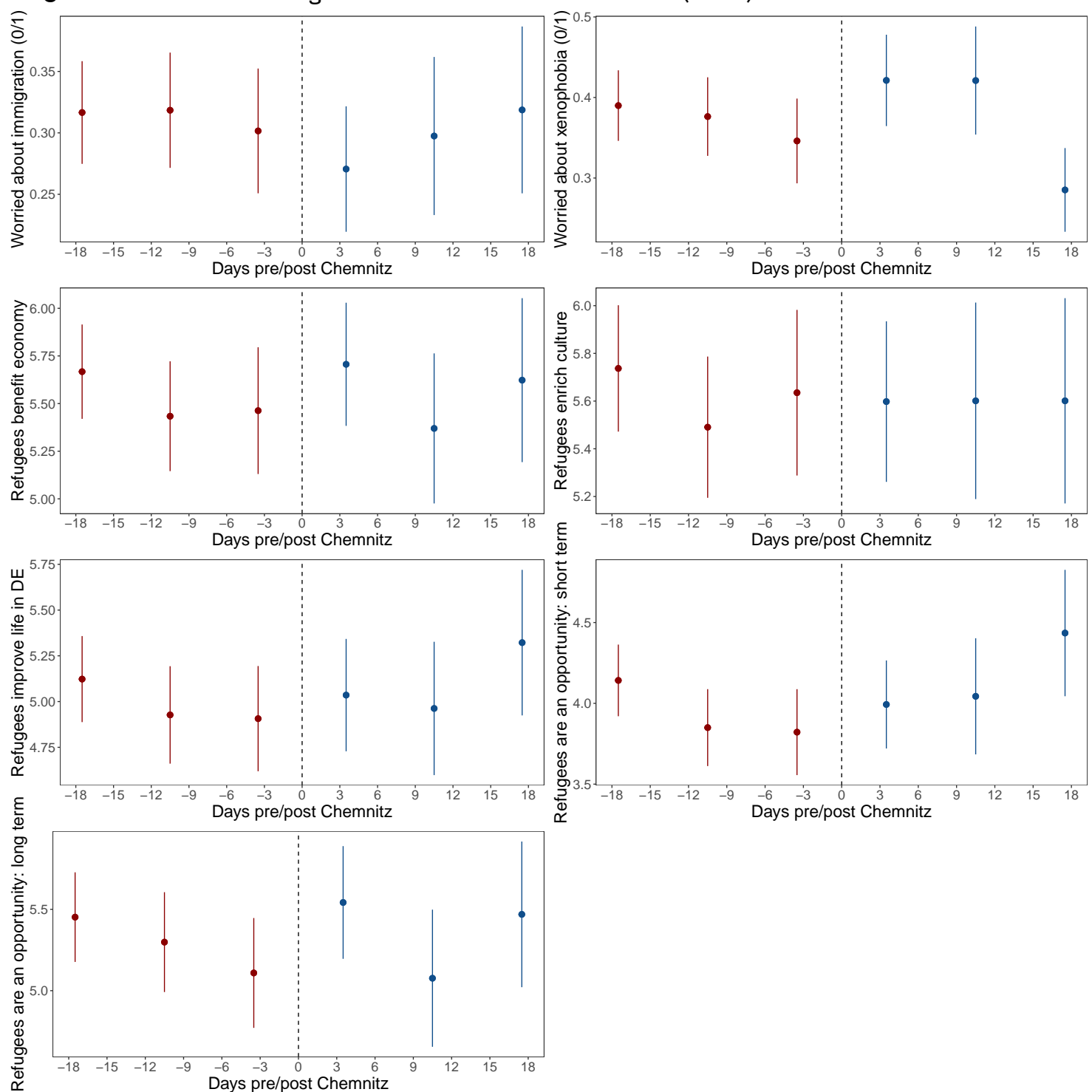

Days pre/post Chemnitz

Note: The figure shows attitudes towards migration among a representative sample of Germans in the threeweek period before and after the Chemnitz incident on August 25, 2018. We compare respondents interviewed right before and after the event $(n=1,964)$. We aggregate the responses to seven different outcome variables measuring attitudes towards migration in weekly bins. We use data from the German Socio-Economic Panel (SOEP) 2018 survey wave. We re-coded the item asking about worries into a binary dummy variable that equals one whenever a respondent replies to be "very concerned" $(=3)$. All other items are measured on a scale from 1 to 11. 
Figure SI 31: Attitudes towards migration before and after Chemnitz: subset of anti-immigrant respondents (SOEP)
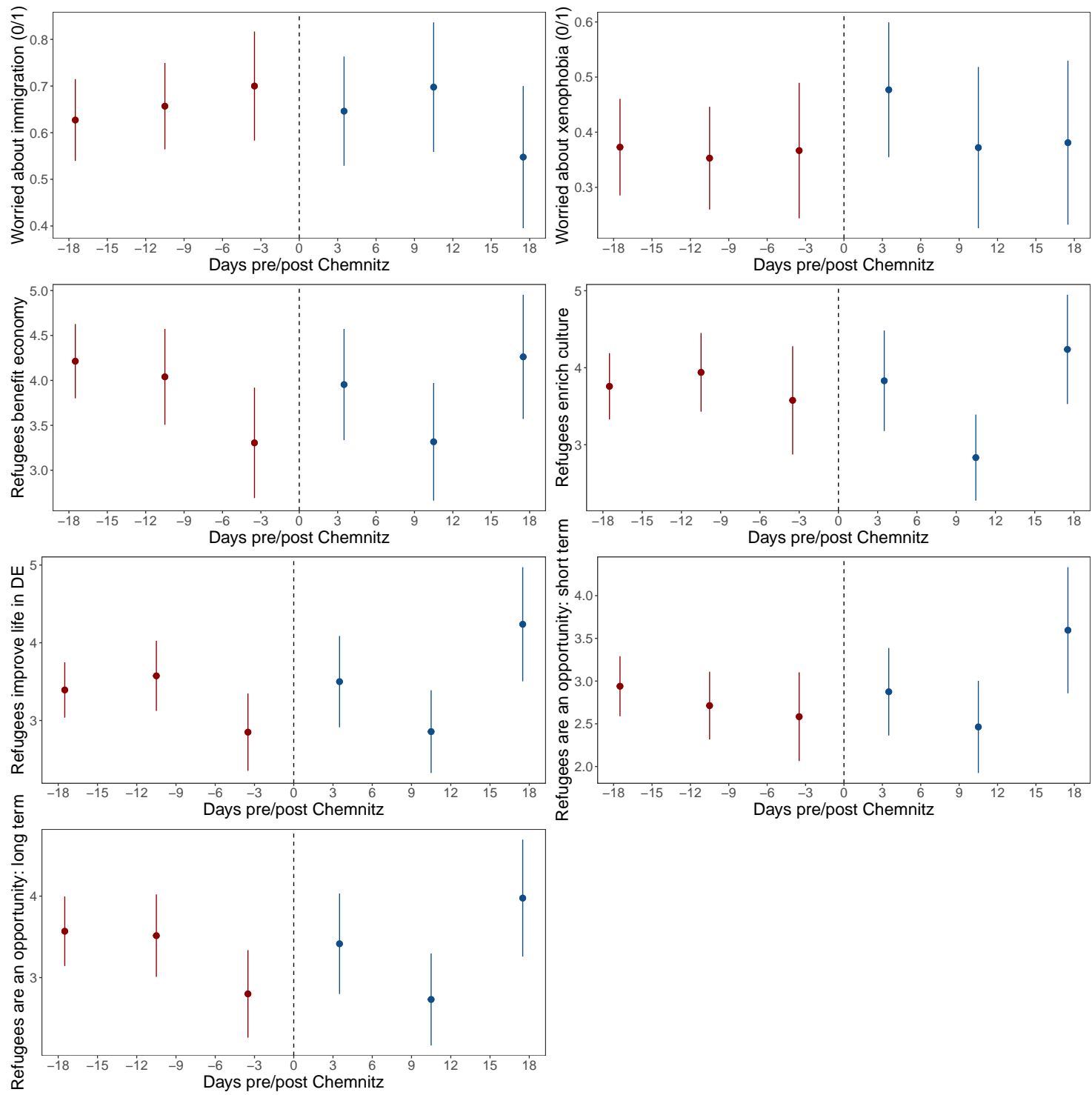

Note: The figure shows attitudes towards migration among a representative sample of Germans in the threeweek period before and after the Chemnitz incident on August 25, 2018. The analysis is analogous to the results shown in figure SI 30 with one difference: here we show the results for the subset of respondents who in 2017 , prior to the Chemnitz events, already expressed anti-immigrant views. Specifically, we subset to respondents who indicated that they are 'somewhat' or 'very' concerned about immigration $(n=430)$. 
Figure SI 32: Attitudes towards migration before and after New Year's eve 2015/2016 (GLES)
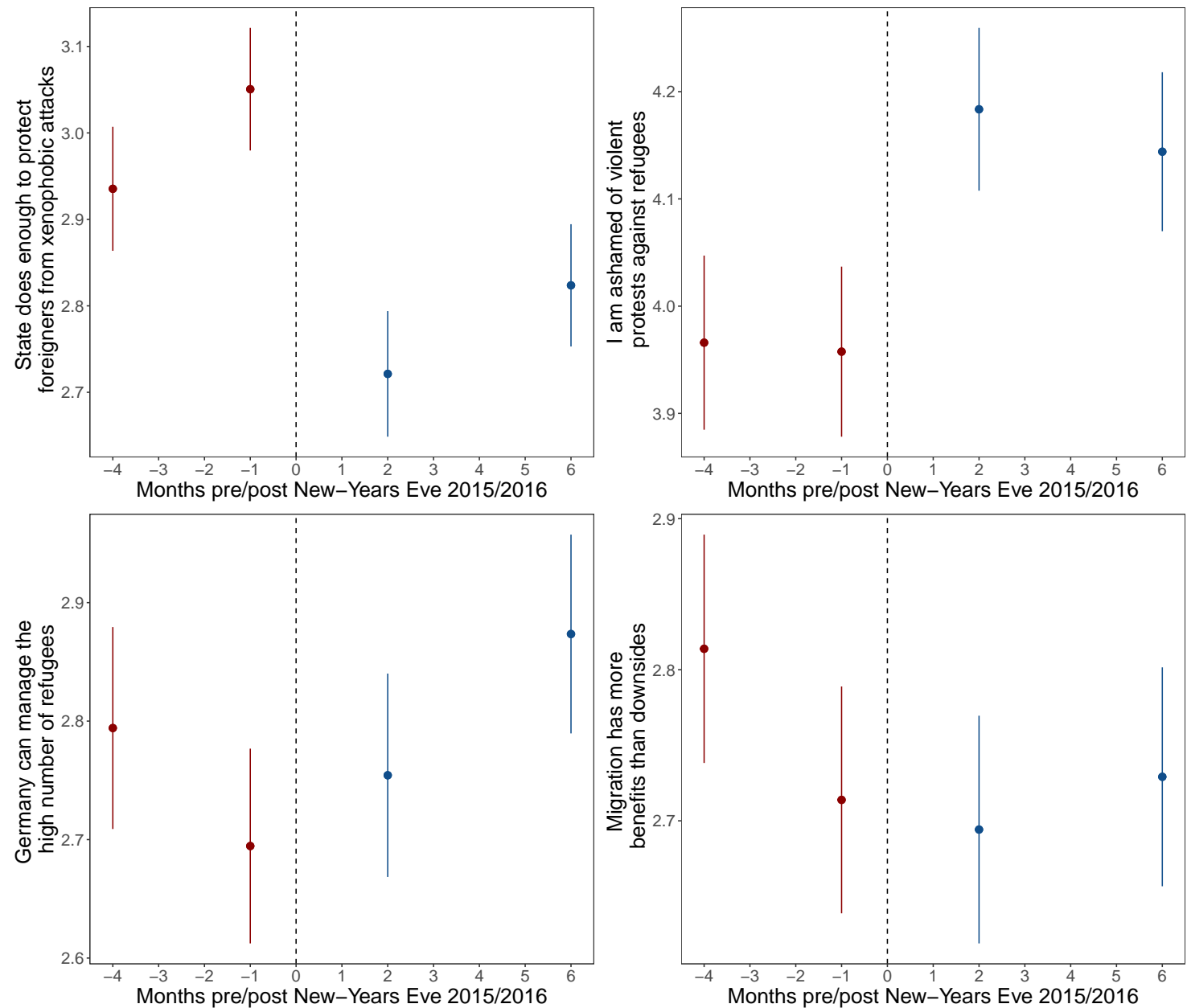

Note: The figure shows attitudes towards migration among a representative sample of Germans in the months before and after the sexual assaults on New-Year's eve 2015-2016 in Cologne. We use data from the 2015 and 2016 online survey waves of the German Longitudinal Election Study (GLES online). This data is available under the study code ZA6832 in the GESIS data archive. 


\section{SI.9 Public opinion about immigration}

Figure SI 33: Public opinion about immigration (2018)

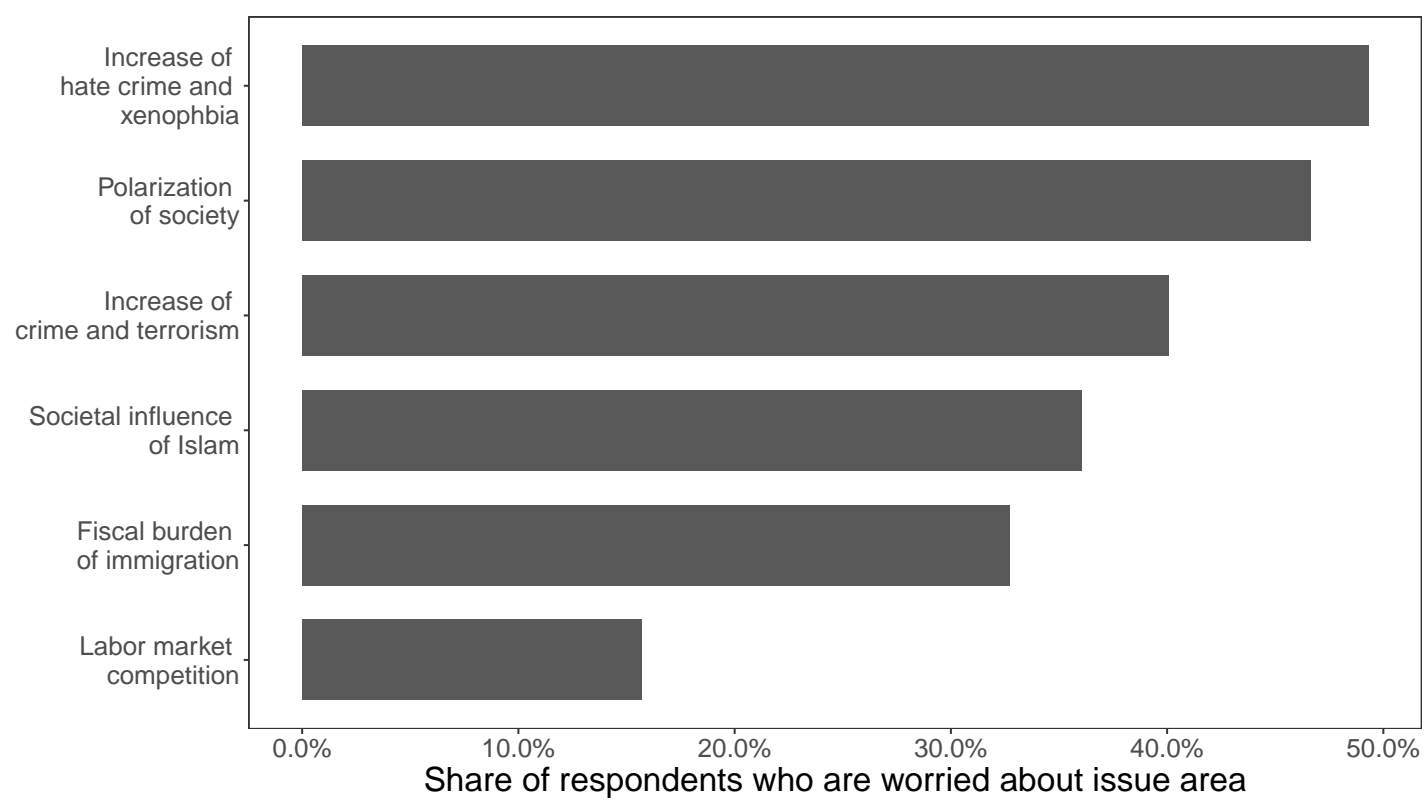

Note: Respondents were asked: 'When you think about the consequences of immigration by refugees and migrants, are you very worried, somewhat worried, not particularly worried or not at all worried about the following things?' The figure shows the share of respondents who are 'rather worried' or 'very worried' about different issues in the context of migration. The sample only includes respondents who were born in Germany. We draw on a representative survey of about 3,000 Germans fielded in November and December 2018 by Faus and Storks (2019). 
Figure SI 34: Issue salience of immigration over time

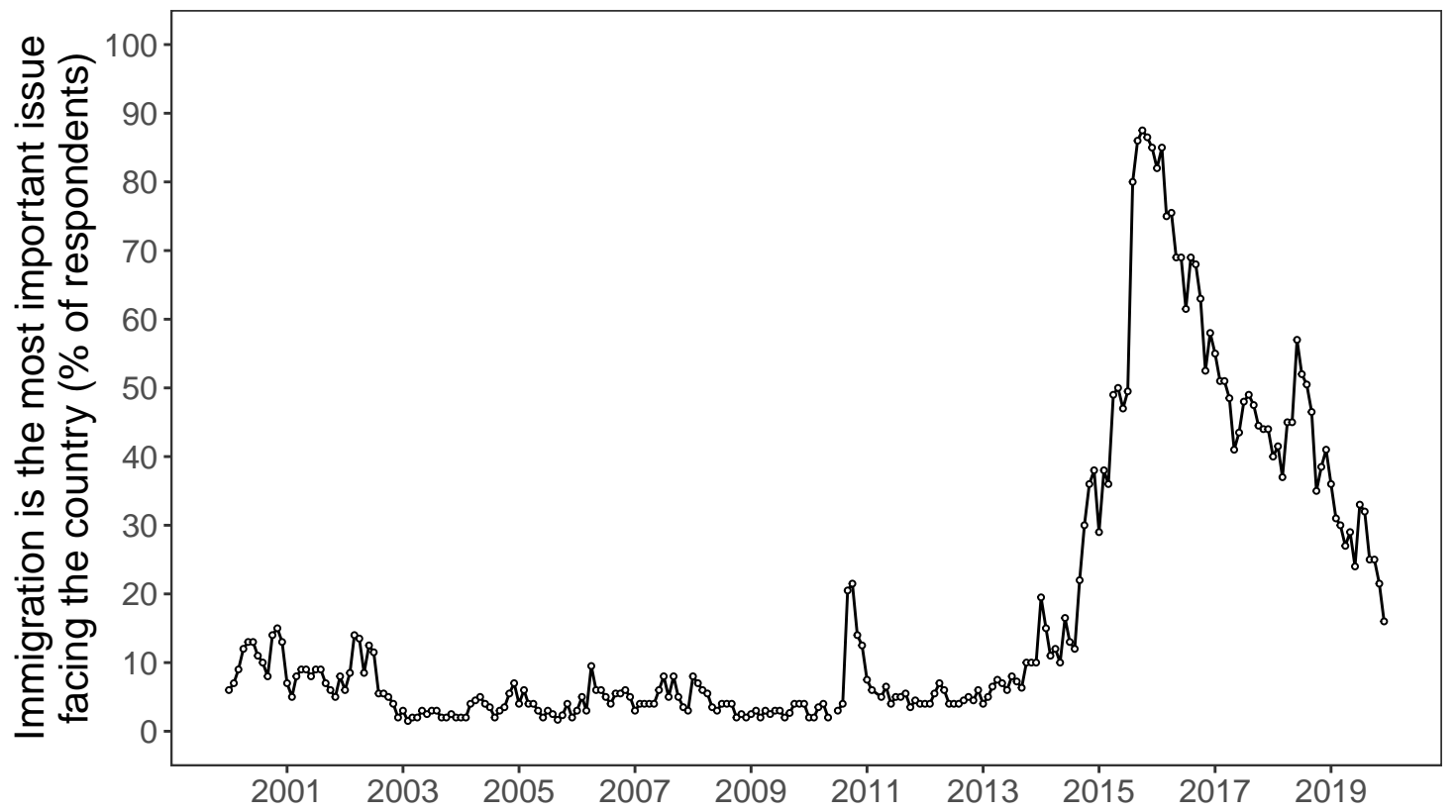

Notes: The Figure shows the share of respondents in the Politbarometer survey (Forschungsgruppe Wahlen 2022) who viewed immigration as the most important issue facing Germany. The Figure shows monthly averages between January 2000 and December 2019. Respondents were allowed to name up to two issues in the survey. The Figure aggregates the answers 'refugees', 'foreigners', and 'integration'. 


\section{SI.10 RD Plots with linear fit}

Figure SI 35: RD Plot with linear fit, subset of violent crime events

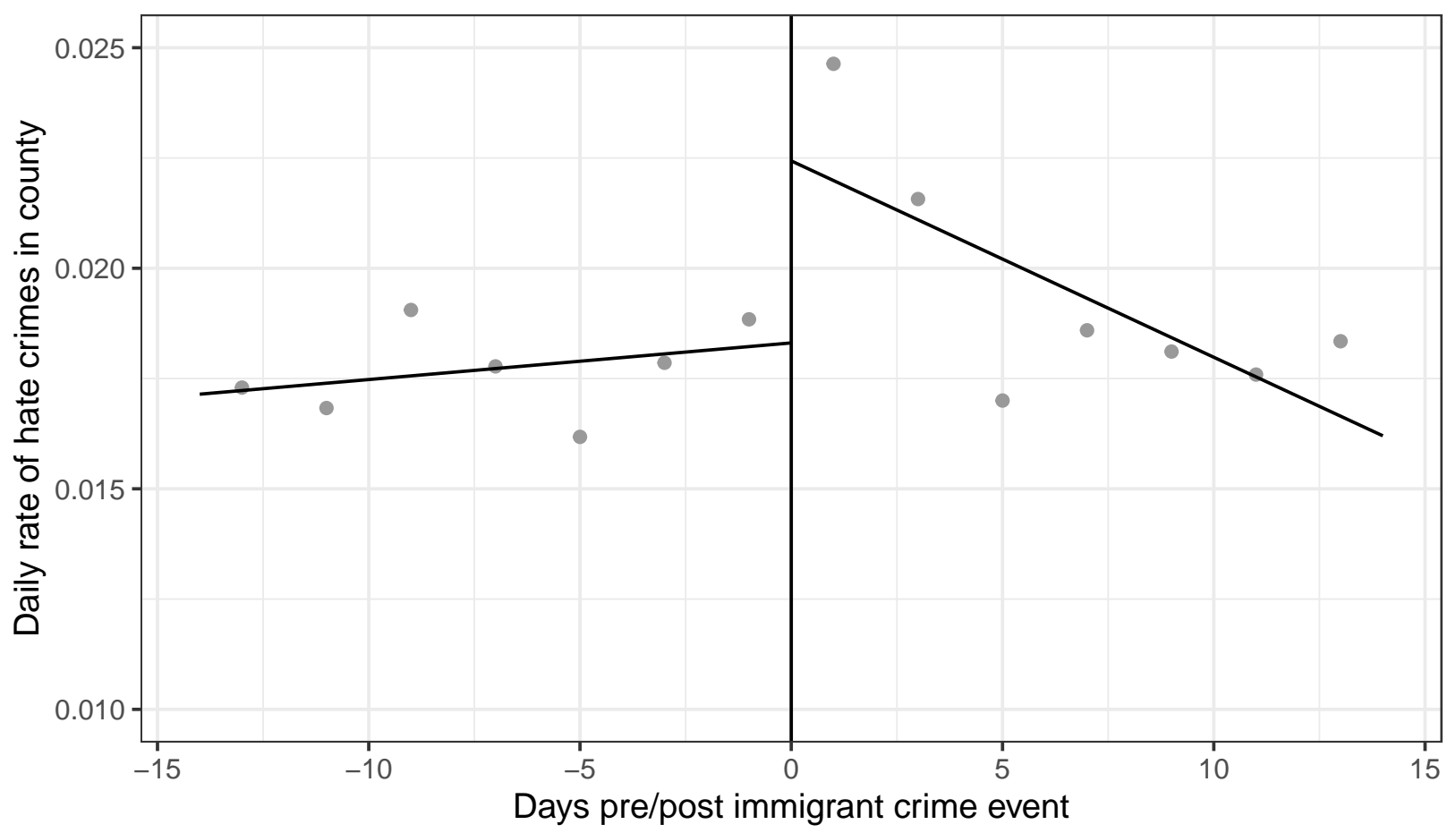

Note: The plot shows the daily rate of hate crimes in the two-week period before and after an immigrant crime event occurred. Error-bars indicate $95 \%$ confidence intervals. The sample is the subset of violent crime events attributed to perpetrators from Muslim-majority/African countries (see section SI.2.8). 
Figure SI 36: RD Plot with linear fit, full sample of refugee-attributed crime events

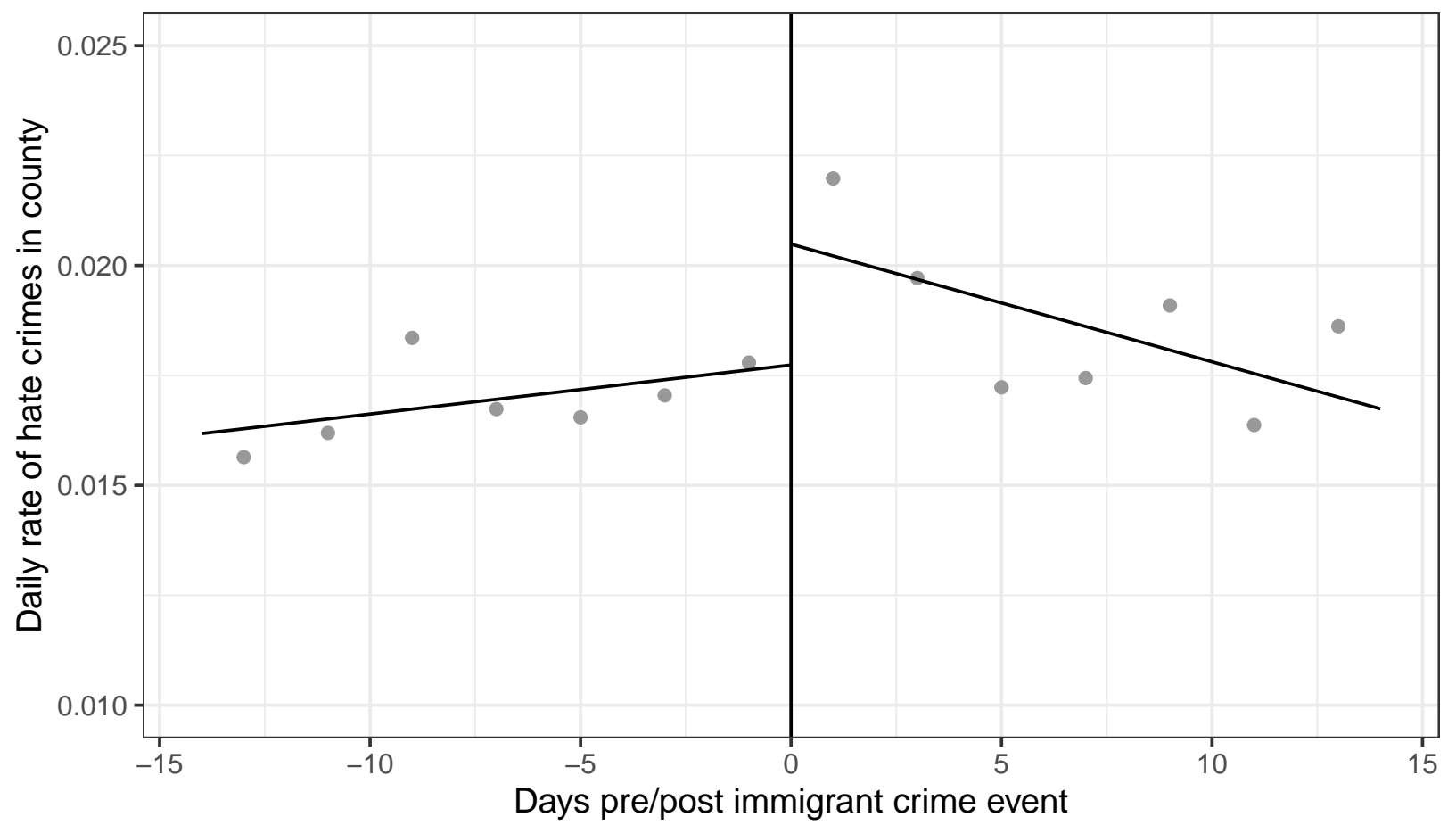

Note: The plot shows the daily rate of hate crimes in the two-week period before and after an immigrant crime event occurred. Error-bars indicate $95 \%$ confidence intervals. 


\section{SI Supporting Information}

\section{SI.11 Test of statistical significance for treatment-moderator interactions}

In section 4.2, we show that the effects we identify are stronger in some localities than in others. We do this by repeating our main analysis in different subsets of the data. Are these differences in the LATE estimates across subsets statistically significant?

A formal statistical significance test for the difference in the LATE estimates across subsets requires additional assumptions. Specifically, we can conduct tests of statistical significance if we are willing to assume that Cov(LATE in high subset, LATE in low subset) $=0$ ).

Building on this assumption, we conduct statistical significance tests for the heterogeneity results presented in in Figure 4. We use the LATE point estimates and associated standard errors within each subset. For both the high/low subset LATE estimates, we draw from a normal distribution with mean equal to the point estimate and standard deviation equal to the estimated standard error. We take 5000 draws and calculate the difference between the high- and low-subset point estimate for each of 5,000 draws. We than calculate the 2.5th, 50th, and 97.5th percentile of the resulting distribution. We present the results in Figure SI 37. Using this procedure, all of the LATE differences in the high/low subsets are statistically significant at $p<0.1$.

Figure SI 37: Confidence intervals for difference between LATE estimates in different subsets

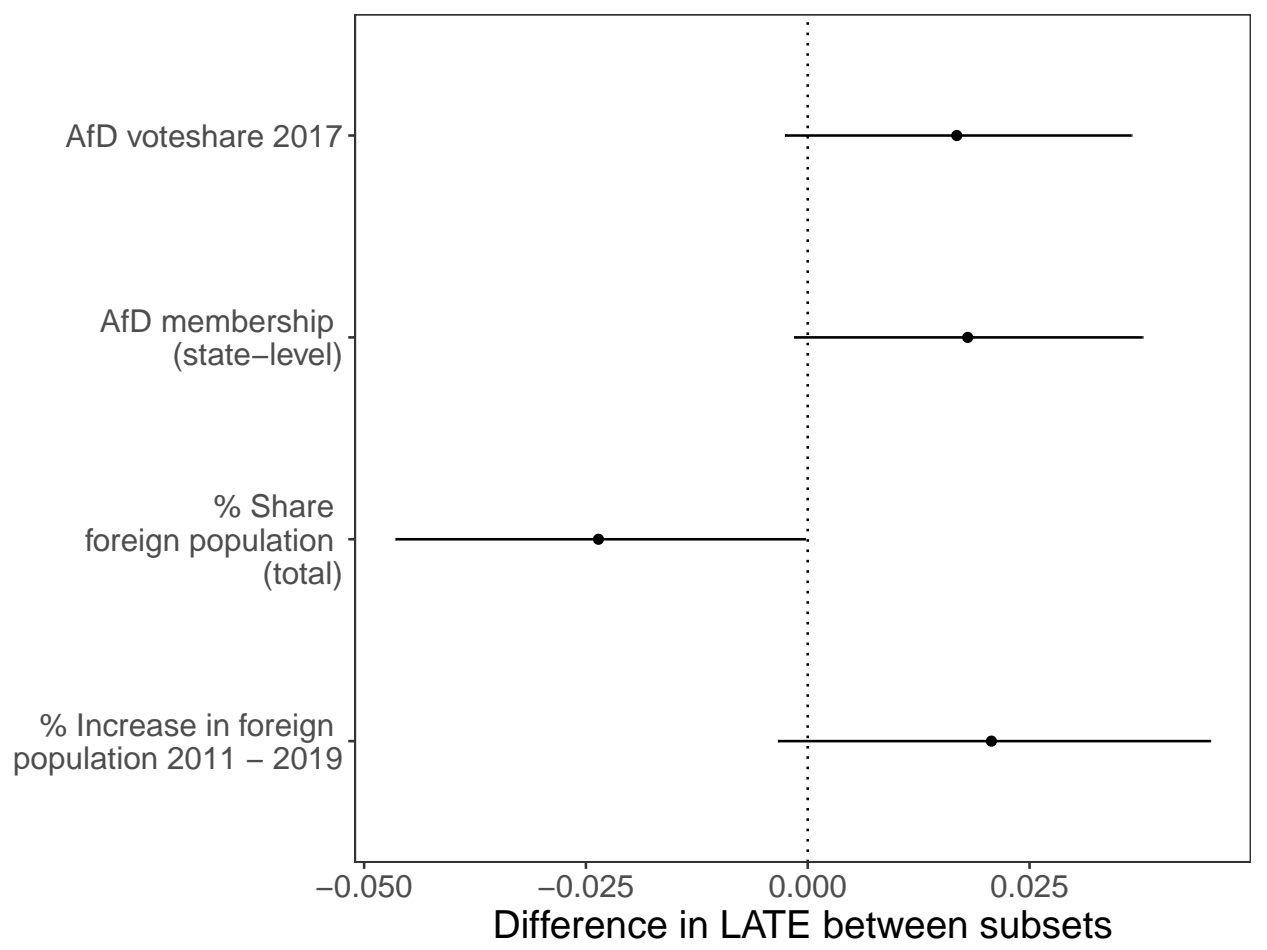

Note: The Figure shows the difference between LATE estimates in high- vs. low-moderator subsets across 5,000 simulations (see also Figure 4). Error-bars indicate $95 \%$ confidence intervals. We provide details on this analysis in section SI.11. 


\section{References: Appendix}

\section{References: Appendix}

Abadie, Alberto, Susan Athey, Guido W Imbens, and Jeffrey Wooldridge. 2017. When should you adjust standard errors for clustering? Technical report National Bureau of Economic Research.

Benček, David, and Julia Strasheim. 2016. "Refugees welcome? A dataset on anti-refugee violence in Germany." Research \& Politics 3 (4).

Bischof, Daniel, and Markus Wagner. 2019. “Do Voters Polarize When Radical Parties Enter Parliament?” American Journal of Political Science 63 (4): 888-904.

Bursztyn, Leonardo, Georgy Egorov, and Stefano Fiorin. 2020. "From extreme to mainstream: The erosion of social norms." American Economic Review 110 (11): 3522-48.

Cattaneo, Matias D, Nicolás Idrobo, and Rocío Titiunik. 2019. A practical introduction to regression discontinuity designs: Foundations. Cambridge University Press.

Faus, Rainer, and Simon Storks. 2019. “Das pragmatische Einwanderungsland." Wie die Deutschen über Migration denken. Bonn: Friedrich-Ebert-Stiftung .

Forschungsgruppe Wahlen. 2022. "Forschungsgruppe Wahlen: Politbarometer." $\quad$ https://www.forschungsgruppe.de/Umfragen/Politbarometer/Langzeitentwicklung__Themen_im_Ueberblick/Politik_II/\#Probl1.

Hestermann, Thomas. 2019.

URL: https: //mediendienst-integration. de/ fileadmin/Expertise_Hestermann_Herkunft_von_ Tatverdaechtigen_in_den_Medien. pdf

Hestermann, Thomas, and Elisa Hoven. 2020. "Crime in Germany as Portrayed by the Alternative for Germany (AfD)." German Law Journal 21 (4): 721-738.

Kustov, Alexander, Dillon Laaker, and Cassidy Reller. 2019. "The stability of immigration attitudes: Evidence and implications." SSRN Working Paper, https://papers.ssrn.com/sol3/papers.cfm?abstract_id=3322121.

Marbach, Moritz, and Guido Ropers. 2019. “Not in My Backyard: Do Increases in Immigration Cause Political Violence?" SSRN, https://papers.ssrn.com/sol3/papers.cfm?abstract_id=3310352.

Nussio, Enzo. 2020. “Attitudinal and Emotional Consequences of Islamist Terrorism. Evidence from the Berlin Attack." Political Psychology 41 (6): 1151-1171.

OECD. 2021. International Migration Outlook 2021. International Migration Outlook OECD.

Reuters Institute. 2018. “Digital News Report 2018.”.

URL: https://reutersinstitute.politics.ox.ac.uk/sites/default/files/digital-newsreport-2018. pdf

Romarri, Alessio. 2020. "Do far-right mayors increase the probability of hate crimes? Evidence from Italy." SSRN Working Paper, https://papers.ssrn.com/sol3/papers.cfm?abstract_id=3506811.

van Um, Eric, Michael Huch, and Mathias Bug. 2015. “Lokale Kriminalitätsberichterstattung: Abbild oder Zerrspiegel von Kriminalität?" DIW Wochenbericht 82 (12): 288-294.

World Bank. 2022. "International Migrant Stock (\% of Population) I Data." https://data.worldbank.org/indicator/SM.POP.TOTL.ZS. 